\section{The Relationship between the two forms of Glycogen Phosphorylase \\ in Dictyostelium discoideum}

by

APPROVED:

Esmail Shokrai

Charles L. Rutherford, thaiman

\author{
Venil Naranan \\ Dissertation submitted to the Faculty of the \\ Virginia Polytechnic Institute and State University \\ in partial fulfillment of the requirements for the degree of \\ Ph.D. \\ in \\ Microbiology
}

Asim Esen

Bruce J. 1 urici

John L. Jopnson

August 25, 1987

Blacksburg, Virginia 
The Relationship between the

two forms of Glycogen Phosphorylase

in Dictyostelium discoideum

by

Venil Naranan

Charles L. Rutherford, Chairman

Microbiology

(ABSTRACT)

The slime mold Dictyostelium discoideum has two developmentally regulated forms of the enzyme glycogen phosphorylase. The inactive ' $b$ ' form requires 5'AMP for activity and is present in early development, whereas the active ' $a$ ' form is S'AMP independent and is present in late development. Polyclonal antibodies raised to purified forms of the enzyme show low cross-reactivity. The anti-' $a$ ' is specific for a $104 \mathrm{kd}$ protein associated with phosphorylase ' $a$ ' activity; the anti-' $b$ ' is specific for a $92 \mathrm{kd}$ protein associated with the ' $\mathrm{b}$ ' activity. The two antibodies inhibit the activities of their corresponding antigens, furthermore, each antibody recognizes the proteolytic products of its corresponding antigen. In the presence of exogenously added $\mathrm{Mn}^{2+}$ and ATP, the ' $\mathrm{b}$ ' form shows apparent conversion to a 5'AMP independent form as detected spectrophotometrically. This apparent conversion is accompanied by in vitro phosphorylation of the ' $\mathrm{b}^{\prime}$ enzyme by a $\mathrm{Mn}^{2+}$ dependent protein kinase. The ' $b$ ' kinase also phosphorylates casein in the presence of $\mathbf{M g}^{2+}$ or $\mathrm{Mn}^{2+}$. In vivo phosphorylation of the ' $\mathrm{b}$ ' form was observed in early development. Phosphorylation of the ' $\mathrm{b}$ ' form did not result in the appearance of the $104 \mathrm{kd}$ protein. At this point, it is unclear whether Dictyostelium phosphphorylase ' $a$ ' represents a phosphorylated and activated form of the ' $b$ ' form, or whether it represents a separate gene product. 


\section{Acknowledgements}

I am deeply grateful to Dr. C.L. Rutherford for accepting me into his laboratory. His high professional standards and methodical work habits have provided an excellent example for me. His constructive criticisms and eye for detail have also contributed much to my learning. I am also indebted to my colleagues

$$
\text { for their suggestions, help and camaraderie. }
$$

I would also like to thank my committee members Dr. J. Johnson, Dr. B. Turner, Dr. A. Esen, and Dr. B. Wallace for their time and advice. I am especially indebted to Dr. E. Shokraii for readily agreeing to substitute for Dr. Wallace at this late stage.

My most grateful thanks are extended to my family and relatives for their moral support. Their unquestioned faith in me has been inspirational when experiments slumped and spirits flagged. 


\section{Table of Contents}

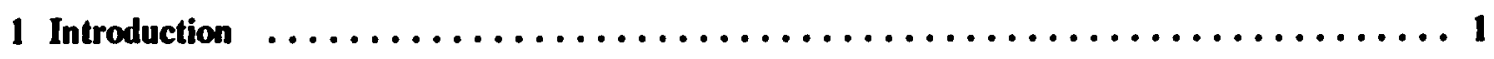

1.1 The Life Cycle of Dictyostelium discoideum $\ldots \ldots \ldots \ldots \ldots \ldots \ldots \ldots \ldots, \ldots$

1.2 The Role of Cyclic AMP in Dictyostelium development $\ldots \ldots \ldots \ldots \ldots \ldots$

1.3 The cAMP Dependent Protein Kinase $\ldots \ldots \ldots \ldots \ldots \ldots \ldots \ldots \ldots \ldots$

1.4 Glycogen Metabolism in Dictyostelium discoideum. $\ldots \ldots \ldots \ldots \ldots \ldots \ldots 6$

1.5 Rationale and Objectives $\ldots \ldots \ldots \ldots \ldots \ldots \ldots \ldots \ldots \ldots \ldots \ldots$.

2.0 The immunologic relationship between the two forms of phosphorylase $\ldots \ldots \ldots \ldots \ldots 11$

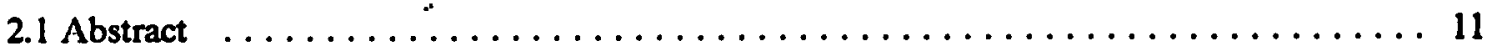

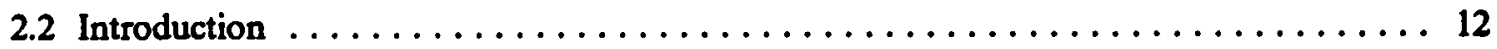

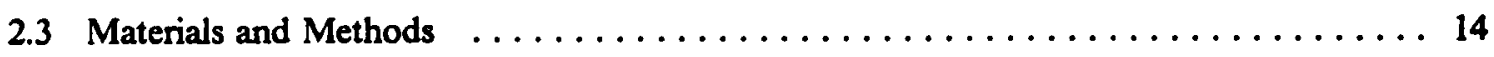

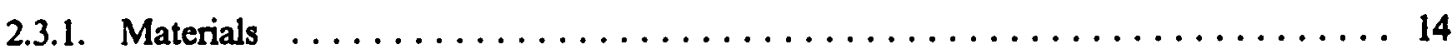

2.3.2 Cell Harvest and Development. $\ldots \ldots \ldots \ldots \ldots \ldots \ldots \ldots \ldots \ldots \ldots \ldots$

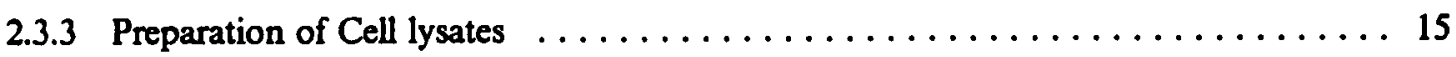

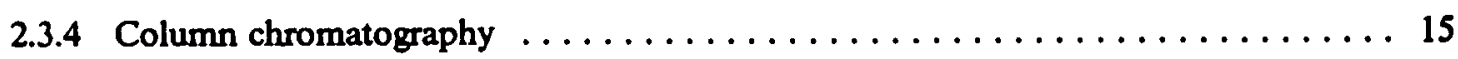

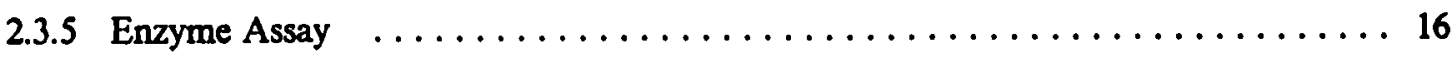

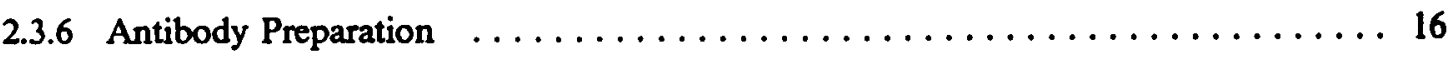

Table of Contents $\quad$ iv 
2.3.7 Immunoprecipitation analyses $\ldots \ldots \ldots \ldots \ldots \ldots \ldots \ldots \ldots \ldots \ldots \ldots, 17$

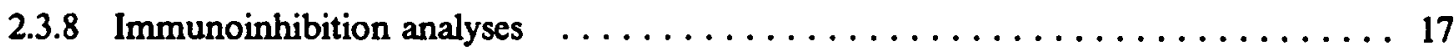

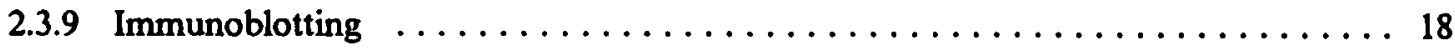

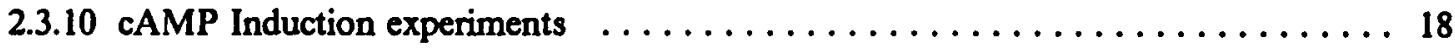

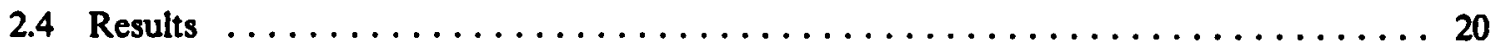

2.4.1. Phosphorylase activity during Dictyostelium development. $\ldots \ldots \ldots \ldots \ldots \ldots 20$

2.4.2. Immunologic analyses of phosphorylase ' $a$ ' and $' b$ ' $\ldots \ldots \ldots \ldots \ldots \ldots . \ldots 29$

2.4.3. Subunit molecular weights of phosphorylase ' $a$ ' and ' $b$ '. $\ldots \ldots \ldots \ldots \ldots \ldots . \ldots 37$

2.4.4. cAMP regulation of phosphorylase ' $a$ ' activity. $\ldots \ldots \ldots \ldots \ldots \ldots \ldots \ldots 43$

2.4.5. Immunotitration of phosphorylase ' $a$ ' activity. $\ldots \ldots \ldots \ldots \ldots \ldots \ldots \ldots 47$

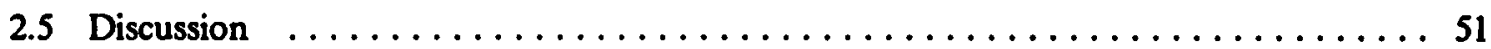

3.0 Glycogen Phosphorylase ' $b$ ' in Dictyostelium: stability and Endogenous phosphorylation .. 54

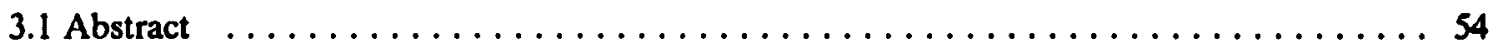

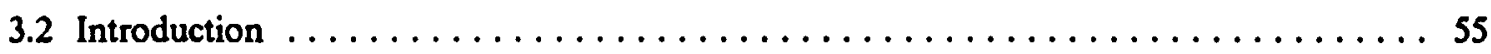

3.3 Materials and Methods $\ldots \ldots \ldots \ldots \ldots \ldots \ldots \ldots \ldots \ldots \ldots \ldots \ldots, \ldots \ldots \ldots$

3.3.1 Materials $\ldots \ldots \ldots \ldots \ldots \ldots \ldots \ldots \ldots \ldots \ldots \ldots \ldots \ldots \ldots \ldots \ldots \ldots$

3.3.2 Cell Harvest and Development. ........................ 57

3.3.3 Preparation of Cell lysates $\ldots \ldots \ldots \ldots \ldots \ldots \ldots \ldots \ldots \ldots \ldots \ldots \ldots \ldots, 58$

3.3.4 Column chromatography $\ldots \ldots \ldots \ldots \ldots \ldots \ldots \ldots \ldots \ldots \ldots \ldots, 58$

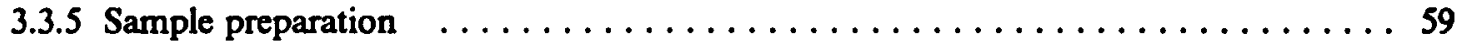

3.3.6 Glycogen Phosphorylase Assay $\ldots \ldots \ldots \ldots \ldots \ldots \ldots \ldots \ldots \ldots . \ldots 9$

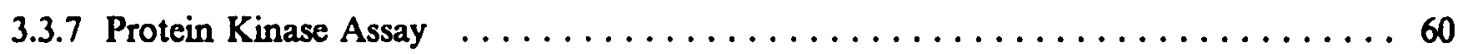

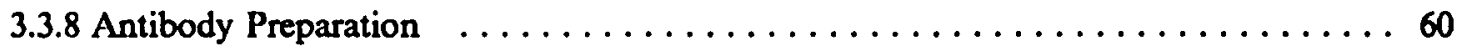

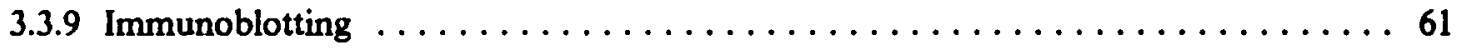

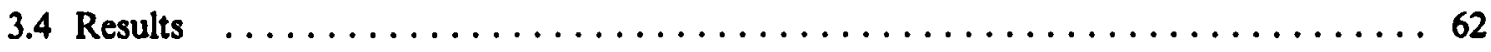

3.4.1 Phosphorylase activity during the Dictyostelium growth phase. $\ldots \ldots \ldots \ldots 62$ 
3.4.2 Effects of sample preparation on the apparent molecular weight of phosphorylase ' $b$ '

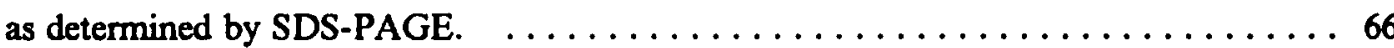

3.4.3. Conversion of S'AMP dependent into S'AMP independent activity in the presence

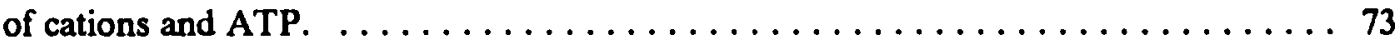

3.4.4 Phosphorylation of Dictyostelium phosphorylase ' $b$ ' in vitro and in vivo. . . . . 74

3.4.5 Characterization of the casein and ' $\mathrm{b}$ ' kinase activities $\ldots \ldots \ldots \ldots \ldots \ldots$

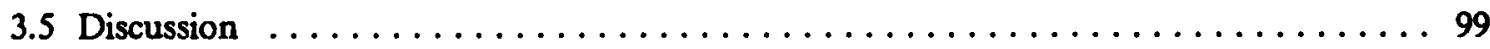

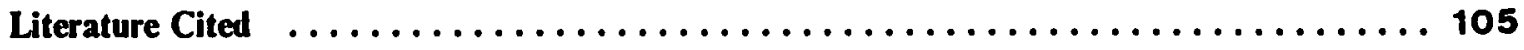

Table of Contents 


\section{List of Figures}

1. The life cycle of Dictyostelium

discoideum.

2. The regulation of glycogen phosphorylase via a cAMP dependent cascade

3. Westem blot analysis of phosphorylase ' $a$ ' and ' $b$ ' activities from four developmental stages.

4 A. Western blot analysis of peptide maps of phosphorylase ' $a$ ' and ' $b$ ' activities using ' $b$ ' antiserum

4 B. Western blot analysis of peptide maps of phosphorylase ' $a$ ' activity using ' $a$ ' antiserum

5. Phosphorylase ' $b$ ' activity from the amoeba stage immunoprecipitated and western blotted with both antisera

6 A. Culmination stage phosphorylase ' $a$ ' and ' $b$ ' activities immunoprecipitated with both antisera and western blotted with ' $b$ ' antiserum

6 B. Culmination stage phosphorylase ' $a$ ' and ' $b$ ' activities immunoprecipitated with both antisera and western blotted with ' $b$ ' antiserum

$6 \mathrm{C}$. Culmination stage phosphorylase ' $a$ ' activity immunoprecipitated with both antisera and 
western blotted with ' $a$ ' antiserum

7. Subunit molecular weight of partially

purified phosphorylase ' $a$ '

8. In vitro phosphorylation of phosphorylase

' $b$ ' from amoeba

9. cAMP induction of phosphorylase ' $a$ '

activity in shaking cultures

10. Immunotitration of phosphorylase ' $a$ ' activity from crude extracts

by anti-' $a$ ' antiserum

11. Phosphorylase activity during the growth

phase of Dictyostelium amoebae

12. Effect of choice of extraction buffer on the

molecular weight of phosphorylase ' $b$ '

13. Effects of methods of sample extraction on

the molecular weight of phosphorylase ' $b$ '

14. Phosphorylase ' $b$ ' and protein

kinase activities from De52

chromatography of amoebae

$15 \mathrm{~A}$. Partial separation of ' $\mathrm{b}$ ' enzyme

and ' $b$ ' kinase activities upon

Sephacryl S-300 gel filtration

$15 \mathrm{~B}$. In vitro phosphorylation of the

$92 \mathrm{kd}$ ' $\mathrm{b}$ ' subunit by the ' $\mathrm{b}$ ' kinase

(westem blot)

$15 \mathrm{C}$. In vitro phosphorylation of the

$92 \mathrm{kd}$ ' $\mathrm{b}$ ' subunit by the ' $\mathrm{b}$ '

kinase (autoradiogram)

16. Phosphorylation of the $92 \mathrm{kd} \mathrm{'} \mathrm{b}$ '

subunit in vivo

$17 \mathrm{~A}$. The $\mathrm{pH}$ and cation requirements

for casein kinase activity

$17 \mathrm{~B}$. The $\mathrm{pH}$ and cation requirements

for ' $b$ ' kinase activity

18 A. Manganese dependent phosphorylation of

the $92 \mathrm{kd}$ ' $\mathrm{b}$ ' subunit by the ' $\mathrm{b}$ ' kinase

in vitro (westem blot)

18 B. Manganese dependent phosphorylation of

the $92 \mathrm{kd}$ ' $b$ ' subunit by the ' $b$ ' kinase

in vitro (autoradiogram) 


\section{List of Tables}

1. Glycogen Phosphorylase activities during the

life cycle of Dictyostelium

discoideum

2. Immunoinhibition analyses of glycogen

phosphorylase ' $a$ ' and ' $b$ ' activities

3. Effects of nucleotides and cations on

the 5'AMP dependence of phosphorylase ' $b$ '

4. Substrate specificities of casein/endogenous protein kinase activities 


\section{Introduction}

Organismal development is a process involving growth, morphogenesis and cellular differ-

entiation. In the past, the mechanics of development have been explored by experimental embryologists and histochemists. During the last decade, the application of biochemical techniques has helped elucidate the mechanisms underlying cellular differentiation. Cellular specialization is best understood in a simple eucaryote like the cellular slime mold Dictyostelium discoideum . Further, Dictyostelium development also displays certain unique features that render it a model system of choice for developmental biologists. Firstly, the terminally differentiated slime mold contains only two cell types, thus allowing for a very basic investigation into the problems of multicellularity. Secondly, the processes of growth and differentiation are temporally separated in Dictyostelium , thus simplifying the task of experimental interpretation. Additionally, synchronous slime mold populations can be routinely cultured in sufficient quantities for biochemical analyses.

\subsection{The Life Cycle of Dictyostelium discoideum}

This cellular slime mold grows as unicellular myxamoebae on forest soils (Loomis 1975). 


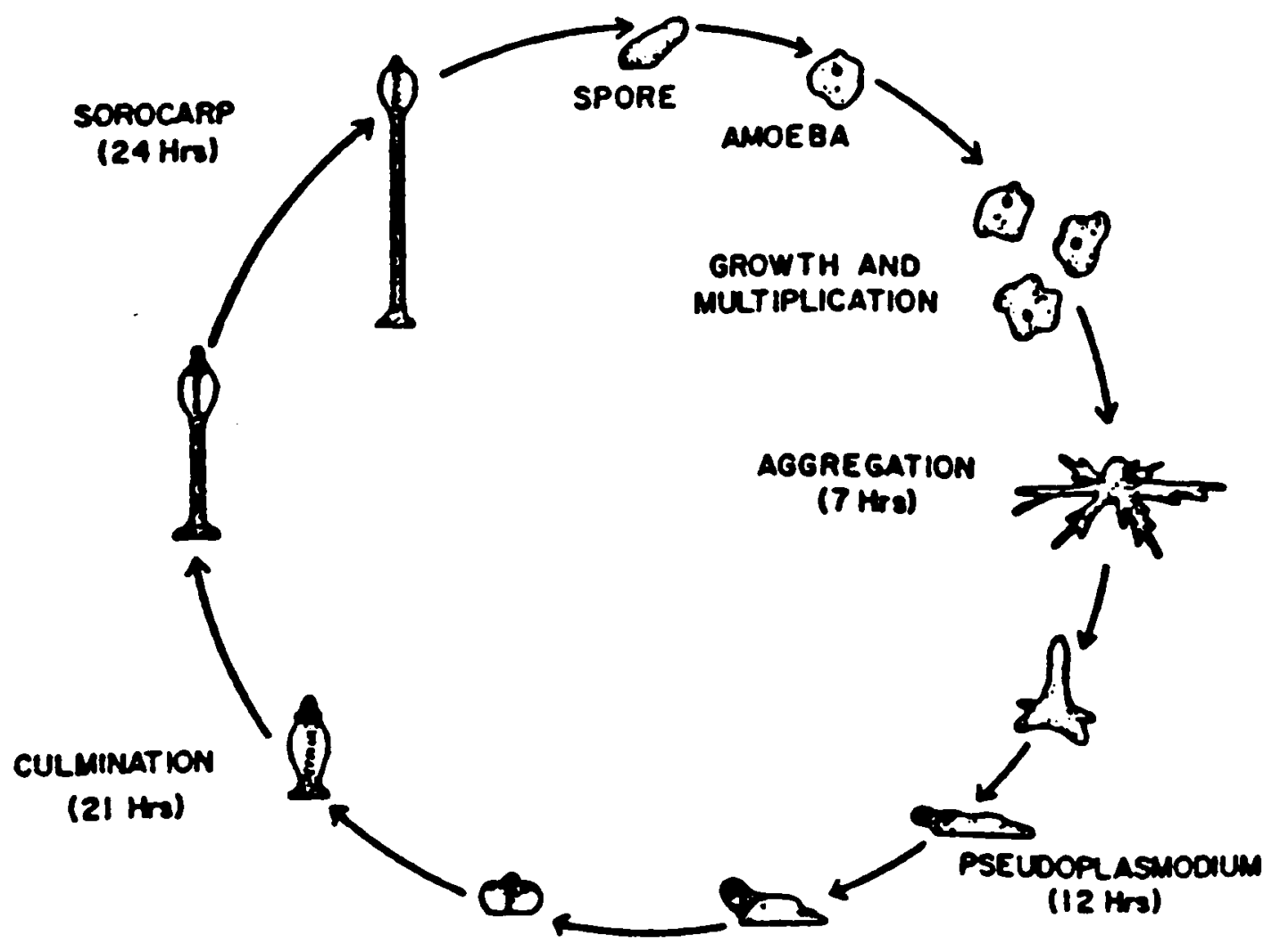

The life cycle of Dictyosteliun discoideum 
The Dictyostelium life cycle is initiated upon starvation by the amoebae (figure 1 on page 2). Amoebae starved for 7-10 hours aggregate into a multicellular mass consisting of approximately $10^{3}$ cells. This aggregation event is triggered by the chemotactic agent cyclic AMP (cAMP) (Konijin et al,1968). The aggregate now deposits a sheath of slime and migrates horizontally as a slug or pseudoplasmodium. It is the slug that first shows signs of cellular differentiation. It contains anterior prestalk cells and posterior prespore cells characterized by thick walled vesicles (Maeda \& Takeuchi, 1969; Hohl \& Hamamoto, 1969). Within the next 10 hours, (18-20 hours into the life cycle) the tip of the slug ceases its forward movement and points upward, while the prestalk cells secrete a cellulosic stalk before differentiating into dead stalk cells (George et al 1972). In this developmental stage termed culmination, the slime mold contains terminally differentiated stalk cells and maturing prespore cells. The prespore cells mature as the entire prespore mass is lifted off the ground by the apically elongating stalk. A single spore upon germination will repeat the entire life cycle.

\subsection{The Role of Cyclic AMP in Dictyostelium development}

Besides functioning as a chemotactic agent during aggregation, cAMP functions as a morphogen during the differentiation of the two cells types. Intracellular levels of cAMP are elevated during the postaggregative developmental stages (Malkinson \& Ashworth 1973; Pahlic \& Rutherford 1979; Merkle et al 1984). Other studies indicate that the intracellular cAMP shows a differential distribution, with prestalk cells containing 40-70\% greater levels than the prespore cells. Exogenously added cAMP induces stalk cell differentiation, although a low molecular weight heat stable molecule called differentiation inducing factor (DIF) is also required (Town et al 1976; Kay \& Jermyn 1983). Cyclic AMP in the absence of DIF and in the presence of cell-cell contact has been shown to induce spore cell differentiation. Indeed, it has been suggested that CAMP is not pathway specific with respect to the differentiation of the two cell types, i.e. all amoebae commence spore cell differentiation under cAMP's influence, but some are diverted into stalk cell formation by the action of DIF and the ammonium ion. 
Cyclic AMP is also involved in the regulation of cell type patterning. For instance, amputated slugs will reapportion their cell mass in order to maintain the normal ratio of prestalk to prespore cells (Raper 1940; Bonner and Slifkin 1949). Furthermore, slug halves containing prespore cells, degenerate when grown in the presence of high levels of cAMP, whereas those containing prestalk cells differentiate normally (George 1977). Other work has shown that the tip of an individual organism produces cAMP, which elicits a chemotactic response from the prestalk cells (Maeda \& Maeda 1974; Sternfield \&. David 1981; Matsukuma \& Durston 1979). Such chemotaxis within an individual may be the mechanism for morphogenetic movements of cells during the culmination stage. On a biochemical level, it is clear that cAMP is required for the synthesis and maintenance of developmentally regulated enzymes and late stage mRNA's (Gross et al 1981; Kay et al 1979; Landfear \& Lodish 1980; Town \& Gross 1978). Addition of exogenous cAMP reinduces the transcription of the mRNA's that were degraded in the absence of cAMP (Barklis \& Lodish 1983; Blumberg et al 1982; Mehdy et al 1983). The protein products of the cAMP regulated late stage mRNA's are not yet known.

\subsection{The cAMP Dependent Protein Kinase}

After the discovery of cAMP dependent protein kinase (cAMP Prk) as the mediator of cAMP effects in mammalian muscle, and the vital role of cAMP during Dictyostelium morphogenesis, attempts to identify a similar enzyme in Dictyostelium were underway (Weinstein \& Koritz 1973). However, it was not until 1977 that a cAMP Prk was first reported in this organism (Sampson 1977). Confirmation of its presence by other groups took an additional five years (Rutherford et al 1982; Leichtling et al 1982; de Gunzburg \& Veron 1982). The Dictyostelium cAMP Prk has been isolated, characterized, and its developmental regulation examined (Cooper et al 1983; Rutherford et al 1984; Majerfield et al 1982; Leichtling et al 1984). The increased activity of this cAMP Prk during development parallels the rise of intracellular cAMP concentrations during the slime mold life cycle. Using slug cells separated by density gradient centrifugation, Schaller and 
coworkers (1984) reported that the prespore cells contained 4-5 times the amounts of catalytic and regulatory subunits than were found in the prestalk cells. In a later study using micro-dissected individuals, Vaughan \& Rutherford (1986) found no differential distribution of the enzyme until late development, when spore cells contained four fold higher enzyme levels than stalk cells. More recently, translocation of the enzyme's subunits into the nucleus has been reported (Woffendin et al 1986). It is therefore likely that the effects of cAMP on postaggregative development are mediated by phosphorylation of nuclear and cytosolic proteins by the cAMP Prk. However, the recent literature suggests that the expression of certain cell type specific genes occurs in the absence of an intracellular increase of cAMP (Haribabu \& Dottin 1986; Oyama \& Blumberg 1986. Datta \& Firtel 1987).These researchers therefore claim that the cAMP Prk does not modulate the expression of these developmentally regulated genes. Further research will be required to prove such a hypothesis.

On the other hand, several enzymes involved with intermediary metabolism in eucaryotes have been shown to be regulated by reversible cAMP dependent phosphorylation (Cohen 1985). Extracellular signals that trigger cAMP dependent protein phosphorylation range from the binding of hormones, neurotransmitters, and growth factors to cell surfaces. Usually the activity of a key regulatory enzyme in a metabolic pathway is regulated via reversible phosphorylation. Two major effects occur in response to such phosphorylation; an alteration of the Vmax. for the reaction catalyzed by phosphorylated enzyme, or a change in the $\mathrm{Km}$ of the phosphorylated enzyme for its substrates (Vmax is defined as the maximal velocity of an enzyme catalysed reaction. The $\mathrm{Km}$ is defined as the substrate concentration at which the velocity of the enzyme catalysed is half maximal). The activities of four mammalian enzymes have been proven to be modulated by reversible cAMP dependent phosphorylation. These include, liver pyruvate kinase, acetyl- Co A carboxylase, pyruvate dehydrogenase from adipose tissue and muscle phosphorylase kinase. To date, there have been no reports of physiologically significant substrates for the Dictyostelium cAMP Prk. We hypothesize that cAMP regulates cell type differentiation in Dictyostelium at the biochemical level. Our recent work suggests that glycogen metabolism in Dictyostelium is regulated by cAMP. 


\subsection{Glycogen Metabolism in Dictyostelium discoideum.}

As mentioned earlier, the developmental program of Dictyostelium is initiated by starvation. Evidence suggests that the polysaccharide end products which accumulate during differentiation are primarily derived from glycogenolysis. These end products are,

1. Cellulose which is utilized for stalk formation (Ward \& Wright 1965; Wright et al 1968; Rosness \& Wright 1974)

2. Trehalose, which is required for spore cell maturation (Sargent \& Wright 1961; Wright \& Marshall 1971)

3. Mucopolysaccharide which is required for construction of the slime sheath (Sussman \& Osbom 1964).

Thus, glycogen degradation in this slime mold is a developmentally regulated event and is required for successful differentiation rather than energy production. Investigators have measured a three fold increase in the rate of glycogen tumover in vivo during development. (Marshall et al 1970; Gustafson \& Wright 1972). This is paralleled by a 5.10 fold increase in the specific activity of the glycogen degradative enzyme, glycogen phosphorylase. Thus, the increase in phosphorylase activity is more than adequate to account for the three - fold increase in glycogen turnover rates (Wright et al,1968; Jones \& Wright 1970; Firtel \& Bonner 1972,). Glycogen tumover in this slime mold is compartmentalized. Harris \& Rutherford (1976) showed that the phosphorylase activity was localized specifically to prestalk cells which migrate down through the prespore mass during development. Prespore cells also show glycogen degradation as they moved toward the apex of the stalk during terminal differentiation. The levels of inorganic phosphate (one of the substrates for phosphorylase) were found to increase dramatically in the stalk (Rutherford, 1976a). Net glycogen breakdown occurs during terminal differentiation, since glycogen synthetase activity is inhibited by 
the increasing levels of phosphate, and is localized primarily to the prespore cells during the culmination stage. Our interest in glycogen phosphorylase stems from its unique physiological role explained above. Furthermore, the activities of glycogen phosphorylase and the cAMP Prk show similar profiles during the developmental cycle, suggesting that the phosphorylase may be activated directly or indirectly by the cAMP Prk.

\subsection{Rationale and Objectives}

Previous investigators found a single form of Dictyostelium phosphorylase. This enzyme was 5'AMP independent, unaffected by nucleotides and glycolytic intermediates, strongly inhibited by nucleotide sugars and reducing agents, and competitively inhibited by uridine diphosphoglucose (UDPG). In all these respects, the Dictyostelium phosphorylase reported in the literature was similar to mammalian glycogen phosphorylase ' $a$ '. The chemical reaction catalyzed by phosphorylase ' $a$ ' is shown below.

(Glucose) $\mathrm{n}+\mathrm{Pi}=======>$ (Glucose) $\mathrm{n} \cdot 1+$ Glucose-1-Phosphate

The discovery of a 5'AMP dependent form of Dictyostelium glycogen phosphorylase a few years ago, raised several questions. The newly discovered phosphorylase was present early in development (phosphorylase ' $\mathrm{b}$ ). Firstly, we determined why previous investigators had not detected the ' $b$ ' enzyme. In previous studies, cells were routinely lysed by freeze- thaw, and in some cases, the crude extracts were subjected tc a heat treatment at $50^{\circ} \mathrm{C}$ for 15 minutes in order to remove heat labile contaminant proteins. We showed that each of these steps results in a total loss of phosphorylase ' $b$ ' activity. We also showed that activation of the ' $b$ ' form results in a 50 fold decrease in the Km's for the substrates glycogen and inorganic phosphate, with no apparent change in the Vmax of the enzyme. Thus, the phosphorylase 'a' does not require S'AMP for activity and has a $\mathbf{4 5}$ fold greater affinity for inorganic phosphate, and a 55 fold greater affinity for glycogen than 
phosphorylase ' $b$ '. Secondly, we addressed the mechanism of phosphorylase activation. Previous studies suggested that the increased specific activity of the 5'AMP independent enzyme during the developmental cycle resulted from an increase in the rate of de novo protein synthesis. Thus, transcriptional control was the proposed mechanism of developmental regulation of phosphorylase activity. With our discovery of an inactive, 5'AMP dependent form of Dictyostelium phosphorylase, questions regarding the relationship between the 5' AMP dependent (the ' $b$ ' form) and the 5'AMP independent form (the ' $a$ ' form ) of the enzyme arose. A cAMP mediated regulation of glycogen phosphorylase activity appeared to be a realistic working hypothesis, since Dictyostelium glycogen degradation occurs at a point when maximum cAMP Prk activity was measured. Furthermore, our preliminary studies showed that the combined specific activities of the phosphorylase ' $a$ ' and ' $b$ ' forms remained constant during the Dictyostelium life cycle. The latter observation strongly supported the idea that the phosphorylase ' $b$ ' was being converted into the ' $a$ ' form in some manner. In mammals, cAMP Prk has been shown to mediate such a conversion. The laboratories of Krebs and Sutherland simultaneously determined that phosphorylation of rabbit muscle glycogen phosphorylase ' $b$ ' resulted in its conversion to the ' $a$ ' form (Krebs \& Fisher 1956; Krebs \& Graves 1959; Wosilait \& Sutherland 1956). The enzyme that catyalyzed this phosphorylation event was termed glycogen phosphorylase kinase. Walsh et al proceeded to show that the phosphorylase kinase itself undergoes activation upon phosphorylation by the cAMP Prk (Walsh et al 1968). Thus, the phosphorylation dephosphorylation cascade greatly amplifies the effect of cAMP on glycogen metabolism (figure 2 on page 9). Indeed, glycogen phosphorylase kinase is the focal enzyme for the regulation of glycogen metabolism by nervous and hormonal stimuli (Cohen et al 1973). Mammalian phosphorylase kinase has been extensively studied over the past four decades by several laboratories. Lower eucaryotes e.g. Neurospora crassa were also shown to regulate their glycogen metabolism via a similar cAMP dependent cascade (Tellez-Inon, \& Torres 1970) Specific aims of this project are described below:

1. Detection of the phosphorylase ' $a$ ' and ' $b$ ' forms by immunoprecipitation during the Dictyostelium developmental cycle. 
2. Demonstration of phosphorylation of the phosphorylase ' $b$ ' by an endogenous protein kinase under in vitro and in vivo conditions.

3. Characterization of the putative phosphorylase kinase.

4. Demonstration of phosphorylase activation concommitant with the phosphorylation of the ' $b$ ' form. 


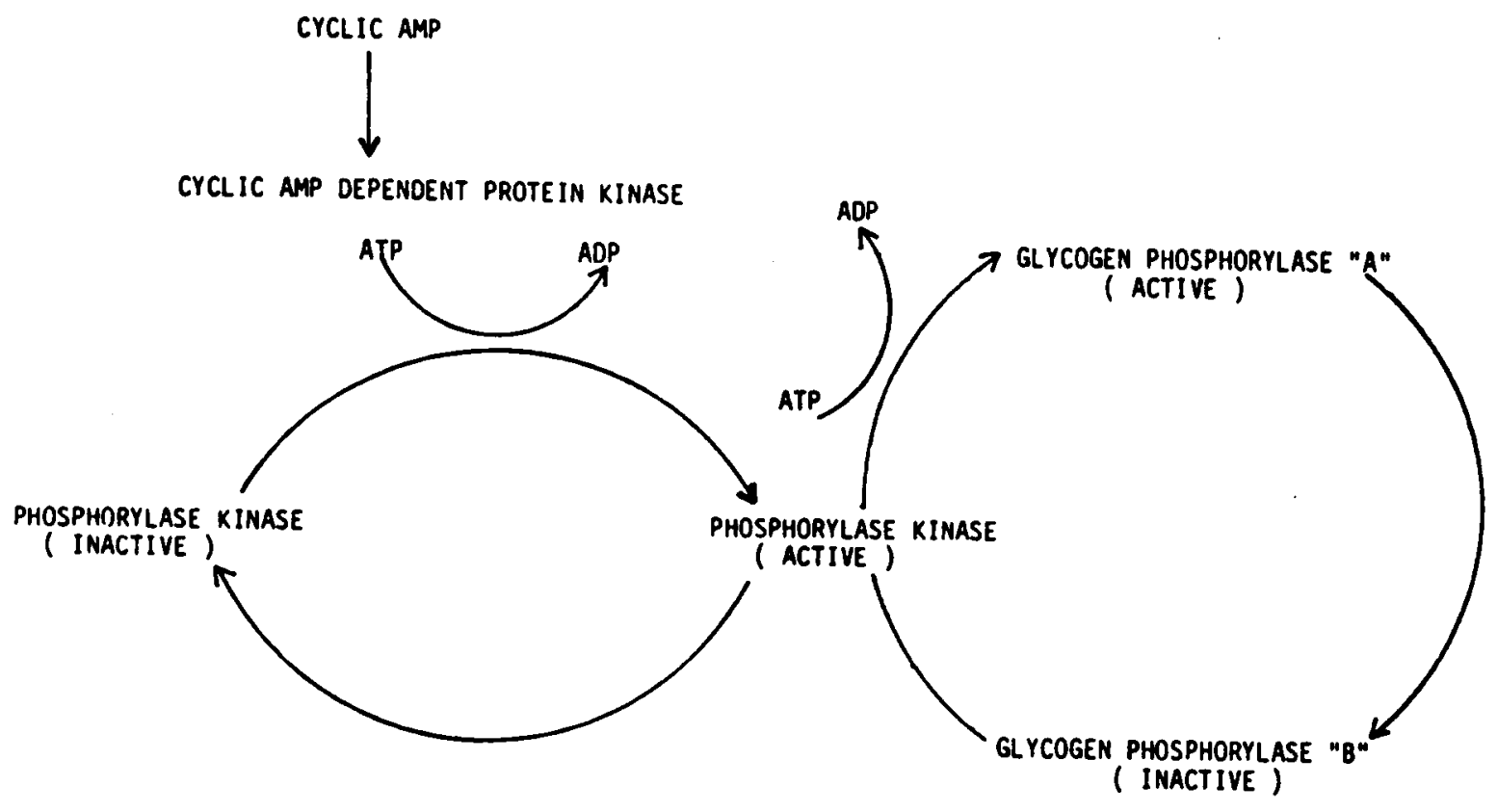

THE REGULATION OF GLYCOGEN DEGRADATION VIA A CAMP DEPEMDENT CASCADE 


\subsection{The immunologic relationship between the two forms of phosphorylase}

\subsection{Abstract}

In the slime mold Dictyostelium discoideum, glycogen phosphorylase exists in active and inactive forms. The activity of the ' $b$ ' form is dependent on S'AMP, while the activity of the ' $a$ ' form is 5'AMP independent. The two forms are developmentally regulated; the ' $a$ ' activity increases throughout development while the ' $b$ ' activity decreases. Polyclonal antibodies raised to purified forms of the enzyme show low cross-reactivity. The anti-' $a$ ' is specific for a $104 \mathrm{kd}$ protein associated with phosphorylase ' $a$ ' activity; the anti-' $b$ ' is specific for a $92 \mathrm{kd}$ protein associated with the ' $b$ ' activity. The two antibodies inhibit the activity of their corresponding antigens. The in vitro phosphorylation of the partially purified ' $b$ ' form by an endogenous protein kinase is demonstrated. This phosphorylation does not result in the appearance of the $104 \mathrm{kd}$ protein associated with ' $\mathrm{a}$ ' activity. Data showing that the phosphorylase ' $a$ ' activity and the $104 \mathrm{kd}$ protein are cAMP inducible are presented. 


\subsection{Introduction}

We are testing the hypothesis that cAMP $\left(3^{\prime} 5^{\prime}\right.$ cyclic adenosine monophosphate) regulates the alternate pathways of aging and differentiation in Dictyostelium discoideum . Thus far, the literature has established that cAMP in this slime mold modulates the differentiation of its two cell types, namely spore and stalk cells (Kay et al., 1979). More recently, the expression and stabilization of various developmentally regulated genes have been attributed to altered intracellular cAMP levels (Barklis and Lodish, 1983; Landfear et al., 1982; Town and Gross, 1978; Blumberg et al., 1982; Mehdy et al., 1983). In several systems, a cAMP dependent protein kinase (cAMP Prk) mediates cAMP effects by changing the phosphorylation state of its protein substrates (Walsh et al., 1968). Several laboratories, including our own, have recently described a cAMP Prk in Dictyostelium discoideum (Sampson, J., 1977; Rutherford et al., 1982; Cooper et al., 1983; Schoen et al., 1983; Majerfield et al., 1984; Leichtling et al., 1984; Rutherford et al., 1984). We are now engaged in identifying its endogenous substrates. As is the case in mammals, a likely substrate for kinase mediated regulation is the enzyme glycogen phosphorylase (1,4- $\alpha$-D-glucan:orthosphate a-glucosyl transferase; EC 2.4.1.1.) This is a realistic hypothesis, since an inactive $5^{\prime}$ AMP dependent form of the phosphorylase has been discovered in our laboratory (Rutherford and Cloutier, 1986). Previously, only the active, S'AMP independent form of the enzyme was known in this organism (Marshall et al., 1970; Gustafson and Wright, 1972; Wright et al., 1968; Jones and Wright, 1970; Firtel and Bonner, 1972; Rutherford and Harris, 1976). We are now investigating whether the inactive phosphorylase ' $\mathrm{b}$ ' is activated via a cAMP Prk mediated phosphorylation. Another reason for our interest in glycogen phosphorylase concerns its physiological role in the organism's differentiation. Previous studies showed that this enzyme is active at terminal development, when a cellulosic stalk is constructed (Marshall et al., 1970). Indeed, the glucose units generated by phosphorylase activity are utilized solely for cellulose synthesis, rather than energy metabolism (Gustafson and Wright, 1972; Wright et al., 1968). I therefore chose to work on the mechanism of developmental regulation of glycogen phosphorylase in this organism. The first step 
has been the isolation of purified forms of the phosphorylase, and the generation of polyclonal antibodies to each. Presumably the degree of immunological relatedness between these enzyme forms will help determine whether Dictyostelium phosphorylase ' $a$ ' results from a phosphorylation mediated conversion of the ' $b$ ' form, or whether the two forms of the of phosphorylase represent separate gene products. 


\subsection{Materials and Methods}

\subsubsection{Materials}

$\left[\gamma^{32} \mathrm{P}\right]$ ATP (25 Ci/mmol) was purchased from ICN. Nitrocellulose was purchased from Fisher, DE52 cellulose from Whatman, and Protein A (Pansorbin cells) from Calbiochem. Other reageants were purchased from Sigma.

\subsubsection{Cell Harvest and Development.}

Dictyostelium discoideum (AX-3) was grown in liquid HLS medium on a rotary shaker as previously described (Thomas and Wright, 1976, Part II). The resulting amoebae were harvested by centrifugation in a continuous flow rotor, then were washed and resuspended in $50 \mathrm{mM}$ Tris- $\mathrm{HCl}$, pH 7.5, containing $2 \mathrm{mM}$ benzamidine, $2 \mathrm{mM}$ mercaptoethanol and $0.02 \%$ sodium azide (buffer $A$ ). When differentiated cells were required, the amoebae were washed free of media, diluted 1:3 (weight:volume) in $7 \mathrm{mM} \mathrm{N}$-morpholino ethanesulfonic acid, pH 6.5, containing 20 $\mathrm{mM} \mathrm{KCl}$ and $5 \mathrm{mM} \mathrm{MgSO}_{4}$ (buffer B) and plated on non-nutrient agar (Rutherford, 1976). For DE52 chromatography of amoeba and culmination stages, approximately 25 grams of cells from each stage were harvested in 5 volumes of cold buffer A. All subsequent steps were carried out at $4^{\circ} \mathrm{C}$.

The stage study in Fig 3 was carried out as follows. Amoebae were pelleted by centrifugation at $1,800 \times \mathrm{g}$ for $4 \mathrm{~min}$, and were washed once in buffer $\mathrm{B}$. These cells were resuspended in thrice the volume of buffer, then $0.4 \mathrm{ml}$ of this suspension were plated onto Gelman GN-6 membrane filters supported by Gelman absorbent pads. Both the membranes and pads were pre-soaked for 
$30 \mathrm{~min}$ in buffer $\mathrm{B}$. At the required stage, the membranes were frozen at $-70^{\circ} \mathrm{C}$. Upon thawing, $0.5 \mathrm{ml}$ of buffer $A$ was applied to each pad. The lysates were scraped from the membranes and then centrifuged at $14,500 \times \mathrm{g}$ for $6 \mathrm{~min}$. The supernatant was used to prepare gel samples for SDSPolyacrylamide gel electrophoresis (SDS-PAGE) as described below.

\subsubsection{Preparation of Cell lysates}

Washed cells were suspended in 5 volumes of cold buffer $A$ and sonicated by subjection to three 45 second exposures to a $2 \mathrm{~cm}$ probe of a sonic cell disrupter (Model 300, Fisher). This lysate was centrifuged for 20 mins at $8000 \times \mathrm{g}$ and the resulting supernatant centrifuged at $100,000 \times \mathrm{g}$ for an hour. Differentiated cells were homogenized with three strokes of a Potter-Elvehjem tissue grinder and then sonicated as described for amoebae.

\subsubsection{Column chromatography}

The $100,000 \times \mathrm{g}$ supernatant was batch treated with 0.1 volume of DE52 cellulose resin that had been equilibrated in buffer $\mathrm{A}$. After stirring $10 \mathrm{~min}$, the resin was settled by centrifugation and poured into a column $(3 \mathrm{~cm} \times 6 \mathrm{~cm})$. Bound proteins were eluted with an 8 hour linear $0 \cdot 0.25$ $\mathrm{M} \mathrm{KCl}$ gradient in buffer $\mathrm{A}$. Column fractions were then assayed for glycogen phosphorylase activity in the presence and absence of 5' AMP as described below. Phosphorylase ' $a$ ' activity eluted at $50 \mathrm{mM} \mathrm{KCl}$, while the ' $\mathrm{b}$ ' form eluted at $180 \mathrm{mM} \mathrm{KCl}$. 


\subsubsection{Enzyme Assay}

A $20 \mu \mathrm{l}$ sample of a given enzyme preparation was added to $200 \mu \mathrm{l}$ of reaction mixture containing $50 \mathrm{mM}$ Imidazole ( $\mathrm{pH} 6.8$ ), $2.5 \mathrm{mg} / \mathrm{ml}$ glycogen, $5 \mathrm{mM} \mathrm{MgCl}, 0.5 \mathrm{mM}$ NADP, 50 $\mu \mathrm{g} / \mathrm{ml}$ glucose-1.6 diphosphate, $2 \mathrm{mM} \mathrm{K} \mathrm{HPO}_{4}, 0.3 \mu \mathrm{m} / \mathrm{ml}$ glucose-6-phosphate dehydrogenase, and $0.4 \mu \mathrm{m} / \mathrm{ml}$ phosphoglucomutase. The temperature of the assay mixture was maintained at approximately $23^{\circ} \mathrm{C}$. A molar extinction coefficient of $6.2 \times 10^{3}$ was used to quantitate NADPH formation at $340 \mathrm{~nm}$. One unit of activity is defined as the amount of enzyme that catalyzes the synthesis of $1 \mu \mathrm{mol} \mathrm{NADPH} / \mathrm{min}$ at $23^{\circ} \mathrm{C}$.

\subsubsection{Antibody Preparation}

Both the ' $a$ ' and ' $b$ ' forms of the phosphorylase were purified to homogeneity by anion exchange chromatography and affinity chromatography. (Rutherford and Cloutier, 1986). The purified forms were subjected to preparative SDS-PAGE, upon which a single protein band was observed for each enzyme form. These protein bands were then sliced and eluted from the gel slices electrophoretically. The eluates were used as antigens. Two New Zealand white rabbits were each injected with 50-150 $\mathrm{\mu g}$ of purified protein in complete Freunds adjuvant. The rabbits were reinjected with 50-100 $\mu \mathrm{g}$ protein in incomplete Freunds adjuvant at two week intervals. After 6 weeks, the presence of antibody to the protein was confirmed by western blotting. Whole blood was allowed to clot overnight at $4^{\circ} \mathrm{C}$, then centrifuged at $10,000 \times \mathrm{g}$ for $10 \mathrm{~min}$. The serum was divided into $300 \mu \mathrm{l}$ aliquots and stored frozen at $-20^{\circ} \mathrm{C}$ for subsequent use. Both antiserum preparations had similar titres; a 1:500 dilution of each serum was used for immunostaining and immunoprecipitation. 


\subsubsection{Immunoprecipitation analyses}

Partially purified phosphorylase ' $a$ ' and ' $b$ ' activity peaks obtained by DE52 Cellulose chromatography were used for these experiments. Typically, $0.5 \mathrm{ml}$ of an active fraction with activity ranging from 5-20 nmoles $/ \mathrm{min} / \mathrm{ml}$ were incubated with $0.1 \mathrm{ml}$ of crude, undiluted antiserum for $45 \mathrm{mins}$ at $25^{\circ} \mathrm{C}$. Protein A (20 mg) was then added in order to pellet the antigen - antibody complex (1800 x $\mathrm{g}$ for $8 \mathrm{mins})$. The resulting pellet was washed five times in order to remove proteins bound nonspecifically to the protein A (wash $1,2 \mathrm{ml}$ of $0.1 \% \mathrm{SDS}$ in $\mathrm{H}_{2} \mathrm{O}$; wash $2,2 \mathrm{ml}$ of $0.1 \%$ SDS; washes $3-5,3 \mathrm{ml}$ each of cold buffer A). The immune complexes were eluted from the protein A pellet by boiling for $2 \mathrm{~min}$ in $0.1 \mathrm{ml}$ buffer A containing $2 \%$ SDS and 5\% dithiothreitol. After pelleting the protein A, the supernatant was mixed with sucrose crystals and $0.02 \%$ pyronin $\mathrm{Y}$ in preparation for SDS-PAGE.

\subsubsection{Immunoinhibition analyses}

Phosphorylase ' $a$ ' and ' $b$ ' activities from DE52 chromatography were used for these analyses. The respective activities were equalized to approximately $15 \mathrm{nmoles} / \mathrm{min} / \mathrm{ml}$ by dilution in buffer A. A $0.1 \mathrm{ml}$ sample of each antiserum (1:5 in buffer A) was incubated with $0.1 \mathrm{ml}$ of the enzyme fraction overnight at $4^{\circ} \mathrm{C}$ and then centrifuged at $12,000 \times \mathrm{g}$ for 10 mins. The resulting supernatants were then assayed for phosphorylase activity as described above. Percent inhibition of enzyme activity was calculated by comparing the activities in samples incubated with antisera versus those incubated with a preimmune control serum. 


\subsubsection{Immunoblotting}

Proteins resolved by SDS-PAGE were electrophoretically transferred to nitrocellulose membranes using a Hoefer transfer chamber and a power source (model TE51) set at 1.2 amps for one hour. The transfer buffer contained $192 \mathrm{mM}$ glycine and $20 \%$ methanol in $25 \mathrm{mM}$ Tris- $\mathrm{HCl}$, pH 8.3 (Towbin et al 1979). After transfer, the nitrocellulose was placed in $50 \mathrm{ml}$ of $50 \mathrm{mM}$ Tris-HCL, pH 7.6, $200 \mathrm{mM} \mathrm{NaCl}$ and $0.1 \%$ Tween 20 (buffer C), and gently shaken for 20-30 $\min$. The buffer was then replaced with $50 \mathrm{ml}$ of fresh buffer $\mathrm{C}$ containing $100 \mu \mathrm{l}-300 \mu \mathrm{l}$ of the appropriate undiluted antiserum. After 1-12 hours of incubation with the antibody, the nitrocellulose was rinsed several times with fresh $50 \mathrm{ml}$ solutions of buffer C. A $50 \mathrm{ml}$ solution of buffer C containing $1 \mu \mathrm{g} / \mathrm{ml}$ protein A - peroxidase was then placed onto the blot and incubated with gentle shaking for $\mathrm{lhr}$. The nitrocellulose was rinsed with two $50 \mathrm{ml}$ volumes of buffer $\mathrm{C}$ and then with $50 \mathrm{ml}$ of buffer $\mathrm{C}$ lacking Tween 20 (buffer $\mathrm{C}^{\prime}$ ). The nitrocellulose was then exposed to $48 \mathrm{mls}$ of peroxidase reaction mixture containing $17 \%$ methanol, $24 \mathrm{mg}$ of 4 -chloro-1-napthol, and $0.008 \% \mathrm{H}_{2} \mathrm{O}_{2}$ in buffer $\mathrm{C}$ for $30-120 \mathrm{~min}$. In some cases, the western blots were stained for protein by using $0.1 \%$ napthol-blue black (amido black) in methanol, water, and acetic acid (4.5:4.5:1 ratio, $v / v / v)$. The destaining solution contained $90 \%$ methanol and $2 \%$ acetic acid. Autoradiography of the blots was performed using a Kodak intensifying screen and Kodak XAR-5 X-ray film.

\subsubsection{0 cAMP Induction experiments}

Logarithmically growing AX-3 amoebae were plated onto non-nutrient agar in buffer B and then placed at $4^{\circ} \mathrm{C}$ for $12 \mathrm{hrs}$. One aliquot of these starved cells was removed from the agar, washed twice in buffer B, and resuspended at $5 \times 10^{6}$ cells $/ \mathrm{ml}$ in buffer B either in the presence or absence of $1 \mathrm{mM}$ cAMP. Another aliquot of starved cells was treated similarly except that the buffer used was $10 \mathrm{mM}$ Na-K phosphate buffer (buffer D) $+/-1 \mathrm{mM}$ cAMP. Thirty mls. of these cells were 
placed in $125 \mathrm{ml}$ Erlenmyer flasks and were shaken at $150 \mathrm{rpm}$ on an orbital shaker (Model 3520, Lab-Line Instruments). At 0,5 , and 10 hours post shaking, $5 \mathrm{ml}$ of cells were removed from each flask. These cells were centrifuged, resuspended in buffer D, and lysed by sonication as explained earlier. The lysates were centrifuged at $14,500 \times \mathrm{g}$ for 6 mins. The resulting supernatants were assayed for phosphorylase activity, and prepared for SDS-PAGE samples immediately. 


\subsection{Results}

\subsubsection{Phosphorylase activity during Dictyostelium development.}

Previous studies of glycogen phosphorylase in Dictyostelium showed that the enzyme was developmentally regulated. Little or no activity was present in early development, followed by a peak of activity in the culmination stage of development. The activity of this enzyme was not affected by S'AMP. With our discovery of an inactive S'AMP dependent form of the phosphorylase, questions regarding the relationship between the two enzyme forms and the mechanism of developmental regulation of phosphorylase activity arose (Rutherford and Cloutier, 1986). Using DE52 cellulose anion exchange chromatography, we have shown that the 5'AMP dependent activity (the ' $b$ ' form) is present in the early stages of Dictyostelium differentiation, namcly amoebae and aggregated amoebae (Rutherford and Cloutier, 1986). Over the next 18-20 hours, these multicellular aggregates differentiate into stalk and spore cells, thereby traversing the 'slug' and 'culmination' stages. It is during the latter stages that the S'AMP independent activity (the ' $a$ ' form) increases. Furthermore, the phosphorylase ' $b$ ' activity decreases during these later stages. This is observed as a thirteen - fold decrease in the 5' AMP dependence of the enzyme activity. Further, Table 1 shows that at any given point in the life cycle, the sum of the specific activities of ' $a$ ' and ' $b$ ' forms remains equal, at approximately $250 \mathrm{nmols} / \mathrm{min} / \mathrm{mg}$ dry wt (Table 1). This value is similar to the maximum Dictyostelium phosphorylase activities reported in the literature (Marshall et al., 1970; Gustafson and Wright, 1972; Wright et al., 1968; Jones and Wright, 1970; Firtel and Bonner, 1972; Rutherford and Harris, 1976; Thomas and Wright, 1976, Part I; Thomas and Wright, 1976, Part II Higgins \& Dahmus 1982).

Extracts from each of the stages shown in Table 1 were also subjected to SDS-PAGE, then western blotted, and stained with a mixture of our antisera. The aim was to monitor the banding pattern of the phosphorylase protein as its activity changed during development. The 
phosphorylase from the amoeba stage was entirely in the ' $b$ ' form as shown by the 5'AMP dependent activity (Table 1). Upon western blotting a doublet protein at $92 \mathrm{kd}$ stained by the anti-' $b$ ' antiserum was associated with the ' $b$ ' activity (Fig 3, lane 1-3). At the aggregation stage a higher molecular weight protein doublet appeared at $104 \mathrm{kd}$. The presence of this $104 \mathrm{kd}$ protein, as detected by western blotting, coincided with the appearance of ' $a$ ' activity as shown in Table 1 . The lower member of this doublet (arrow) intensified as phosphorylase 'a' activity increased during later stages (Table 1; Fig 3, lanes 3,4). It should also be pointed out that the corresponding drop in phosphorylase ' $b$ ' activity during these later stages was not accompanied by diminished intensity of the $92 \mathrm{kd}$ protein (Fig 3, lanes 1-4). I have occasionally observed a series of intermediate protein bands between the 104 and $92 \mathrm{kd}$ bands, suggestive of proteolysis of the $104 \mathrm{kd}$ protein occurring in these samples. If additional phosphorylase ' $\mathrm{b}$ ' ( $92 \mathrm{kd}$ protein) was being produced by proteolysis of the $104 \mathrm{kd}$ protein, it was inactive, since all late stage activity was totally 5'AMP independent (Table 1). 
Figure 3: Western blot analysis of phosphorylase ' $a$ ' and ' $b$ ' activities from four developmental stages

Cells were harvested in buffer $A$ and lysed by freezing at $-70^{\circ} \mathrm{C}$. The thawed lysates were centrifuged at $14,500 \times \mathrm{g}$ for 6 mins and prepared for SDS-PAGE and western blotting. The western blots were stained with a mixture of antisera: (lane 1) amoebae, (lane 2) aggregation (lane 3) early slug, (lane 4) migrating slug, (lane 5) early culmination, (lane 6) late culmination. The arrow indicates the position of the lower member of the $104 \mathrm{kd}$ ' $\mathrm{a}$ ' subunit doublet protein. 


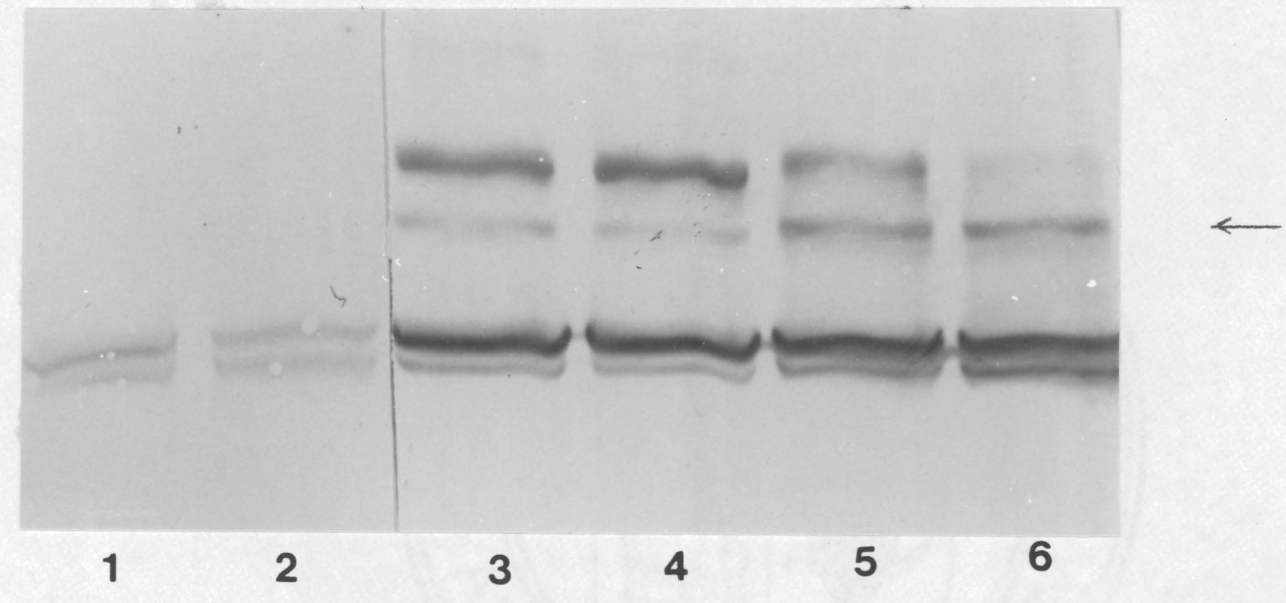


During the studies of the two enzyme forms at different stages of development, I occasionally observed low molecular weight proteins on SDS-PAGE that were recognized by the antisera. In order to determine whether these small proteins were cross-reactive antigens or degradation products of phosphorylase, I subjected purified forms of Dictyostelium phosphorylase to proteolysis, SDS-PAGE and westem blotting. The resulting peptide maps are shown in figure 4. Fig $4 \mathrm{~A}$ shows that the anti-' $\mathrm{b}$ ' does recognize the degradation products of phosphorylase ' $\mathrm{b}$ ' (lanes 3,4). In fact, all of the peptides that were produced by proteolysis (as observed by protein stain) were recognized by the antiserum. Furthermore, Fig $4 \mathrm{~A}$ shows that anti- $\mathrm{b}$ ' does not cross-react with the degradation products of commercial rabbit skeletal muscle phosphorylase ' $b$ ' (lanes 5,6$)$. Likewise, Fig 4B shows that the ' $a$ ' antiserum detects the fragments produced by digestion of the the ' $a$ ' form (lanes 1,2 ) and does not cross-react with those of the rabbit phosphorylase ' $b$ ' (lane 5). These results show that each antiserum was specific for its antigen as well as its proteolytic fragments. This data did not unequivocally show whether the peptide maps represented similar or different proteins. However, it did enable me to monitor the stability of the antigens during the following immunoprecipitation experiments. 
Figure 4A: Western Blot analysis of peptide maps of phosphorylase ' $a$ ' and ' $b$ ' activities using ' $b$ ' antiserum

Purified preparations of each form were resolved on preparative SDS-PAGE gels. The resulting protein bands were sliced, and equivalent amounts of the two forms were inserted into wells of a $15 \%$ SDS polyacrylamide gel. $0.4 \mu \mathrm{g}$ of V8 protease were then overlaid onto the slices. The gel was run according to the Laemmli protocol and western blotted as described. (Lanes 1-2) Dictyostelium phosphorylase ' $a$ ' + V8, (lanes 3-4) Dictyostelium phosphorylase ' $b$ ' + V8, (lanes 5-6) Rabbit phosphorylase ' $\mathrm{b}$ ' + V8. 
A

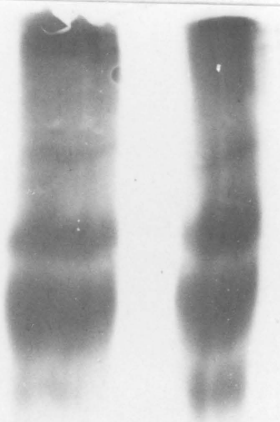

1

2

3

4

5

6 
Figure 4B: Westem blot analysis of peptide maps of phosphorylase ' $a$ ' activity using ' $a$ ' antiserum

Purified phosphorylase ' $a$ ' was visualized by preparative SDS-PAGE. The resulting protein band was inserted into wells of a $15 \%$ SDS-polyacrylamide gel. $0.4 \mu \mathrm{g}$ of V8 protease was then overlaid onto the slices. The gel was run according to the Laemmli protocol and western blotted. (Lanes 1-2) Dictyostelium phospohorylase ' $a$ ' + V8, (lane 3) Dictyostelium phosphorylase ' $a$ ' - V8, (lanes 4-5) Rabbit phosphorylase ' $b$ ' + V8. 


\section{B}

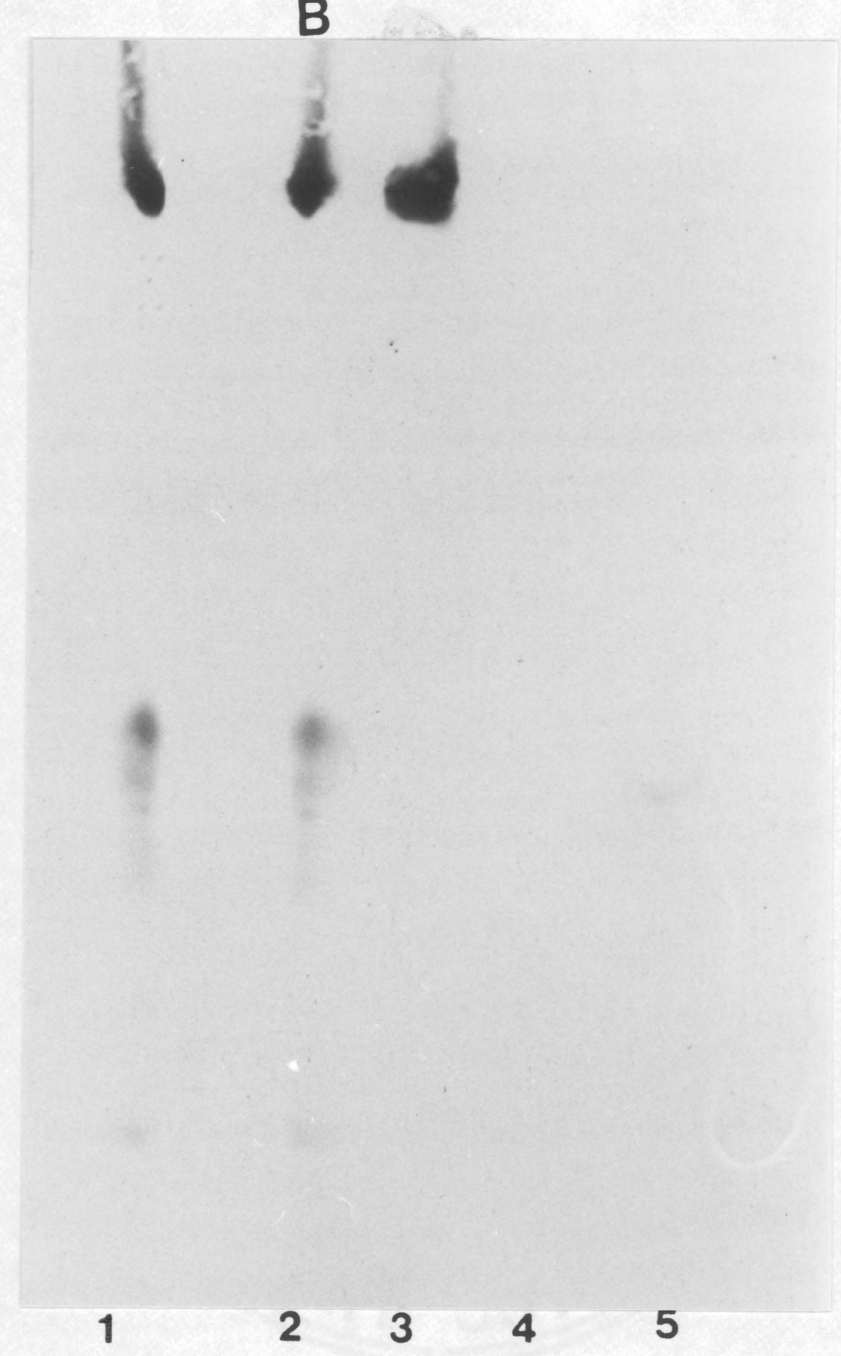




\subsubsection{Immunologic analyses of phosphorylase ' $a$ ' and ' $b$ '}

It was necessary to obtain partially purified forms of the ' $a$ ' and ' $b$ ' enzymes in order to perform immunoprecipitation and immunoinhibition analyses on them. The first step was to test various concentrations of antisera, and antiserum/protein A ratios in order to optimize conditions for immunoprecipitation. The protocol used (see Materials and Methods) enabled $\mathbf{9 0 \%}$ immunoprecipitation of the antigen(s) from any given extract. Preimmune controls were performed in all immunoprecipitation and immunoinhibition experiments. The next step was to choose a chromatographic procedure that would separate the ' $a$ ' and ' $b$ ' forms. We have previously shown that DE52 cellulose chromatography effectively separated the ' $a$ ' and ' $b$ ' forms of the phosphorylase. Thus, Figs 5 and 6 present data from immunoprecipitation analyses of phosphorylase ' $a$ ' and ' $b$ ' obtained by DE52 chromatography of amoeba and culmination stages. Figure 5 shows westem blots of amoeba phosphorylase ' $b$ ' activity from a DE52 cellulose column. These samples were immunoprecipitated and stained with either anti-' $b$ ' (Fig 5A) or anti-'a' (Fig SB). The anti- ' $b$ ' stained western blot in Fig SA shows that the ' $b$ ' antiserum immunoprecipitates a protein doublet of 92 kilodaltons (ianes $2,4,6,8$ ). This protein is also weakly immunoprecipitated by the ' $a$ ' antiserum (lanes 1,3,5,7), suggesting partial cross-reactivity between antisera. Fig 5B shows the anti-'a' stained portion of the same western blot. The only protein observed was the 92 $k d$ protein derived from anti- $b$ ' immunoprecipitates of fractions containing the peak of ' $b$ ' form activity (lanes 4,6). The anti-'a' did not immunoprecipitate sufficient enzyme protein from these fractions in order to produce a band detectable by anti-'a' staining (lanes $1,3,5,7$ ). 
Figure 5: Phosphorylase ' $b$ ' activity from the amoeba stage immunoprecipitated and western blotted with both antisera

Fig 5A. An anti-' $b$ ' stained western blot of ' $b$ ' enzyme immunoprecipitated with anti- $b$ ' (lanes 2,4,6,8), and anti-' $a$ ' (lanes 1,3,5,7). Fig 5B. An anti-' $a$ ' stained blot of ' $b$ ' enzyme activity immunoprecipitated with anti- $\mathrm{b}^{\prime}$ (lanes $2,4,6,8$ ), and anti-' $\mathrm{a}$ ' (lanes $\left.1,3,5,7\right)$. 


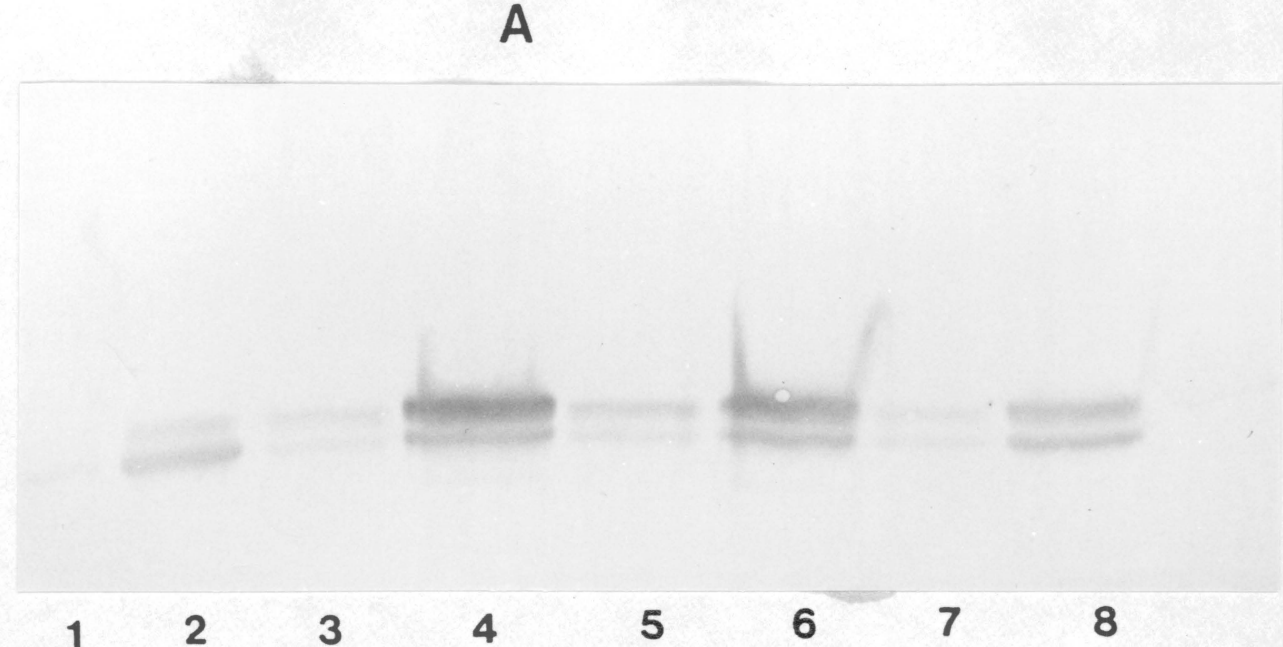

12

34

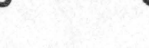

B

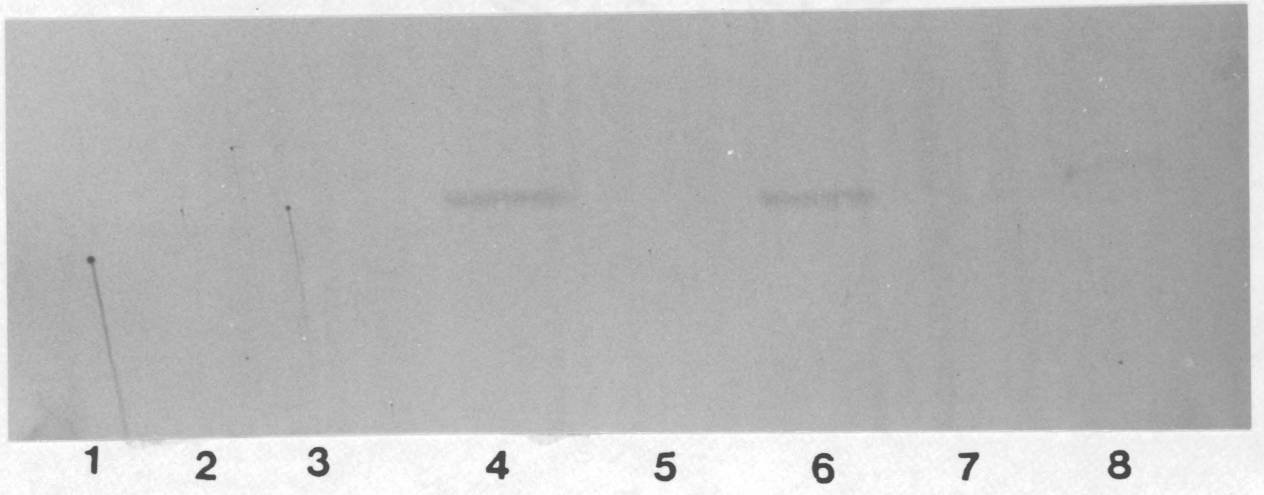


Figure 6 shows results of a similar experiment from the culmination stage. At this stage of development DE52 cellulose chromatography clearly separated ' $a$ ' and ' $b$ ' activity peaks (Rutherford and Cloutier, 1986). Thus, each form of the enzyme could be analyzed by immunoprecipitation and westem blotting. The anti-' $b$ ' stained western blot (Fig 6A) shows that immunoprecipitation of the DE52 cellulose fractions containing ' $\mathrm{b}$ ' activity yielded the $92 \mathrm{kd}$ protein (lanes $2,4,6,8,10$ ). The ' $a$ ' antiserumn weakly immunoprecipitates this protein from the same samples (lanes 1,3,5,7,9), again suggesting poor cross-reactivity between antigens. Similar experiments on DE52 fractions containing only ' $a$ ' activity from culmination stage revealed an interesting difference in that the $92 \mathrm{kd}$ protein was absent and was replaced by a protein doublet of $104 \mathrm{kd}$ (Figures 6B \& 6C). The $104 \mathrm{kd}$ doublet was immunoprecipitated by the 'a' antiserum only (Fig 6B,6C, lanes 1,3). The intensity of the $104 \mathrm{kd}$ protein (as measured by western blotting) paralleled the phosphorylase ' $a$ ' activity in these DE52 cellulose fractions (as measured spectrophotometrically). Although the anti-' $\mathrm{b}^{\prime}$ antibody could not immunoprecipitate the $104 \mathrm{kd}$ protein (Fig 6B,6C, lanes 2,4), the anti - $\mathrm{b}^{\prime}$ could recognize the $104 \mathrm{kd}$ protein band since this protein was stained on nitrocellulose (Fig 6C, lanes 1,3). This phenomenon may be due to the greater affinity of anti- ' $b$ ' for denatured phosphorylase ' $a$ ' on nitrocellulose as opposed to the native enzyme during immunoprecipitation. 
Figure 6A,6B: Culmination stage phosphorylase ' $a$ ' and ' $b$ ' activities immunoprecipitated with both antisera and western blotted with ' $b$ ' antiserum

Fig 6A. An anti- $b$ ' stained blot of phosphorylase ' $b$ ' activity immunoprecipitated with both antisera. In lanes $1,3,5,7,9$ the phosphorylase ' $b$ ' activity peak was immunoprecipitated with anti-' $a$ '. In lanes $2,4,6,8,10$ the ' $b$ ' activity peak was immunoprecipitated with anti-' $b$ '. Fig 6B. An anti-' $b$ ' stained blot of phosphorylase ' $a$ ' activity immunoprecipitated with anti-' $a$ ' (lanes 1,3 ) and anti- $b$ ' (lanes 2,4). 
A
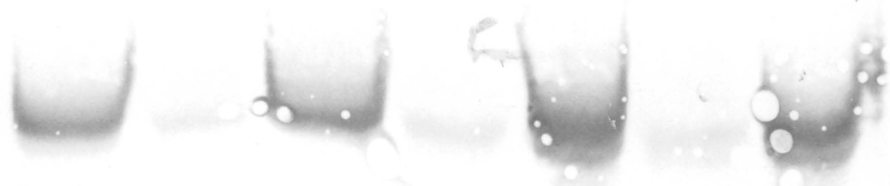

123

345

56

$7 \quad 8 \quad 9$

$9 \quad 10$

B 
Figure 6C: Culmination stage phosphorylase ' $a$ ' activity immunoprecipitated with both antisera and western blotted with ' $a$ ' antiserum

An anti-' $a$ ' antiserum stained blot of phosphorylase ' $a$ ' activity immunoprecipitated with anti-' $a$ ' (lanes 1,3) and anti-' $b$ ' (lanes 2,4). 
C

1

2

3

4

2.0 The immunologic relationship between the two forms of phosphorylase

36 
The specificity of the antisera for their respective forms of phosphorylase was also demonstrated by immunoinhibition of enzyme activity. Table 2 shows that the ' $b$ ' antiserum did not inhibit phosphorylase ' $a$ ' activity, wheras the ' $a$ ' antiserum caused a $67 \%$ inhibition of ' $a$ ' activity. Conversely, phosphorylase ' $b$ ' activity was completely inhibited by the anti - ' $b$ ' antibody, and marginally inhibited by anti - ' $a$ ' antiserum. The low cross-reactivity of anti - ' $a$ ' for the ' $b$ ' enzyme would explain the minor $92 \mathrm{kd}$ protein observed in anti - ' $a$ ' immunoprecipitates of ' $b$ ' enzyme from amoeba (Fig $5 \mathrm{~A}$, lanes $1,3,5,7$ ) and culmination stage (Fig $6 \mathrm{~A}$, lanes $1,3,5,7,9$ ).

\subsubsection{Subunit molecular weights of phosphorylase ' $a$ ' and ' $b$ '}

The data presented in Figures 5 and 6 suggest that in partially purified extracts, the phosphorylase ' $b$ ' monomer has a molecular weight of $92 \mathrm{kd}$, whereas the phosphorylase ' $a$ ' monomer corresponds to the $104 \mathrm{kd}$ protein. The De52 cellulose fractions containing ' $a$ ' activity , were subjected to an additional purification by hydroxylapatite chromatography and determined its molecular weight following its elution from the resin The $104 \mathrm{kd}$ and $92 \mathrm{kd}$ proteins obtained from culmination stage phosphorylase ' $a$ ' and ' $b$ ' DE52 samples were used as standards in this experiment (Fig 7, lanes 8,9). Figure 7 shows that the hydroxylapatite purified phosphorylase ' $a$ ' protein comigrates with the $104 \mathrm{kd}$ protein (Fig 7, lanes 1-5,10) and is therefore clearly of higher molecular weight than the ' $b$ ' form. 
Figure 7: Molecular weight of partially purified phosphorylase ' $a$ '

Phosphorylase ' $a$ ' from culmination stage was purified to near homogeneity by DE52 Anion exchange and Hydroxylapatite chromatographies. The resulting protein was subjected to SDS-PAGE and western blotting and the blot then stained with a mixture of antisera. (lanes 1-5) DE52 column fractions containing phosphorylase ' $a$ ' activity, (lane 6) blank, (lane 7) Rabbit phosphorylase ' $\mathrm{b}$ ', (lanes 8-9) the $104 \mathrm{kd}$ and $92 \mathrm{kd}$ doublet proteins respectively, from the slug stage, (lane 10) Hydroxylapatite purified phosphorylase ' $a$ '. 


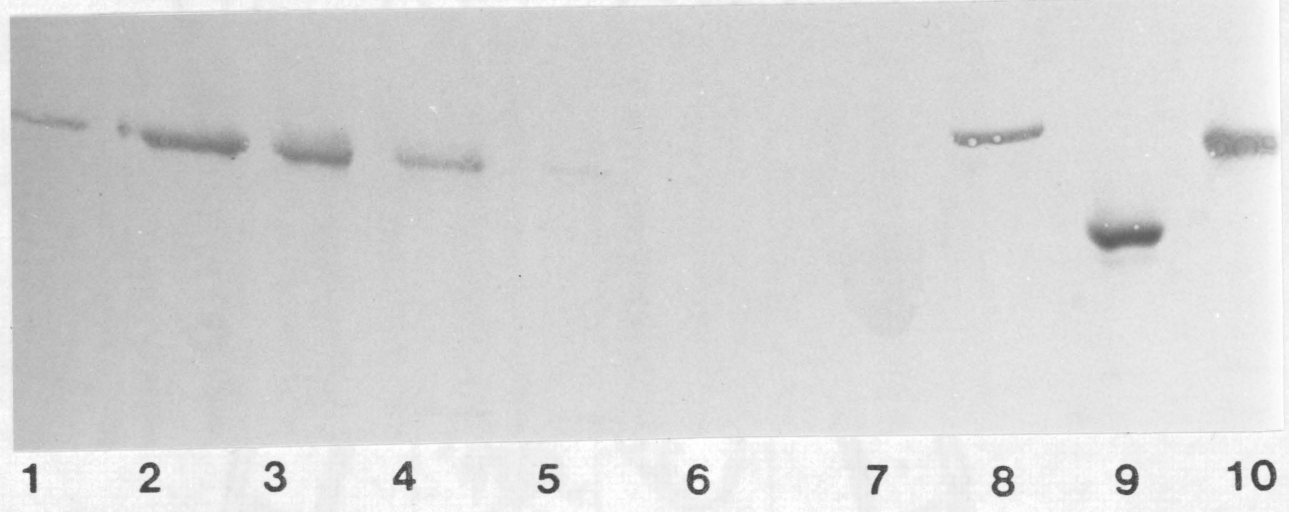


The higher molecular weight observed for purified Dictyostelium phosphorylase 'a' may indicate that it represents a gene product distinct from the ' $b$ ' form. Alternately, phosphorylation of ' $b$ ' form may retard the migration of the protein on SDS-PAGE and result in only an apparent increased molecular weight (Mammalian phosphorylase ' $a$ ' which is a tetramer, contains 1 mole phosphate/mole of monomer. The ' $a$ ' and ' $b$ ' forms of the enzyme have a subunit molecular weight of $98 \mathrm{kd})$. However, precedents for an apparent molecular weight shift of phosphoproteins occur in the literature (Dahmus, 1981). The next step was to determine whether phosphorylase ' $\mathrm{b}$ ' is phosphorylated during the developmental cycle. Figure 8 on page 47 shows the in vitro phosphorylation of amoeba ' $b$ ' enzyme by an endogenous protein kinase that coelutes with it on DE52 cellulose chromatography. This protein kinase required $5 \mathrm{mM} \mathrm{Mg}^{2+}$ or $\mathrm{Mn}^{2+}$ and micromolar concentrations of ATP for activity (Fig 8B, lanes 2-4, 6,7). This kinase is not activate in the presence of $5 \mathrm{mM} \mathrm{Ca}^{2+}$ (Fig $8 \mathrm{~B}$, lane 1). Interestingly, the molecular weight of the phosphorylated ' $\mathrm{b}$ ' form remained at $92 \mathrm{kd}$; that is, it did not shift to a $104 \mathrm{kd}$ position as would be predicted by the reasoning stated above. This may be because incomplete phosphorylation of the ' $b$ ' form was obtained; i.e. sequential phosphorylation at multiple sites by single or multiple kinases may be necessary to convert the ' $b$ ' form into the larger S'AMP independent ' $a$ ' form. Furthermore, it is possible that only a small, undetectable fraction of the ' $b$ ' form undergoes complete phosphorylation and therefore conversion. This hypothesis would explain the inability to detect a reproducible decrease in S'AMP dependence of the enzyme after phosphorylation of the ' $b$ ' form (data not shown). I have also observed an in vivo phosphorylation of the ' $b$ ' form from the amoeba and aggregation stages of development. No increase in molecular weight of the phoshorylated ' $\mathrm{b}$ ' form was observed in these experiments (see sections 3.4.4.and 3.4.5). The in vivo phosphorylation of the ' $\mathrm{b}$ ' enzyme has not been demonstrated in later development, possibly due to the presence of endogenous protein phosphatases or a lack of the appropriate protein kinase (s) (see section 3.4.5). 
Figure 8: In vitro phosphorylation of phosphorylase ' $b$ ' from amoeba

Fig 8A. Western blot. Fig 8B. Autoradiogram of the western blot. Phosphorylase ' $b$ ' activity was obtained by DE52 anion exchange chromatography. This sample was then incubated at $25^{\circ} \mathrm{C}$ for $15 \mathrm{mins}$ in the presence of $1.7 \mu \mathrm{m}\left[\gamma^{32} \mathrm{P}\right]$ ATP ( $30 \mathrm{Ci} / \mathrm{mmol}$ ) and varying levels of cation in buffer A, pH 8.0, containing $5 \mathrm{mM}$ EGTA and $20 \mathrm{mM} \mathrm{NaF}$. The reaction was stopped by boiling in the presence of $2 \%$ SDS and $5 \%$ dithiothreitol. The arrow indicates the position of the $92 \mathrm{kd}$ protein, (lane 1) $7 \mathrm{mM} \mathrm{CaCl}_{2}$, (lane 2) $7 \mathrm{mM} \mathrm{MgCl}$, (lane 3-4) 7 and $14 \mathrm{mM} \mathrm{MnCl}$ respectively, (lane 5) absence of exogenous cations, Lanes 6-8 show similar results with another sample of phosphorylase ' $\mathrm{b}$ ', (lanes 6-7) 7 and $14 \mathrm{mM} \mathrm{MnCl}_{2}$, (lane 8) absence of exogenous cation. 
A
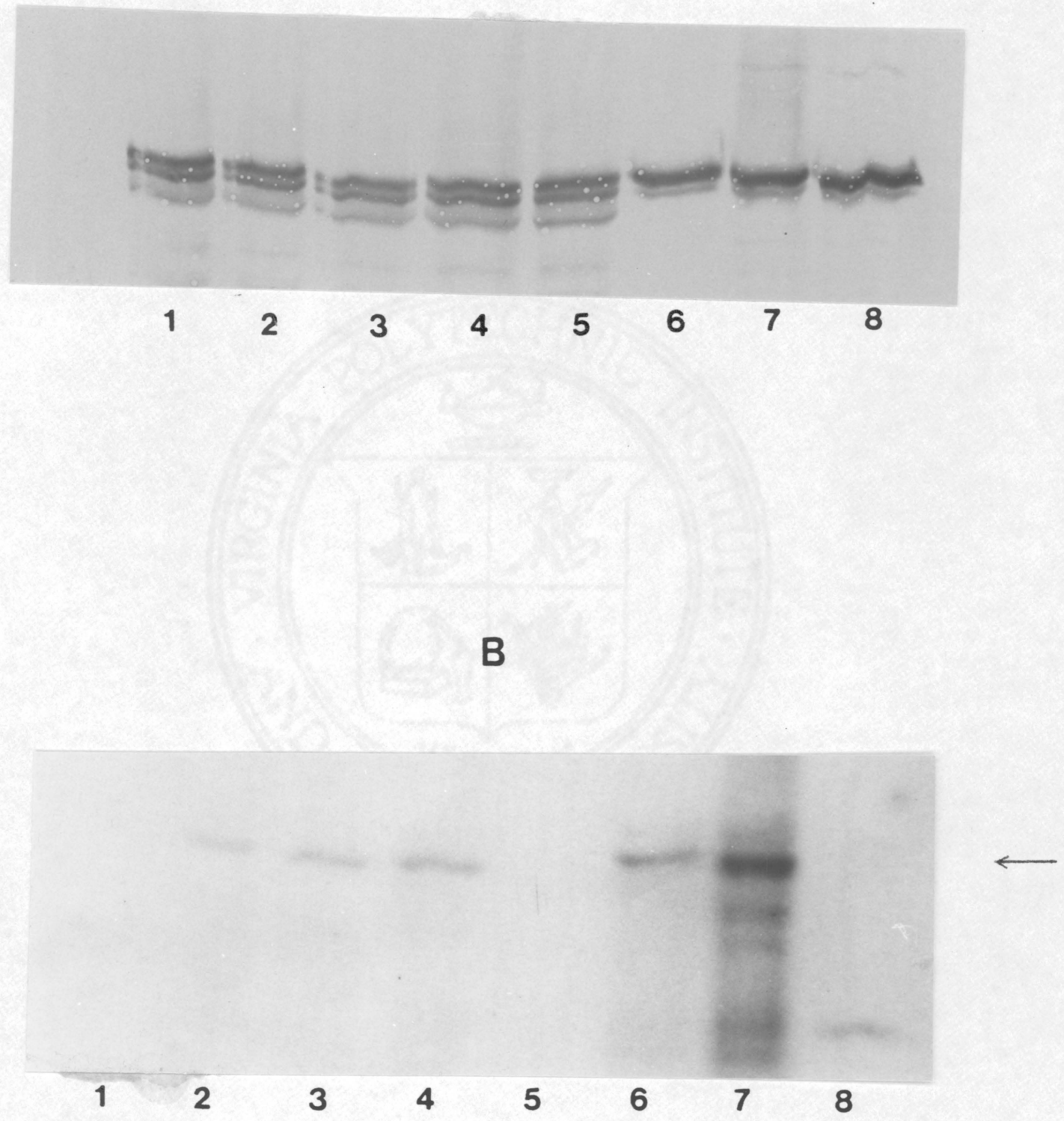


\subsubsection{CAMP regulation of phosphorylase ' $\mathbf{a}$ ' activity.}

Cyclic AMP perturbation of intact amoebae and the subsequent analysis of the glycogen phosphorylase lends further support to the hypothesis that the $104 \mathrm{kd}$ protein represents Dictyostelium phosphorylase ' $a$ '. It has been established in the literature that exogenously added cyclic AMP (cAMP) induces phosphorylase activity in shaken cell suspensions wherein cell contact is negligible (Schapp and van Driel, 1985). Figure 9 shows the parallel induction by cAMP of 5'AMP independent phosphorylase activity, and the appearance upon immunoblotting, of the 104 kd protein (Fig 9A, lanes 1,3 Fig 9B, lane 10). The induction of phosphorylase ' $a$ ' activity by cAMP was accompanied by a corresponding decrease in their phosphorylase ' $b$ ' activities. There was a $60 \%$ decrease in ' $b$ ' enzyme activity accompanied by a corressponding $60 \%$ increase in the ' $a$ ' enzyme activity measured in the + cAMP flasks. The anti- ' $a$ ' stained western blot in Fig 9B showed an intense $104 \mathrm{kd}$, band (lane 10) when compared with the corresponding band in the anti' $b$ ' stained western blot (Fig 9A, lanes 1,3 ). This is because anti- ' $b$ ' cross reacts weakly with the $104 \mathrm{kd}$ protein. The cells shaken in the absence of cAMP lacked the $104 \mathrm{kd}$ protein and the ' $\mathrm{a}$ ' activity. The latter extracts contained phosphorylase ' $b$ ' activity throughout the duration of the experiment as well as the $92 \mathrm{kd}$ protein (Fig 9A, lanes 2,4; Fig 9B, lane 11). Decreasing the level of cAMP added, to $0.1 \mathrm{mM}$ cAMP, to shaking cultures was insufficient to induce the $104 \mathrm{kd}$ protein and phosphorylase 'a' activity (Fig 9A, lanes 5,6).

The cAMP induction of the phosphorylase ' $a$ ' could be due to initiation of transcription or translation, or to cAMP activation of the cAMP Prk which in turn phosphorylates and activates a phosphorylase kinase. In order to determine if the cAMP - induced ' $a$ ' protein is due to phosphorylation, these experiments have been repeated in medium containing ${ }^{32} \mathrm{P}$ orthophosphate. To date, I have observed the presence of the phosphorylated $92 \mathrm{kd}$ protein either in the presence or absence of cAMP. The $104 \mathrm{kd}$ protein does not appear to be phosphorylated in the cAMP containing flasks although induction of the ' $a$ ' enzyme occurred. These data do not necessarily rule out cAMP dependent phosphorylation as the mechanism of phosphorylase 
activation for the following reason; we were unable to detect any cAMP dependent phosphorylation of proteins in these experiments (as measured by autoradiography) although cAMP Prk activity was measured in flasks shaken in the presence or absence of cAMP. The kinase was 6-8 fold dependent upon cAMP in both types of flasks, suggesting that it was present as a holoenzyme. However, the actual state of dissociation of the catalytic and regulatory subuntits of the kinase in vivo was not measurable, since we have shown previously that the subunits have rapid reassociation kinetics (Vaughn, 1985). Therefore, a true estimate of cAMP Prk activity and that of its putative substrate phosphorylase kinase cannot be determined under these experimental conditions. We are also performing experiments to determine whether the cell surface cAMP receptor is involved in mediating cAMP's inductive effect on phosphorylase ' $a$ '. The literature suggests that this receptor activates gene expression via a mechanism that does not involve the cAMP Prk (Haribabu and Dottin, 1986; Oyama and Blumberg, 1986). 
Figure 9: cAMP induction of phosphorylase ' $a$ ' activity in shaking cultures

Starved amoebae were resuspended at a density of $5 \times 10^{6} \mathrm{cells} / \mathrm{ml}$ in buffer B (Fig 9A, lanes 1-4 ;

Fig 9B, lanes 10-11) or buffer D (Fig 9A, lanes 5,6) in the presence or absence of $1 \mathrm{mM}$ cAMP. After 5 and 10 hours of shaking, $30 \mathrm{ml}$ of cells were harvested, sonicated and assayed for phosphorylase activity. The western blot in Fig 9A was stained with anti - ' $b$ ' antiserum while that in Fig 9B was stained with anti - 'a' antiserum. Fig 9A. (lane 1) 5 hrs. shaking in 1mM cAMP, (lane 2) 5 hrs. shaking in - cAMP, (lane 3) 10 hrs. shaking in 1mM cAMP, (lane 4) $10 \mathrm{hrs.} \mathrm{shaking}$ in - cAMP, (lane 5) 10 hrs. shaking in $0.1 \mathrm{mM}$ cAMP, (lane 6) 10 hrs. shaking in - cAMP, (lane 7) 104 kd protein standard from culmination stage 'a' enzyme. (lane 8) 92 kd protein standard from culmination stage 'b' enzyme, (lane 9) rabbit phosphorylase ' $b$ ' standard (92 kd). Fig 9B. (lane 10) $10 \mathrm{hrs}$. shaking in $1 \mathrm{mM}$ cAMP, (lane 11) $10 \mathrm{hrs}$. shaking in - cAMP. The arrow indicates the position of the $104 \mathrm{kd}$ ' $\mathrm{a}$ ' enzyme subunit. 


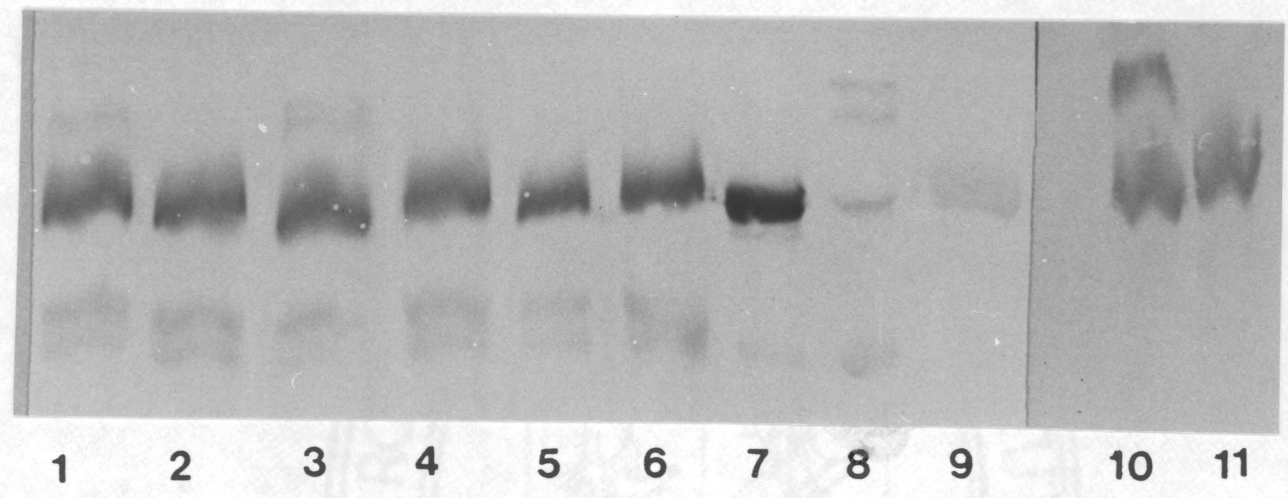




\subsubsection{Immunotitration of phosphorylase ' $a$ ' activity.}

One method used to examine whether an increase in enzyme activity is due to accumulation of enzyme molecules (de novo synthesis) or due to an activation of preexisting enzyme is immunotitration (Mayer and Walker, 1980). Immunotitrations were carried out on dilutions of $10,000 \times \mathrm{g}$ supernatants from different developmental stages. The results of immunotitration with the anti- ' $a$ ' antibody are shown in figure 10. The equivalence points (the concentration of ' $a$ ' antiserum required to completely inhibit phosphorylase ' $a$ ' activity from a given extract) for all three stages were identical. This would normally indicate that the enzyme activity/molecule of enzyme protein is the same for all stages of development. Therefore, the increase in activity of the ' $a$ ' form during development would be attributed to an increase in the number of enzyme molecules, rather than to activation of a preexisting inactive form. Although immunotitration is a commonly used technique for distinguishing between de novo synthesis and activation of inactive enzyme, there are some considerations that should be evaluated in this particular case. For example, implicit in the experiment is that antibody against an active form of the enzyme will cross-react with the inactive form. If this were true, then competition between the active and inactive forms would occur during immunotitration, resulting in different equivalence points as phosphorylase ' $b$ ' to ' $a$ ' conversion occurs. However, if the antibody to the active form does not cross-react well with the inactive form, then identical equivalence points would result - even though the mechanism by which the active form appears is via activation of the inactive form. The results in Fig 10 must therefore be interpreted with caution, for if the actual mechanism of the appearance of the ' $a$ ' activity is by conversion of the ' $b$ ' form one would expect nearly identical equivalence points, because we have shown that the anti-' $a$ ' cross-reacts poorly with the ' $b$ ' form. Alternately, if the anti-' $a$ ' does not cross-react with the ' $b$ ' form because it represents a separate protein, the immunotitration as shown in Fig 10 is a valid indication that the ' $\mathrm{a}$ ' form appears as the result of de novo synthesis. This argument hinges on the low cross-reactivity between anti-' $a$ ' and the ' $b$ ' enzyme. If phosphorylation were the mechanism of phosphorylase ' $b$ ' to ' $a$ ' conversion, it is conceivable that 
the resulting conformational change would create significant antigenic differences between the two enzymes forms, and therefore result in the low cross-reactivity between antisera (Table 2). 
Figure 10: Immunotitration of phosphorylase ' $a$ ' activity from crude extracts by anti - ' $a$ ' antiserum

Cells at the aggregation, slug and culmination stages were lysed by sonication and centrifuged at $14,500 \times \mathrm{g}$ for 10 mins. The resulting supernatants were diluted in buffer $\mathrm{A}$ in order to obtain 15 nmoles $/ \mathrm{min} / \mathrm{ml}$ of ' $\mathrm{a}$ ' activity. A $0.2 \mathrm{ml}$ sample of each diluted sample was incubated with anti - ' $\mathrm{a}$ ' antiserum and protein $A$ as descibed. The amount of residual activity vs. initial phosphorylase ' $a$ ' activity was plotted for each stage. 


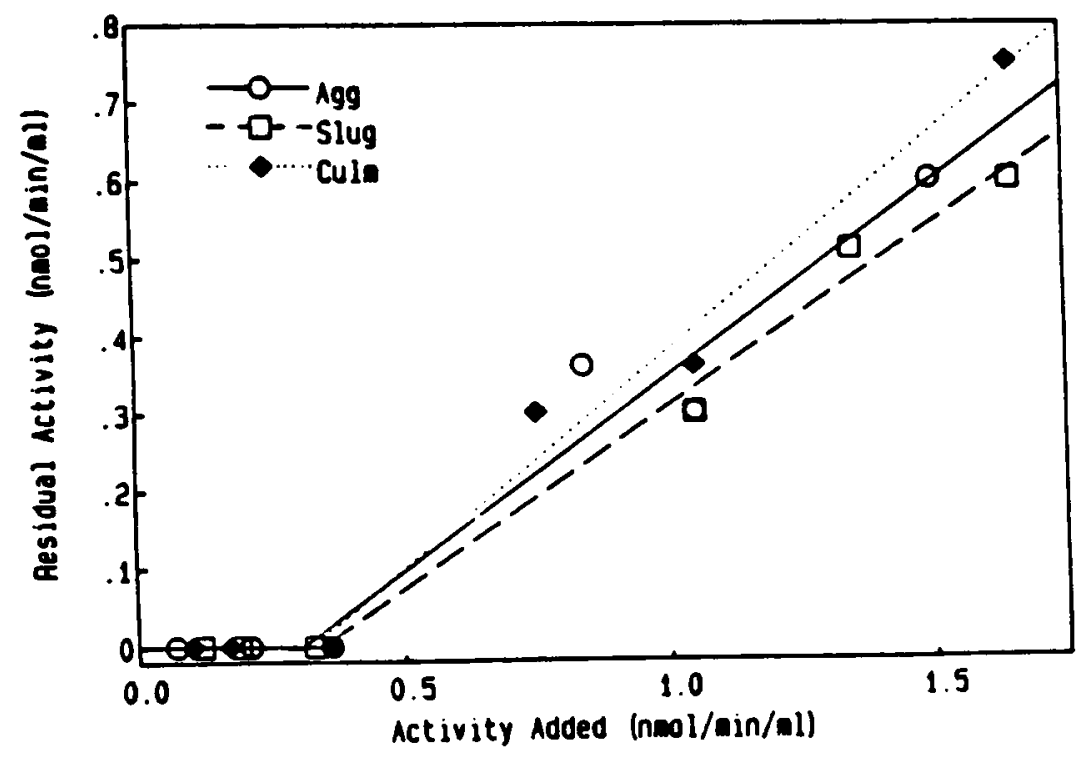




\subsection{Discussion}

The immunological data presented above show that the anti- ' $a$ ' antibody is specific for the $104 \mathrm{kd}$ doublet protein, and cross-reacts weakly with the $92 \mathrm{kd}$ protein. Conversely, the ' $\mathrm{b}$ ' antiserum is specific for the $92 \mathrm{kd}$ protein and cross-reacts weakly with the $104 \mathrm{kd}$ protein. The specificity of the antisera are clearly demonstrated in Table 2 , where only $0-15 \%$ percent crossreactivity exists between antisera. Since the specificity of the antisera was demonstrated by two different techniques, immunoprecipitation and immunoinhibition, these data reflect molecular differences between the two forms of the enzyme. The possibility that immunological crossreactivity exists between antigens without affecting their corresponding activities is unlikely, since the ' $a$ ' and ' $b$ ' antisera are specific for the $92 \mathrm{kd}$ and $104 \mathrm{kd}$ ' $a$ ' and ' $b$ ' subunit proteins respectively (Figs 5,6$)$. Whether this molecular difference arises due to altered conformation of the ' $a$ ' protein due to conversion of the ' $b$ ' form via phosphorylation, or other covalent modifications, or is due to the action of different genes, is unclear. Unless some epigenetic mechanism of activation of the ' $\mathrm{b}$ ' form is evoked, it is difficult to explain the concomitant decrease of ' $b$ ' activity and increase of ' $a$ ' activity with a constant combined specific activity during development. It is interesting to note that most lower eucaryotes that exhibit two forms of glycogen phosphorylase utilize a phosphorylation mediated conversion mechanism (Fosset et al., 1971; Tellez-Inon and Torres, 1970; Hayakawa, 1985).

The data also show that Dictyostelium phosphorylase 'a' is a protein with subunit molecular weight of $104 \mathrm{kd}$. The appearance of the $104 \mathrm{kd}$ protein parallels the appearance of ' $a$ ' enzyme activity during development (Fig 3). This protein is specifically immunoprecipitated by the anti ' $a$ ' antibody from crude extracts of cAMP induced cells (Fig 9), and partially purified phosphorylase ' $a$ ' samples (Fig 6\&7). The significance of the doublet versus singlet form of the the $104 \mathrm{kd}$ protein remains unclear at this point. On the other hand, the phosphorylase ' $b$ ' protein is clearly associated with the $92 \mathrm{kd}$ protein (Fig 3, Table 1, Fig 9). The $92 \mathrm{kd}$ protein is specifically immunoprecipitated from the amoeba stage (Fig 5). Furthermore, the $92 \mathrm{kd}$ protein can be phosphorylated in vitro by 
an endogenous protein kinase (Fig 8). Previous reports had shown that Dictyostelium phosphorylase ' $a$ ' is a 5'AMP independent enzyme that appears in mid-late development (Marshall et al., 1970; Gustafson and Wright, 1972; Wright et al., 1968; Jones and Wright, 1970; Firtel and Bonner, 1972; Rutherford and Harris, 1976; Thomas and Wright, 1976, Part I; and Thomas and Wright, 1976, Part II). The data on the molecular weight of this enzyme appear ambiguous. Thomas and Wright (1976, Part I) reported a molecular weight of $210 \mathrm{kd}$ for partially purified phosphorylase 'a' by gel filtration analysis. They also reported a molecular weight of $200 \mathrm{kd}$ for the purified enzyme by nondenaturing gel electrophoresis (Thomas and Wright, 1976, Part I). However, the subunit molecular weight of purified phosphorylase 'a' observed by them was $95 \mathrm{kd}$, rather than an expected figure of 100-105 kd, based on their gel filtration and nondenaturing gel electrophoresis data. Further, Thomas, and Wright (1976, Part II) were able to immunoprecipitate a $95 \mathrm{kd}$ protein with antibody raised to a purified phosphorylase ' $a$ ' preparation. However, it is important to note that molecular weights estimated by gel filtration are subject to an error of 10-15 $\%$. Higgins and Dahmus (1982), however, observed 101 and 105 kd proteins that crossreacted with the antibody against their $90 \mathrm{kd}$ phosphorylase ' $a$ ' subunit. Furthermore, they obtained synthesis of a $105 \mathrm{kd}$ phosphorylase ' $\mathrm{a}$ ' subunit by in vitro translation of Dictyostelium mRNA in the presence of the protease inhibitor phenylmethylsulphonylfluoride (PMSF) at a final concentration of $1 \mathrm{mM}$. They concluded that the $105 \mathrm{kd}$ protein represented an inactive precursor of the ' $a$ ' enzyme. It is possible that the $90-95 \mathrm{kd}$ protein that Thomas \& Wright and Higgins \& Dahmus reported as the subunit of phosphorylase ' $a$ ', may have been the ' $b$ ' enzyme subunit. The ' $b$ ' subunit may have cross-reacted strongly with their anti - ' $\mathrm{a}$ ' antibody. Alternately, the 90-95 kd protein observed by these investigators may have represented proteolysed or dephosphorylated active ' $a$ ' enzyme. If the latter case were applied to the $92 \mathrm{kd}$ protein described, it would not explain why the anti - 'a' antibody cross-reacted weakly with our $92 \mathrm{kd}$ protein, since each of our antibodies strongly recognized degradation products of its specific antigen (Fig 4). Furthermore, if our $92 \mathrm{kd}$ protein represented a truncated but active ' $a$ ' enzyme, it would be difficult to explain why this protein has always been associated with 5'AMP dependent ' $b$ ' enzyme that peaks in early development (Figs 3,5, Table 1). 
Thomas and Wright (1976) concluded that the increase in ' $a$ ' enzyme activity during development was due to de novo protein synthesis, since the specific radioactivity of immunoprecipitated enzyme corresponded with the amount of acid insoluble protein obtained at each developmental stage (Rutherford and Harris, 1976). They were unable to perform this experiment with amoebae and aggregation stages due to the low activity of the enzyme at these stages (Thomas and Wright, 1976, Part II). This, together with the fact that their antibody may have cross- reacted strongly with the phosphorylase ' $b$ ', may have prevented them from detecting the unstable $104 \mathrm{kd}$ ' $\mathrm{a}$ ' protein immunologically. We therefore plan to use our antisera for isolation of the mRNA('s) for these enzyme forms. As a step in this direction, we are investigating the time of synthesis of the ' $a$ ' form by in vivo labelling studies. We are also pursuing amino acid sequencing of the phosphorylase ' $a$ ' and ' $b$ ' forms, and cloning of their gene(s). This information will enable accurate molecular weight determination of the ' $a$ ' and ' $b$ ' forms and aid in the identification of potential phosphorylation sites and domains that are unique to either enzyme form. 


\subsection{Glycogen Phosphorylase ' $b$ ' in Dictyostelium: stability and Endogenous phosphorylation}

\subsection{Abstract}

The slime mold Dictyostelium discoideum has two forms of the enzyme glycogen phosphorylase. The inactive phosphorylase ' $\mathrm{b}$ ' form requires 5 'AMP for activity and is present in early development. The active phosphorylase ' $a$ ' form is 5'AMP independent and occurs during later development. We here show that the $92 \mathrm{kd} \mathrm{'} \mathrm{b}$ ' enzyme subunit exists either as a singlet or a doublet upon SDS-PAGE, depending on the method of sample extraction. In the presence of exogenously added $\mathrm{Mn}^{2+}$ and ATP, the phosphorylase ' $\mathrm{b}$ ' shows apparent conversion into a 5'AMP independent form as measured by enzyme activity. In addition, $\mathrm{Mn}^{2+}$ and ATP also support an in vitro phosphorylation of the $92 \mathrm{kd}$ phosphorylase ' $\mathrm{b}$ ' subunit. We also demonstrate phosphorylation of the ' $\mathrm{b}$ ' enzyme subunit in vivo by ${ }^{32}$ - $\mathrm{P}$ incorporation into the enzyme protein. A protein kinase responsible for the observed in vitro phosphorylation of the phosphorylase ' $b$ ' subunit is characterized. 


\subsection{Introduction}

Earlier studies on the glycogen phosphorylase in Dictyostelium discoideum reported that the enzyme was developmentally regulated (Firtel \& Bonner 1972b; Gustafson \& Wright 1972; Jones \& Wright 1970; Marshall et al 1970; Rutherford \& Harris 1976; Wright et al 1968 Higgins \& Dahmus ). These studies found little or no phosphorylase activity during early development, followed by a peak of 5'AMP independent activity during late development. We have recently reported on the purification and characterization of two forms of glycogen phosphorylase, a S'AMP dependent ' $b$ ' form and a S'AMP independent ' $a$ ' form (Rutherford \&Cloutier 1986). With our discovery of an inactive S'AMP dependent form of Dictyostelium phosphorylase during early development, questions on the relationship between the two enzyme forms arose. Specifically, we wished to test the idea that active S'AMP independent form of the phosphorylase (phosphorylase ' $a$ ') resulted from a conversion of the inactive 5'AMP dependent form (phosphorylase ' $b$ ') via a cAMP mediated phosphorylation. Although, regulation of phosphorylase activity by phosphorylation - dephosphorylation is a common event in systems that store glycogen as an energy reserve, the unique role played by phosphorylase in Dictyostelium development may necessitate that it is regulated in a different manner. It has been established in the literature that the glucose units produced by the phosphorylase reaction are utilized during terminal differentiation for synthesis of a cellulosic stalk and spore coat, rather than for energy production (Gustafson \& Wright 1972; Marshall et al 1970; Wright et al 1968). Thus, Dictyostelium glycogen degradation is an integral part of a programmed developmental cycle rather than a method of energy production. We, are, therefore considering the possibility that the two forms of Dictyostelium glycogen phosphorylase represent separate gene products. This hypothesis is lent support by the fact that partially purified forms of the enzyme are immunologically distinct and have different subunit molecular weights as detected by western blotting (see section 2.4 .3 ). We showed earlier that the purified phosphorylase ' $\mathrm{b}$ ' has a subunit molecular weight of $92 \mathrm{kd}$, whereas the partially purified ' $a$ ' enzyme has a subunit molecular weight of $104 \mathrm{kd}$. In this chapter we describe the 
phosphorylation of the phosphorylase ' $\mathrm{b}$ ' in vitro and in vivo An endogenous protein kinase that catalyzes this phosphorylation was observed. The phosphorylation occurs under conditions that result in the apparent conversion of phosphorylase ' $b$ ' activity into a S'AMP independent activity. Factors affecting the stability of the $92 \mathrm{kd}$ ' $\mathrm{b}$ ' enzyme subunit and its migration on SDS-PAGE are also examined. 


\subsection{Materials and Methods}

\subsubsection{Materials}

[ $\left.\gamma^{32} \mathrm{P}\right]$ ATP $(25-30 \mathrm{Ci} / \mathrm{mmol})$ was purchased from ICN. Nitrocellulose was purchased from Fisher Products, DE52 cellulose from Whatman, and Protein A (Pansorbin cells) from Calbiochem. Other reageants were purchased from Sigma Chemicals.

\subsubsection{Cell Harvest and Development.}

Dictyostelium discoideum (AX3) was grown in liquid HL5 media on a rotary shaker as previously described (Thomas \& Wright 1976). The resulting amoebae were harvested by centrifugation in a continous flow rotor, then were washed and resuspended in $50 \mathrm{mM}$ Tris- $\mathrm{HCl}$ pH 7.5 containing $2 \mathrm{mM}$ benzamidine, $2 \mathrm{mM}$ mercaptoethanol and $0.02 \%$ sodium azide. (buffer A). When differentiated cells were required, the amoebae were washed free of media, diluted 1:3 (weight:volume) in $7 \mathrm{mM} \mathrm{N}$ - morpholinoethanesulfonic acid, pH 6.8, containing $20 \mathrm{mM} \mathrm{KCl}$ and $5 \mathrm{mM} \mathrm{MgSO}_{4}$ (buffer B). The washed cells were plated onto non- nutrient agar or Gelman GN-6 membrane filters supported by Gelman absorbent pads. (both membranes and pads were pre-soaked for $30 \mathrm{~min}$ in buffer B). At the required developmental stage, cells were harvested off the non-nutrient agar in buffer $A+20 \%$ sucrose, and lysed by sonication. Cells developing on the Gelman membranes were frozen at $-70^{\circ} \mathrm{C}$. Upon thawing, $0.5 \mathrm{ml}$ of buffer $\mathrm{A}$ was applied to each pad. The lysates were scraped from the membranes and then centrifuged; the supernatants were assayed for glycogen phosphorylase activity and prepared for SDS- Polyacrylamide gel electrophoresis (SDS-PAGE). 


\subsubsection{Preparation of Cell lysates}

The washed amoebae (60-100 gm wet weight) were suspended in 3 volumes of cold buffer A containing $20 \%$ sucrose and $1 \mathrm{mg} / \mathrm{l}$ of the protease inhibitor antipain. The cells were sonicated by subjection to five 45 second exposures to a $2 \mathrm{~cm}$ probe of a sonic cell disrupter (Model 300, Fisher). After the lysate was centrifuged at $100,000 \times \mathrm{g}$ for an hour, neutralized protamine sulphate was added at a final concentration of $3 \mathrm{mg} /$ gram wet wt. of cells. This extract was then centrifuged at $100,000 \times \mathrm{g}$ for $45 \mathrm{mins}$ and the resulting supernatant was used for column chromatography. For the experiments shown in Figs 12,13, and 16, cells at the migrating slug stage were harvested from the Gelman membranes as explained earlier. For the experiments shown in Figs 14, 15,17, and 18, phosphorylase ' $b$ ' and casein kinase activities obtained by. De 52 cellulose chromatography were used. The appropriate column fractions were washed with buffer B and subjected to desalting on a Sephadex PD - 10 column in buffer $\mathrm{A}$ at $\mathrm{pH} 8.2$ or $50 \mathrm{mM}$ phosphate buffer $\mathrm{pH} 6.8$ (buffer $\mathrm{C}$ )

\subsubsection{Column chromatography}

The $100,000 \times \mathrm{g}$ supernatant was batch treated with 0.1 volume of DE52 cellulose resin that had been equilibrated in buffer A. After stirring $10 \mathrm{~min}$, the resin was settled by centrifugation. and poured into a column $(3 \mathrm{~cm} \times 6 \mathrm{~cm})$. Bound proteins were eluted with an 8 hour linear 0 $0.25 \mathrm{M} \mathrm{KCl}$ gradient in buffer A containing $10 \%$ glycerol. Phosphorylase ' $\mathrm{b}$ ' and the kinase activities eluted at $150-180 \mathrm{mM} \mathrm{KCl}$, whereas phosphorylase 'a' activity eluted at $50 \mathrm{mM} \mathrm{KCl}$. Column fractions were then assayed for glycogen phosphorylase activity in the presence and absence of 5' AMP as described below. Column fractions were also assayed for protein kinase activities as explained below.

Sephacryl-S-300 gel filtration chromatography was performed in a column $(1.6 \mathrm{~cm} \times 84 \mathrm{~cm})$ which was equilibrated in buffer A pH 8.5 containing $5 \mathrm{mM}$ EGTA and $50 \mathrm{mM} \mathrm{KCl}$. The column 
was then loaded with 1-4 ml sample (desalted concentrate obtained from appropriate De 52 column fractions) and pumped at $30 \mathrm{ml} / \mathrm{h}$. Fractions $(2 \mathrm{ml}$ ) were collected and assayed for phosphorylase ' $b$ ' and protein kinase activities.

\subsubsection{Sample preparation}

Typically, phosphorylase ' $b$ ' and casein kinase activities obtained by DE52 Cellulose chromatography were used for these experiments. The appropriate fractions were concentrated by ultrafiltration through a YM - 30 membrane at 40 psi. The concentrates were washed with buffer B and subjected to desalting on a Sephadex PD - 10 column in buffer A at pH 8.2 or $50 \mathrm{mM}$ phosphate buffer pH 6.8 (buffer C).

\subsubsection{Glycogen Phosphorylase Assay}

A $20 \mu \mathrm{l}$ sample of a given enzyme sample was added to $200 \mu$ of reaction mixture containing $50 \mathrm{mM}$ Imidazole (pH 6.8), $2.5 \mathrm{mg} / \mathrm{ml}$ glycogen, $5 \mathrm{mM} \mathrm{MgCl}, 0.5 \mathrm{mM} \mathrm{NADP}, 50 \mu \mathrm{g} / \mathrm{ml}$ glucose-1-6 diphosphate, $2 \mathrm{mM} \mathrm{K}_{2} \mathrm{HPO}_{4}, 0.3$ units/ml glucose-6-phosphate dehydrogenase, and 0.4 units/ml phosphoglucomutase. The temperature of the assay mixture was maintained at approximately $23^{\circ} \mathrm{C}$. A molar extinction coefficient of $6.2 \times 10^{3}$ was used to quantitate NADPH formation at $340 \mathrm{~nm}$. One unit of activity is defined as the amount of enzyme that catalyzes the synthesis of $1 \mu \mathrm{mol} \mathrm{NADPH} / \mathrm{min}$ at $23^{\circ} \mathrm{C}$. 


\subsubsection{Protein Kinase Assay}

A $40 \mu \mathrm{l}$. sample of desalted concentrate obtained fromthe De52 column was mixed with an equal volume of reaction mixture containing $25 \mathrm{~nm} \gamma^{32} \mathrm{P}$ - ATP $(30 \mathrm{ci} / \mathrm{mmol})$ in buffer $\mathrm{A}$ at $\mathrm{pH}$ 8.2 containing either casein at $2.5 \mathrm{mg} / \mathrm{ml}$ or no exogenously added substrate. The cations $\mathrm{Mn}^{2+}$ and $\mathrm{Mg}^{2+}$ were added at the desired final concentrations of $50 \mu \mathrm{m}-10 \mathrm{mM}$. The total reaction volume was kept constant at $100 \mu \mathrm{l}$. All additions were carried out at $4^{\circ} \mathrm{C}$. The entire mixture was then incubated at $23^{\circ} \mathrm{C}$. for $5-7$ minutes. At the end of the incubation period $50 \mu$ aliquots were removed to $1 \mathrm{~cm}$ squares of Whatman $3 \mathrm{MM}$ paper. The filters were carried through a series of trichloroacetic acid (TCA) washes; wash $1,10 \%$ TCA for 15 mins at $4^{\circ} \mathrm{C}$ wash $2,5 \%$ boiling TCA for 5 mins, wash $3,5 \% \mathrm{TCA}$ at $23^{\circ} \mathrm{C}$ for 10 mins. The filters were then washed in acetone, air dried and counted by liquid scintillation (Tm Analytic). Controls (enzyme blanks) were performed by incubating $40 \mu$ of buffer $A$ with an equal volume of reaction mixture. At the end of the incubation period, $50 \mu \mathrm{l}$ aliquots were removed to $1 \mathrm{~cm}$ squares of Whatman $3 \mathrm{MM}$ paper, washed and counted by liquid scintillation.

\subsubsection{Antibody Preparation}

Both the ' $a$ ' and ' $b$ ' forms of the phosphorylase were purified to homogeneity as determined by SDS-PAGE (Cloutier and Rutherford, 1987). These proteins were subjected to preparative SDS-PAGE, and were then eluted from the gel slices electrophoretically. The eluates were used as antigens. Two New Zealand white rabbits were each injected with 50-150 $\mu \mathrm{g}$ of purified protein in complete Freunds adjuvant. The rabbits were reinjected with 50-100 $\mu \mathrm{g}$ protein in incomplete Freunds adjuvant at two week intervals. After 6 weeks, the presence of antibody to the protein was confirmed by western blotting. Whole blood was allowed to clot overnight at $4^{\circ} \mathrm{C}$, then centrifuged at $10,000 \times \mathrm{g}$ for $10 \mathrm{~min}$. The serum was divided into $300 \mu \mathrm{l}$ aliquots and stored frozen at $-20^{\circ} \mathrm{C}$ 
for subsequent use. Both antiserum preparations had similar titres; a 1:500 dilution of each serum was used for immunostaining and immunoprecipitation.

\subsubsection{Immunoblotting}

Protein samples were prepared for SDS - PAGE by boiling in the presence of $2 \%$ SDS, 5 $\%$ dithiothreitol (DTT) and $0.02 \%$ Pyronin Y. The samples were separated on $6 \%$ SDS - PAGE gels according to the Laemmli protocol (Laemmli 1973). Proteins resolved by SDS -PAGE were electrophoretically transferred to nitrocellulose membranes using a Hoefer transfer chamber and a power source (Model TE51) set at 1.2 amps for one hour. The transfer buffer contained $192 \mathrm{mM}$ glycine and $20 \%$ methanol in $25 \mathrm{mM}$ Tris- $\mathrm{HCl}, \mathrm{pH}$ 8.3. After transfer, the nitrocellulose was placed in $50 \mathrm{ml}$ of $50 \mathrm{mM}$ Tris-HCL, pH 7.6, $200 \mathrm{mM} \mathrm{NaCl}$ and $0.1 \%$ Tween 20 (buffer D), and gently shaken for 20-30 min. The buffer was then replaced with $50 \mathrm{ml}$ of fresh buffer $\mathrm{D}$ containing $100 \mu \mathrm{l}-300 \mu \mathrm{l}$ of the undiluted antiserum. After $1-12$ hours of incubation with the antibody, the nitrocellulose was rinsed several times with fresh $50 \mathrm{ml}$ solutions of buffer D. A $50 \mathrm{ml}$ solution of buffer $\mathrm{D}$ containing $1 \mu \mathrm{g} / \mathrm{ml}$ protein $\mathrm{A}$ - peroxidase was then placed onto the blot and incubated with gentle shaking for $\mathrm{lhr}$. The nitrocellulose was rinsed with two $50 \mathrm{ml}$ volumes of buffer $\mathrm{C}$ and then with $50 \mathrm{ml}$ of buffer $\mathrm{D}$ lacking Tween 20 (buffer $\mathrm{D}^{\prime}$ ). The nitrocellulose was then exposed to $48 \mathrm{mls}$ of peroxidase reaction mixture containing $17 \%$ methanol, $24 \mathrm{mg}$ of 4-chloro-1-napthol, and $0.008 \% \mathrm{H}_{2} \mathrm{O}_{2}$ in buffer $D$ for $30-12 n \mathrm{~min}$. In some cases, the blots were also stained for protein using $0.1 \%$ napthol-blue black (amido black) in methanol, water, and acetic acid (4.5:4.5:1 ratio, $\mathrm{v} / \mathrm{v} / \mathrm{v}$ ). The destaining solution contained $90 \%$ methanol and $2 \%$ acetic acid. Autoradiography of the blots was performed using a Kodak intensifying screen and Kodak XAR-5 X-ray film. 


\subsection{Results}

\subsubsection{Phosphorylase activity during the Dictyostelium growth phase.}

We have previously shown that the early stages of the differentiation phase have an inactive form of phosphorylase which requires 5'AMP for activity (phosphorylase 'b'). In addition, we observed a S'AMP independent phosphorylase ' $a$ ' activity appearing in mid-late development (Rutherford \& Cloutier 1986). The sum of the specific activities of the ' $a$ ' and ' $b$ ' forms of this enzyme remained constant at $0.02 \mu \mathrm{mols} / \mathrm{min} / \mathrm{mg}$ protein. This value is similar to the maximum specific activity of Dictyostelium phosphorylase reported in the literature (Firtel \& Bonner 1972b; Gustafson \& Wright 1972; Jones \& Wright 1970; Marshall et al 1970; Rutherford \& Harris 1976; Wright et al 1968 Higgins \& Dahmus 1982). In Fig 11 glycogen phosphorylase activity during the growth phase of AX-3 amoebae is examined (prior to the differentiation phase). Cells were lysed in buffer $A$ centrifuged at $9,000 \times \mathrm{g}$, and the supernatant assayed for phosphorylase activity in the presence and absence of 5'AMP. No activity was detected in the early logarithmic phase.

Phosphorylase ' $\mathrm{b}$ ' activity was first detected in $9,000 \times \mathrm{g}$ supernatants of cells at a approximate cell density of $1.7 \times 10^{6} / \mathrm{ml}$. The activity reached a maximum value at $0.027 \mu \mathrm{mol} / \mathrm{min} / \mathrm{mg}$ protein during the late logarithmic phase of the growth curve when amoebae reached a cell density of 1.6 x $10^{7} / \mathrm{ml}$. Throughout the growth phase, the phosphorylase activity was completely dependent upon 5'AMP, i.e. the phosphorylase was in the ' $b$ ' form. Thus, as the cells approach stationary phase, the specific activity of the ' $b$ ' form is nearly identical to the sum of the specific activities of the ' $a$ ' and ' $b$ ' forms observed during the later differentiation cycle. Figure 11 also shows that the ' $b$ ' enzyme activity is not constitutive during the Dictyostelium growth phase. We cannot determine from this data of course, whether the increase in ' $b$ ' activity was due to de novo protein synthesis or activation of a preexisting protein. In either case, it is interesting that glycogen levels are undetectable during the growth phase, then increase during the early differentiation cycle. Thus, 
the phosphorylase is present, albeit inactive in the absence of 5'AMP, at a time during which its substrate is not yet synthesized. 
Figure 11: Phosphorylase activity during the growth phase of Dictyostelium amoebae Amoebae at various points along the growth curve were harvested in buffer $A$ and lysed by sonication. The sonicates were centrifuged at $9,000 \times \mathrm{g}$ for 30 minutes. The resulting supernatants were assayed for phosphorylase ' $b$ ' activity either in the presence or absence of 5'AMP. 


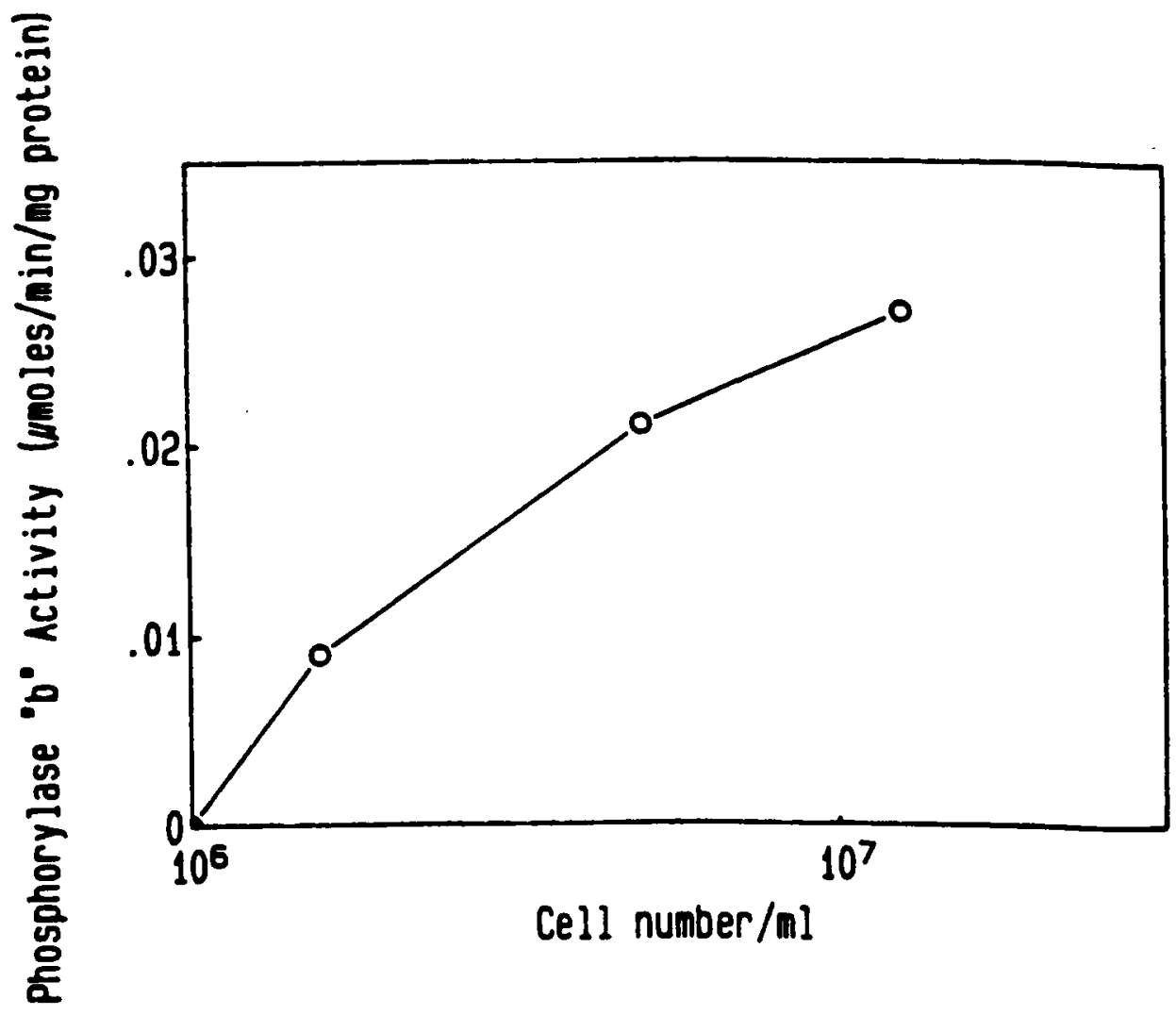


We also observed differential stability of the phosphorylase activity during the growth phase. Phosphorylase ' $b$ ' activity from cells in the early logarithmic phase retained only $15.30 \%$ of its activity after storage at $4^{\circ} \mathrm{C}$ or $-20^{\circ} \mathrm{C}$ for one day. The inclusion of the phosphatase inhibitor $\mathrm{NaF}$ $(25 \mathrm{mM})$, and the protease inhibitor PMSF $(2 \mathrm{mM})$ in these extracts $\left(2 \times 10^{6} \mathrm{cells} / \mathrm{ml}\right)$ did not improve the stability of the ' $b$ ' enzyme. Phosphorylase ' $b$ ' activity obtained from amoebae in the late logarithmic or early stationary phase was more stable to cold storage. Specifically, 80-90\% of the ' $b$ ' enzyme activity was recovered after storage at $4^{\circ} \mathrm{C}$ or $-20^{\circ} \mathrm{C}$ for one day. Therefore, all studies requiring ' $\mathrm{b}$ ' enzyme activity from amoebae utilized cells in the late logarithmic growth phase.

\subsubsection{Effects of sample preparation on the apparent molecular weight of phosphorylase ' $b$ ' as determined by SDS-PAGE.}

Because the ' $b$ ' enzyme activity was shown to be unstable in crude extracts, I determined whether different methods of sample extraction and preparation affected phosphorylase ' $b$ ' activity. I also observed the effects of sample preparation on the banding pattern of the ' $b$ ' enzyme subunit on western blots. The banding pattern of the ' $b$ ' enzyme was of particular interest, for we have observed both a single as well as double band when when western blots were stained with ' $b$ ' antiserum. Figure 12 shows that extraction of amoebae in buffer $A$ resulted in a 92 kd doublet protein that is recognized by the ' $b$ ' antiserum (lanes 7,8 ). We have shown previously that when purified to homogeneity the ' $b$ ' enzyme yields a single band on SDS-PAGE at $92 \mathrm{kd}$. Further, the $92 \mathrm{kd}$ protein is specifically immunoprecipitated by Dictyostelium ' $\mathrm{b}$ ' antiserum and has a subunit molecular weight similar to its rabbit muscle counterpart ( 92 and 98 kilodaltons respectively). We, therefore, concluded that the $92 \mathrm{kd}$ protein (as shown in Fig 2, lanes 7 and 8) represents the Dictyostelium phosphorylase ' $b$ ' The enzyme was also active when extracted in buffer $\mathbf{A}$ at 0.01 $\mu \mathrm{mols} / \mathrm{min} / \mathrm{mg}$ protein. Conversely, extraction of amoebae in buffer B, buffer C, or water containing $2 \mathrm{mM}$ EDTA and $10 \mathrm{mM} \mathrm{2, \beta}$ - mercaptoethanol, resulted in the immunostaining of 
a $92 \mathrm{kd}$ singlet protein along with several protein bands of lower molecular weight (lanes 1-6). None of these extracts yielded measurable phosphorylase ' $b$ ' activity. Thus, buffer $A$ was the most suitable extraction buffer for the maintenance of phosphorylase 'b'activity in low speed supernatants, and extraction of amoebae in buffers B, C, and EDTA-2, $\beta$ mercaptoethanol resulted in a total loss of the ' $b$ ' enzyme activity. Previous studies on Dictyostelium phosphorylase utilized 5mM phosphate buffer pH 6.8, or $50 \mathrm{mM}$ phosphate buffer containing $10 \mathrm{mM} \beta$-mercaptoethanol or EDTA-2, $\beta$ mercaptoethanol as extraction buffers (Jones \& Wright 1970; Thomas \& Wright 1976 Higgins \& Dahmus 1982). This is undoubtedly one of the reasons why these reports failed to detect the ' $b$ ' enzyme. We have already reported on other factors responsible for lack of detection of phosphorylase ' $b$ ' activity by previous investigators (Rutherford \& Cloutier 1986).

We have also found that the method of preparation of crude phosphorylase extracts from the later stages of development influenced the singlet versus doublet nature of the $92 \mathrm{kd}$ phosphorylase 'b' subunit. Figure 13 shows that extracts prepared in buffer $A$ and then centrifuged at $100,000 \times g$ resulted in a $92 \mathrm{kd}$ doublet band (lanes 1-4) wheras extracts centrifuged at a 9,000 $\times \mathrm{g}$ resulted in a singlet band (compare lanes 1-4 with lanes 5-10). The singlet band corresponded with the lower member of the doublet detected in the 100,000 x g supernatant (lanes 5-8). Both 9,000 $\times \mathrm{g}$ and $100,000 \times g$ supernatants had equivalent amounts of phosphorylase activity of $0.01 \mu \mathrm{mols} / \mathrm{min} / \mathrm{mg}$ protein. Recombining a solubilized $100,000 \times \mathrm{g}$ pellet fraction with the $100,000 \times \mathrm{g}$ supernatant yielded the $92 \mathrm{kd}$ double banding on SDS-PAGE (lanes 3 and 4). Since phosphoproteins show retarded molecular weights upon SDS-PAGE with respect to their dephospho forms (Dahmus 1981a), it was possible that the singlet versus doublet forms of the $92 \mathrm{kd}$ ' $b$ ' enzyme protein represented dephospho versus phospho forms of the phosphorylase ' $b$ ', i.e. the lower member of the $92 \mathrm{kd}$ doublet protein may represent the dephosphorylated ' $\mathrm{b}$ ' form of the phosphorylase wheras the upper member of the doublet may represent the phosphorylated enzyme. This idea was tested by preparing the slug stage extracts shown in Fig 13 in the presence or absence of various phosphatase inhibitors. Identical results were obtained in the presence or absence of these inhibitors (lanes 5-6 vs 7-10), suggesting that dephosphorylation was not responsible for conversion of the upper member of the $92 \mathrm{kd}$ doublet into the lower member. Alternatively, it is possible that none 
of the phosphatase inhibitors tested, effectively inhibited a phosphorylase phosphatase. We have however, shown, that $2 \mathrm{mM}$ phenanthroline, $50 \mathrm{mM}$ phosphate, and $5 \mathrm{mM}$ paranitrophenyl phosphate are potent inhibitors of Dictyostelium alkaline phosphatase as well as protein phosphatases that dephosphorylate phospho-kemptide (Ferris \& Rutherford 1986). Kemptide is an artificial hexapeptide substrate for the Dictyostelium cAMP dependent protein kinase. It is also possible that a particulate protease, or one that was pelletable at $100,000 \times \mathrm{g}$, was responsible for degrading the $92 \mathrm{kd}$ doublet form of phosphorylase ' $\mathrm{b}$ ' into the singlet form observed in $9,000 \times \mathrm{g}$ supernatants. I, therefore, tested the effect of inclusion of several different protease inhibitors in buffer $A$ (buffer $A$ was shown to be the best extraction buffer for the ' $b$ ' enzyme in figures 12,13 ). Results obtained show that inclusion of the following protease inhibitors during cell lysis had no effect on the molecular weight or activity of the ' $b$ ' enzyme (PMSF, $170 \mu \mathrm{g} / \mathrm{ml} ; \mathrm{N}$-p-tosyl-1-lysine chloromethyl ketone, $18 \mu \mathrm{g} / \mathrm{ml}$; benzamidine $300 \mu \mathrm{g} / \mathrm{ml}$; N-tosyl-phenylalanine chloromethyl ketone, $17 \mu \mathrm{g} / \mathrm{ml}$; pepstatin A $1 \mu \mathrm{g} / \mathrm{ml}$ ) (data not shown). 
Figure 12: Effect of extraction buffer on the molecular weight of phosphorylase ' $b$ '

5 grams (wet weight) of Ax-3 amoebae were lysed by freeze-thaw at $-70^{\circ} \mathrm{C}$. and resuspended in 25 $\mathrm{ml}$ of various buffers. The lysates were then centrifuged at $27,000 \times \mathrm{g}$ for 20 mins. The supernatants were subjected to SDS-PAGE and western blotting with ' $b$ ' antiserum. (Lanes 1-2) amoebae extracted in buffer B, (lanes 3-4) amoebae extracted in water containing 2 mM EDTA and $14 \mathrm{mM}$ B - mercaptoethanol, (lanes 5-6) amoebae extracted in buffer C, (lanes 7-8) amoebae extracted in buffer $A$, The arrow indicates the position of the lower member of the $92 \mathrm{kd}$ ' $b$ ' subunit doublet protein. 


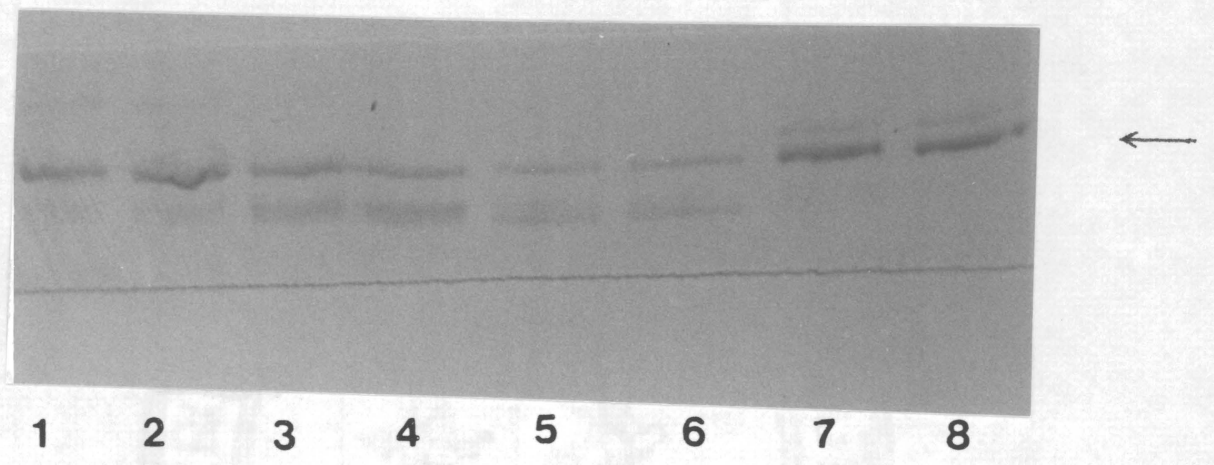


Figure 13: Effects of methods of sample preparation on the molecular weight of phosphorylase ' $\mathbf{b}$ ' Cells at the migrating slug stage ( 0.1 grams wet weight) were lysed by freeze-thaw and harvested in buffer $A$ in the presence or absence of phosphatase inhibitors. The lysates were centrifuged at 9,000 $\mathrm{x} g$ or $100,000 \mathrm{x} \mathrm{g}$ and the resulting supernatants assayed for phosphorylase activity as well as prepared for SDS-PAGE. The gel was then western blotted and probed with Dictyostelium anti ' $\mathrm{b}$ ' antiserum. (lanes 1-2) 100,000 x g supernatant, (lanes 3-4) 100,000 x g supernatant recombined with $100,000 \times \mathrm{g}$ pellet that had been solubilized in $0.1 \%$ Triton X-100, (lanes 5-6) $9,000 \times \mathrm{g}$ supernatant of cells lysed in the presence of buffer A (lanes 7-8) 9,000 x g supernatant of cells lysed in the presence of buffer A containing $50 \mathrm{mM} \mathrm{NaF}$, (lanes 9-10) 9,000 x g supernatant of cells lysed in the presence of buffer A containing $10 \mathrm{mM}$ phenyl phosphate, $2 \mathrm{mM} \mathrm{1,10-phenanthroline} \mathrm{and}$ $60 \mathrm{mM}$ potassium phosphate $\mathrm{pH}$ 7.0. The arrow indicates the position of the lower member of the $92 \mathrm{kd}$ ' $\mathrm{b}$ ' subunit doublet protein. 


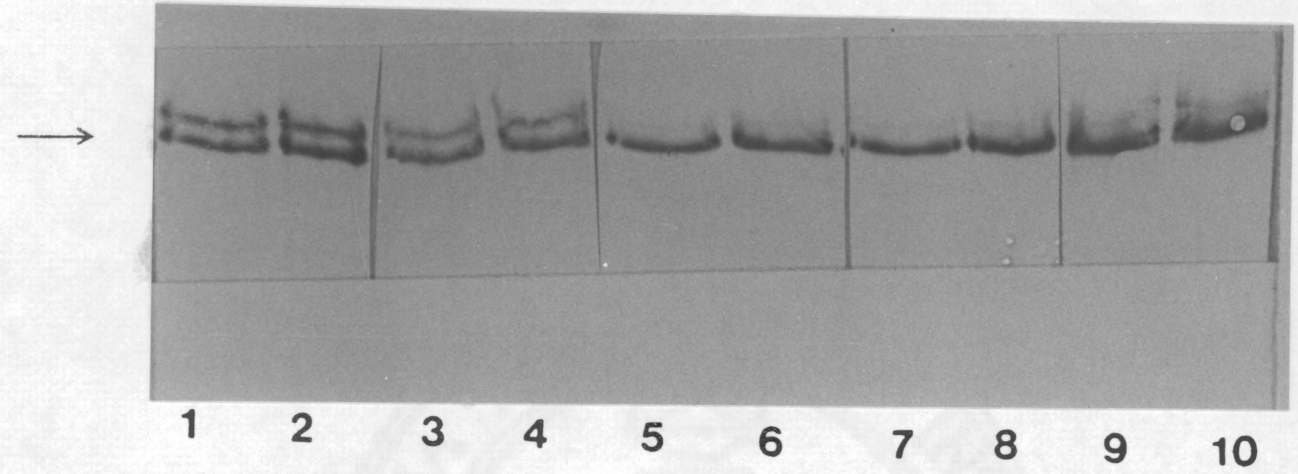




\subsubsection{Conversion of $5^{\prime} A M P$ dependent into $5^{\prime} A M P$ independent activity in the presence of cations and ATP.}

This section describes the attempts made to demonstrate conversion of the 5'AMP dependent phosphorylase ' $b$ ' into the 5'AMP independent ' $a$ ' form by phosphorylation. To this end, the effects of exogenously added cations and ATP on the 5'AMP dependence of the ' $b$ ' enzyme were monitored. Such an approach has been used to demonstrate phosphorylase kinases in other organisms (Fisher \& Krebs 1955; Krebs \& Fisher 1960). We initially attempted to demonstrate conversion of the Dictyostelium phosphorylase in crude extracts or low and high speed supernatants. No conversion of the 5'AMP dependent form into a 5'AMP independent form was observed. Because the results from figure 12 showed that the ' $b$ ' enzyme activity was unstable in low speed supernatants, and because the method of preparation of cell free extracts affected the banding pattern of the phosphorylase ' $b$ ' subunit (Fig 3), partially purified ' $b$ ' enzyme obtained by De52 anion exchange chromatography was used for the following experiments. Fractions containing the phosphorylase ' $b$ ' activity were pooled, concentrated and tested for conversion. Table 3 shows the effects of exogenously added nucleotides and cations on the the 5'AMP dependence of partially purified phosphorylase ' $b$ '. Preincubation of the sample with $4.7 \mathrm{mM}$ ATP resulted in a four fold activation of total phosphorylase activity and a complete loss in the 5'AMP dependence of the ' $b$ ' enzyme, as measured spectrophotometrically (ATP effect). Equimolar amounts of GTP did not significantly affect the 5'AMP dependency, showing that the conversion was specific to ATP.

Because mammalian phosphorylase kinases have an isoelectric point of $\mathrm{pH} 6.0$ and therefore precipitate at this $\mathrm{pH}, \mathrm{I}$ attempted to prepare a kinase fraction by $\mathrm{pH} 6.0$ treatment of Dictyostelium phosphorylase ' $b$ ' fractions from DE52 chromatography of the slug stage, Addition of the resulting neutralized precipitate to the ' $b$ ' enzyme fractions in the presence of exogenous ATP did not result in an augmentation of the ATP effect (Table $3 \mathrm{~B}$ ). I also tested the effects of exogenous cations on the 5'AMP dependence of phosphorylase ' $b$ '. In mammalian systems, addition of $1-10 \mathrm{mM} \mathrm{Mg}^{2+}, \mathrm{Ca}^{2+}$, or $\mathrm{Mn}^{2+}$ in the absence of exogenously added ATP was 
sufficient to activate phosphorylase kinase and result in conversion of phosphorylase ' $b$ ' to ' $a$ '. This conversion occurred since micromolar concentrations of ATP endogenously present in these crude extracts were adequate for phosphorylase kinase activity (Fisher \& Krebs 1955; Krebs \& Fisher 1960). Table $3 \mathrm{C}$ shows that the addition of $15 \mathrm{mM} \mathrm{Mn}^{2+}$ in the absence of exogenously added ATP resulted in a total loss of 5 ' AMP dependence of the Dictyostelium ' $\mathrm{b}$ ' enzyme (addition of 5-7 $\mathrm{mM} \mathrm{Mn}^{2+}$ also caused a similar effect). Addition of $1-10$ micromolar ATP to these extracts did not enhance this apparent conversion of the ' $\mathrm{b}$ ' enzyme in the presence of $\mathrm{Mn}^{2+}$, Thus if conversion were due to a $\mathrm{Mn}^{2+}$ stimulated phosphorylation, the endogenous ATP levels in the Dictyostelium extracts were sufficient to effect complete conversion. Furthermore, equimolar concentrations of $\mathrm{Ca}^{2+}$ and $\mathrm{Mg}^{2+}$ were without effect. The effect of $\mathrm{Mn}^{2+}$ on the S'AMP dependence of the ' $b$ ' enzyme was reversible by desalting the "converted" samples on a Sephadex PD - 10 column. The reversibility of the $\mathrm{Mn}^{2+}$ effect could indicate that $\mathrm{Mn}^{2+}$ is an allosteric

modulator of the ' $b$ ' form rather than a cofactor for a kinase mediated phosphorylation. However, I found that purified samples of the ' $b$ ' enzyme were not similarly affected by $7-15 \mathrm{mM} \mathrm{Mn} \mathrm{m}^{2+}$, thus arguing against an allosteric modulation of the ' $\mathrm{b}$ ' enzyme by $\mathrm{Mn}^{2+}$. Rather, purified samples of the ' $b$ ' enzyme activity were completely inhibited under these conditions. Alternatively, the effect of $\mathrm{Mn}^{2+}$ on the 5 'AMP dependence of the ' $b$ ' enzyme may be due to phosphorylation by a protein kinase that itself has adequate levels of bound ATP to function.

\subsubsection{Phosphorylation of Dictyostelium phosphorylase 'b' in vitro and in vivo.}

Because Table 3 suggested a cation-ATP mediated conversion of the ' $b$ ' enzyme into a SAMP independent form, I examined these extracts for the presence of protein kinase activity. In this section, in vitro as well as in vivo phosphorylation of the $92 \mathrm{kd}$ ' b' enzyme subunit protein is demonstrated. Upon De52 chromatography of 100,000 x g supernatants from the amoeba stage, we routinely observed a protein kinase activity that eluted from the column at a slightly lower salt concentration than that required to elute the phosphorylase ' $b$ ' activity (the protein activity eluted 
at approximately $150 \mathrm{mM} \mathrm{KCl}$ ) (Fig 14). The protein kinase activity was assayed with casein as a substrate in the presence of $2.5 \mathrm{mM} \mathrm{Mg}^{2+}$ and $2.5 \mathrm{mM} \mathrm{Mn}^{2+}$. simultaneously. The kinase showed a molecular weight of approximately 200,000 daltons as determined by Sephacryl-S-300 gel filtration chromatography (data not shown). The casein kinase activity was associated with an endogenous kinase activity (the activity observed when no exogenous substrate was included in the reaction mixture). i.e. the casein kinase appeared to phosphorylate a Dictyostelium substrate present in the De52 fractions. Both casein and endogenous kinase activities were undetectable in $100,000 \times \mathrm{g}$ supernatants of tissue from the amoeba stage, but were measurable following De52 chromatography. Figure 14 shows that the casein kinase activity peak (fractions 52-73) overlapped with a peak of endogenous kinase activity. Both kinase activities overlapped with the ' $b$ ' enzyme activity on the De52 column (The region of overlap is represented by fractions $60-80$ ). It is noteworthy that the endogenous kinase activity peaked at the region of overlap between the casein kinase and phosphorylase ' $b$ ' activitic (fractions 65-70). The combined results of table 3 and figure 14 suggested that the ' $b$ ' enzyme may serve as a substrate for the casein/endogenous kinase activities observed. 
Figure 14: Phosphorylase 'b' and protein kinase activities from De52 chromatography of amoebae extracts

The $100,000 \times \mathrm{g}$ supernatants of amoebae were subjected to chromatography on De52 cellulose as described (see Materials and methods). Column fractions were assayed for phosphorylase ' $b$ ' $(\bullet)$, endogenous ' $b$ ' kinase $(\Delta)$, and casein kinase $(O)$ activities. The thin line represents protein concentration as measured by A $280 \mathrm{~nm}$. 
32p Incorporated (picomoles $\times 10^{-3}$ )

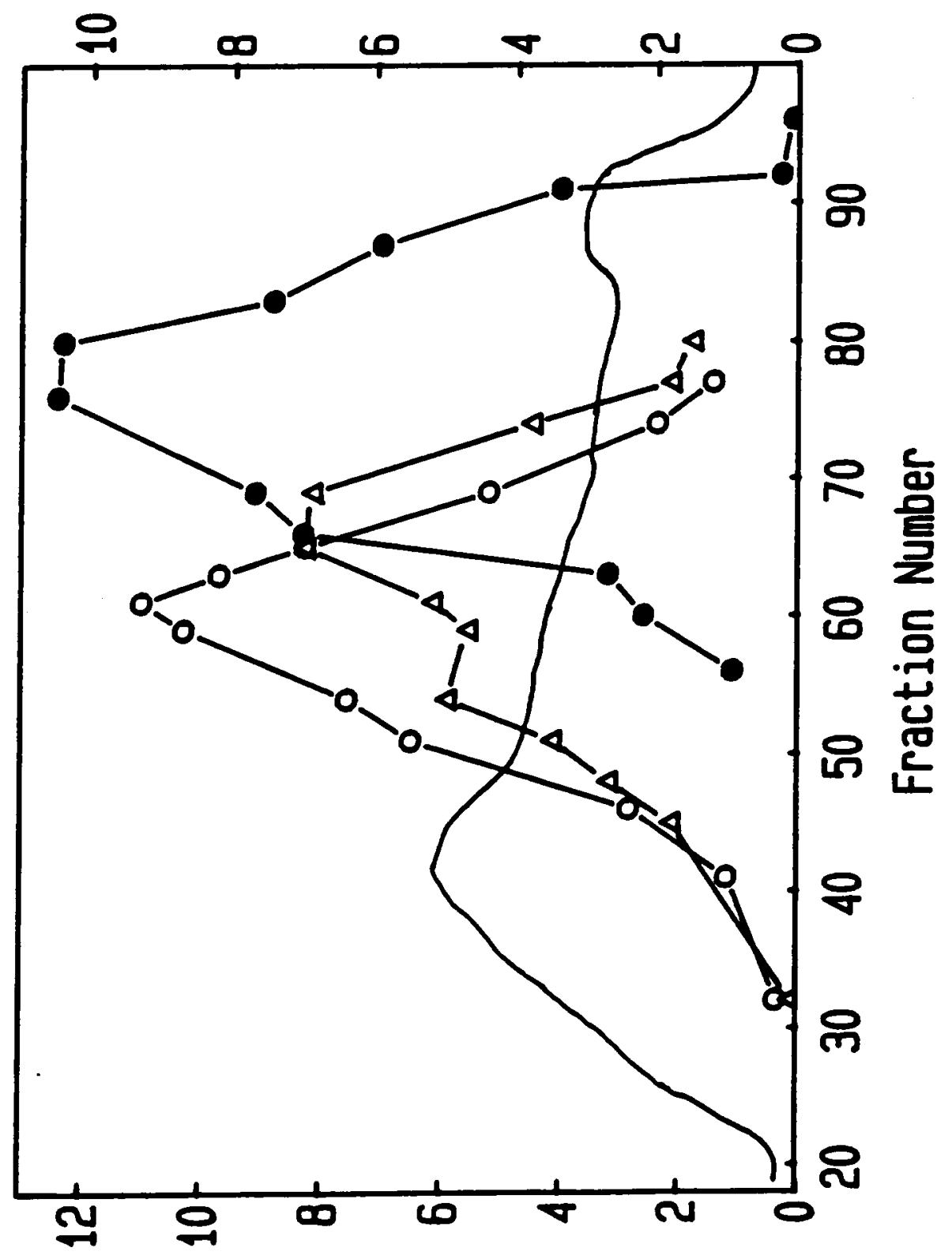

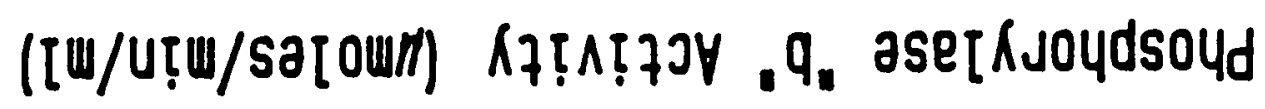


In Figure $15 \mathrm{~A}$ we subjected the endogenous kinase and phosphorylase ' $\mathrm{b}$ ' activities to further purification with the aim of obtaining separate preparations of each enzyme. Figure $15 \mathrm{~A}$ shows the results obtained when De52 fractions containing casein kinase, endogenous kinase and phosphorylase ' $b$ ' activities, were subjected to Sephacryl-S-300 gel filtration and tested for endogenous phosphorylation of the ' $b$ ' enzyme. The S- 300 column yielded adjacent peaks of endogenous kinase (fractions 45-60) and phosphorylase ' $b$ ' activities (fractions 50-77). Thus, the peaks of the phosphorylase ' $b$ ' and endogenous kinase activities were sufficiently separated, such that endogenous phosphorylation of the ' $b$ ' subunit was detected only when the peak kinase (fraction 50) and peak phosphorylase ' $b$ ' (fraction 65) activities were mixed (figures 15 B,C lane 5 on pages 83 and 85 respectively). The peak kinase activity (fraction 50) overlapped with the tail of the phosphorylase ' $b$ ' peak, and therefore did not demonstrate endogenously phosphorylated $92 \mathrm{kd}$ ' $b$ ' enzyme subunit when tested without any additions (figures 15 B,C lane 11). In addition, the fraction containing maximal ' $b$ ' enzyme activity (fraction 65) did not demonstrate endogenously phosphorylated ' $b$ ' enzyme subunit when tested alone (i.e. without the addition of S-300 fractions containing kinase activity) (figures 15 B,C lane 13). Thus, experiment 5A demonstrated that the casein kinase did phosphorylate the $92 \mathrm{kd}$ ' $b$ ' enzyme subunit. Later in this report, we will present data showing that the phosphorylase ' $b$ ' was the major substrate for the endogenous kinase in these fractions. The endogenous kinase will therefore be referred to as the ' $b$ ' kinase for the remainder of this report. 
Figure 15 A: Partial separation of ' $b$ ' enzyme and endogenous ' $b$ ' kinase activities upon Sephacryl-S 300 get filtration

The S-300 column was assayed for endogenous ' $b$ ' kinase $(\Delta)$ and phosphorylase ' $b$ ' $(\bullet)$ activities. The thin line represents protein concentration as measured by $\mathrm{A} 280 \mathrm{~nm}$. Fractions 45-57 contained ' $b$ ' kinase activity whereas phosphorylase ' $b$ ' activity was present in fractions 50-70. The peak ' $b$ ' and ' $b$ ' kinase activities were present in fractions 65 and 50 respectively. 


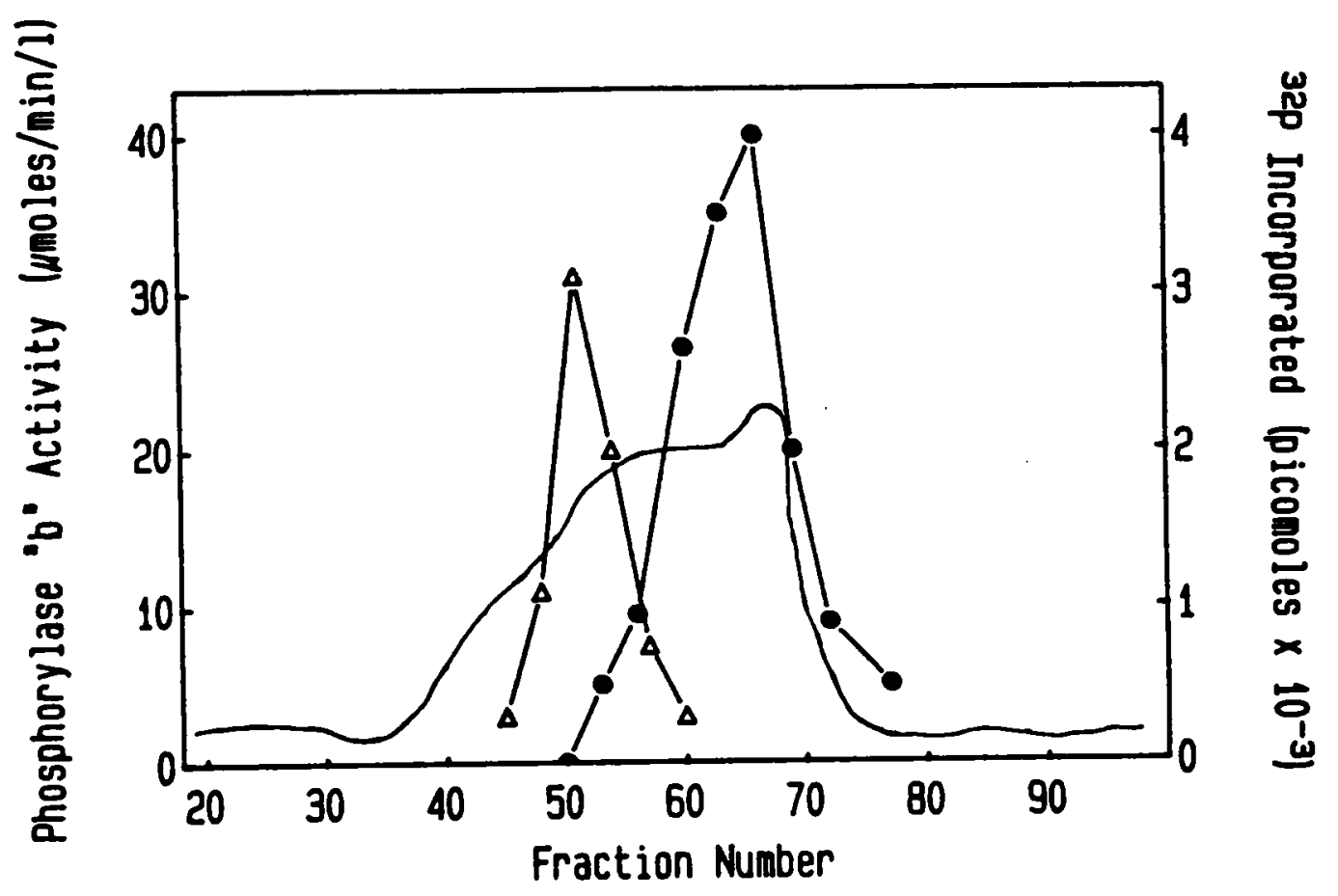


Figure 15 B: In vitro phosphorylation of the $92 \mathrm{kd}$ ' $\mathrm{b}$ ' subunit by the ' $\mathrm{b}$ ' kinase (western blot) Phosphorylase ' $b$ ' activity obtained by De 52 chromatography of tissue from the amoeba stage was concentrated by ultrafiltration and desalted in buffer $A$. The concentrate was loaded onto a Sephacryl-S-300 gel filtration column equilibrated in buffer A containing $50 \mathrm{mM} \mathrm{KCl}$ and $5 \mathrm{mM}$ EGTA at pH 8.5. Column fractions were assayed for phosphorylase ' $b$ ' and ' $b$ ' kinase activities as explained (sections $3.3 .6 \&$ 3.3.7). Endogenous phosphorylation of the $92 \mathrm{kd}$ ' $\mathrm{b}$ ' subunit was tested by mixing various fractions along the ' $b$ ' kinase peak (fractions $45-57$ ) with the fraction containing peak phosphorylase ' $\mathrm{b}$ ' activity (fraction 65) in the presence of $7 \mathrm{mM} \mathrm{Mg}^{2+}, 7 \mathrm{mM}$ $\mathrm{Mn}^{2+}$ and $1.7 \mu \mathrm{m} \mathrm{ATP}(30 \mathrm{ci} / \mathrm{mol}$ ). The reactions were terminated by boiling in the presence of $2 \%$ SDS and $5 \%$ DTT and were then subjected to SDS-PAGE and westem blotting. The resulting westem blot is shown. (Lanes 1-3) void volume S-300 fractions + fraction 65, (lanes 4,6) tail of the ' $b$ ' kinase activity peak + fraction 65 , (lane 5 ) peak ' $b$ ' kinase fraction + fraction 65 , (lanes 7-8) void volume S-300 fractions + buffer, (lanes 9-11) peak 'b' kinase fractions + buffer, (lane 12) fraction $65+$ buffer. 


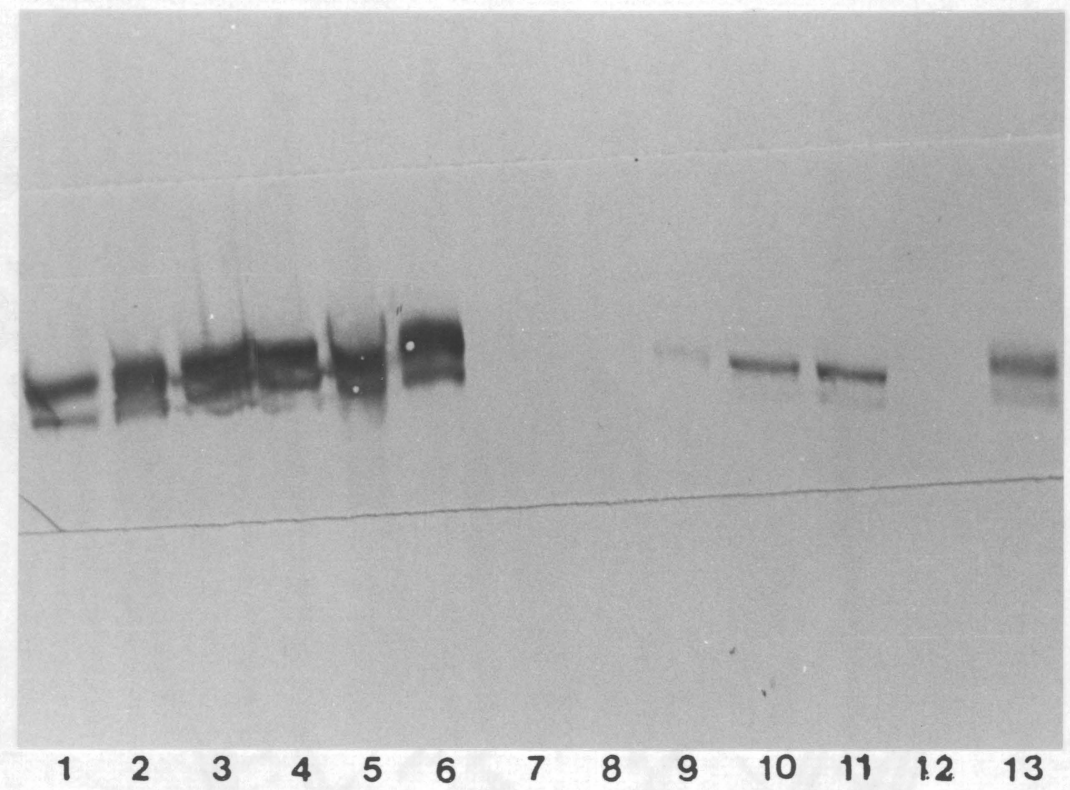




\section{Figure $15 \mathrm{C}$ : In vitro phosphorylation of the $92 \mathrm{kd}$ ' $\mathrm{b}$ ' subunit by the ' $\mathrm{b}$ ' kinase (autoradiogram)}

Phosphorylase ' $\mathrm{b}$ ' activity obtained by De52 chromatography of tissue from the amoeba stage was concentrated by ultrafiltration and desalted in buffer $\mathrm{A}$. The concentrate was loaded onto a Sephacryl-S-300 gel filtration column equilibrated in buffer A containing $50 \mathrm{mM} \mathrm{KCl}$ and $5 \mathrm{mM}$ EGTA at $\mathrm{pH}$ 8.5. Column fractions were assayed for phosphorylase ' $\mathrm{b}$ ' and ' $\mathrm{b}$ ' kinase activities as explained (15 A). Endogenous phosphorylation of the $92 \mathrm{kd}$ ' $\mathrm{b}$ ' subunit was tested by mixing various fractions along the ' $b$ ' kinase peak (fractions 45-57) with the fraction containing peak phosphorylase ' $b$ ' activity (fraction 65 ) in the presence of $7 \mathrm{mM} \mathrm{Mg}^{2+}, 7 \mathrm{mM} \mathrm{Mn}^{2+}$ and $1.7 \mu \mathrm{m}$ ATP $(30 \mathrm{ci} / \mathrm{mol})$. The reactions were terminated by boiling in the presence of $2 \%$ SDS and $5 \%$ DTT and were then subjected to SDS-PAGE and western blotting. The autoradiogram of the resulting western blot is shown. (Lanes 1-3) void volume S-300 fractions + fraction 65, (lanes 4,6) tail of the ' $b$ ' kinase activity peak + fraction 65 , (lane 5) peak ' $b$ ' kinase fraction + fraction 65 , (lanes 7-8) void volume S-300 fractions + buffer, (lanes 9-11) peak ' $b$ ' kinase fractions + buffer, (lane 12) fraction $65+$ buffer. The arrow indicates the position of the phosphorylated $92 \mathrm{kd}$ ' $\mathrm{b}$ ' subunit protein. 


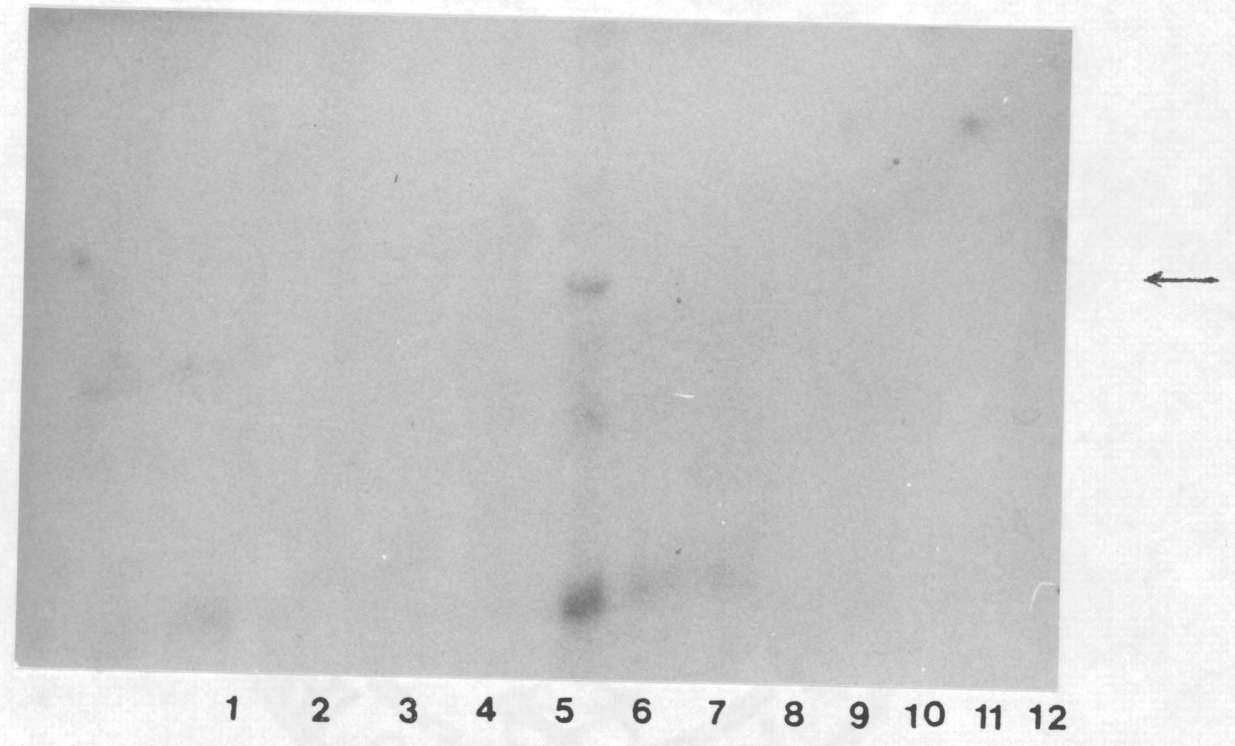


In order to determine whether the endogenous phosphorylation of the ' $b$ ' enzyme had physiological significance, or whether it was an in vitro phenomenon, I tried to demonstrate in vivo phosphorylation of the $92 \mathrm{kd}$ ' $\mathrm{b}$ ' subunit. Amoebae were exposed to ${ }^{32} \mathrm{P}$ for for 1-2 hours; then lysed and subjected to a low speed centrifugation. We first attempted to immunoprecipitate the phosphorylated $92 \mathrm{kd}$ ' $b$ ' subunit from these low speed supernatants with ' $b$ ' antiserum. The $92 \mathrm{kd}$ ' $b$ ' subunit could be immunoprecipitated with high recovery from crude extracts, as visualized by western blotting. However, only rarely was the incorporated ${ }^{32} \mathrm{P}$ retained with the protein during the lengthy immunoprecipitation procedure. We assumed that endogenous protein phosphatases removed the phosphate group from the peptide during immunoprecipitation. We, therefore, used a more rapid method that would enable detection of the phosphorylated $92 \mathrm{kd}$ ' $\mathrm{b}$ ' subunit. Since S'AMP Sepharose specifically binds the ' $\mathrm{b}$ ' enzyme via its 5'AMP binding site (Cloutier and Rutherford 1987), we mixed ${ }^{32} \mathrm{P}$ labelled cell extracts from radiolabelled amoebae with S'AMP Sepharose. The phosphorylated $92 \mathrm{kd}$ ' $\mathrm{b}$ ' subunit was found in the flow-through fraction, i.e. material that did not bind the S'AMP resin (Fig 16 B lanes 9-16). Bound phosphorylase ' $b$ ' was eluted off the 5'AMP resin by pulsing it with $10 \mathrm{mM}$ 5'AMP (Fig 16 A lanes 1-8). The 5'AMP eluted $92 \mathrm{kd} \mathrm{'} \mathrm{b}$ ' subunit was not phosphorylated and is therefore not shown on the autoradiogram in Fig 16 B. The lack of detectable phosphorylated $92 \mathrm{kd} \mathrm{'} \mathrm{b}$ ' subunit obtained in 5'AMP eluate, suggests that the phosphorylated ' $b$ ' enzyme cannot bind to the 5'AMP resin. This inability to bind the S'AMP resin may be due to a conformational change in the ' $b$ ' enzyme as a result of phosphorylation. This explanation is supported by the observation that the late stage phosphorylase ' $a$ ' enzyme does not bind to S'AMP Sepharose under conditions in which the ' $b$ ' form will (Cloutier \& Rutherfore 1987, data in press). These data lend credence to the hypothesis that Dictyostelium phosphorylase ' $a$ ' represents a phosphorylated form of the ' $b$ ' enzyme. We found that the ' $b$ ' enzyme was phosphorylated in vivo during the early developmental stages (1-15 hours into the developmental cycle ). Figure 16 shows in vivo phosphorylation of the ' $b$ ' enzyme from the amoebae stage (Fig 16 A: western blot, Fig 16 B: corresponding autoradiogram). during the immunoprecipitation protocol. Optimal phosphorylation of the $92 \mathrm{kd}$ ' $\mathrm{b}$ ' subunit was observed when cells at the amoeba or aggregation stage, $\left(0.1 \mathrm{~g}\right.$ wet weight) were pulsed with $1 \mathrm{mCi}{ }^{32} \mathrm{P}$. 
orthophosphate for $0.5 \cdot 1.5$ hours (data not shown). Cells radiolabelled later in the differentiation cycle did not show a phosphorylated $92 \mathrm{kd}$ ' $\mathrm{b}$ ' subunit protein. Indeed, it is significant that the observed in vitro and in vivo phosphorylation of the 'b' enzyme occured in the amoeba stage of development prior to the appearance of ' $a$ ' enzyme activity which is present during late development (Figs 16,18). (The in vivo phosphorylation top of the ' $b$ ' form was also detected in the aggregation stage of development, just prior to detection of phosphorylase 'a' activity: data not shown). This data is compatible with the hypothesis which states that phosphorylation is the mechanism of conversion of phosphorylase ' $b$ ' into ' $a$ '. Taken together, the data in figures 14-16 and table 3 pointed to the existence of a Dictyostelium phosphorylase kinase which phosphorylates and converts the the phosphorylase ' $b$ ' form into a S'AMP independent form during early development. 
Figure 16: Phosphorylation of the $92 \mathrm{kd}$ ' $\mathrm{b}$ ' subunit in vivo

Logarithmically growing amoebae ( 0.1 grams wet weight) were plated onto Gelman filters in buffer B. The amoebae were allowed to develop for 1 or 3 hours prior to being radiolabelled. Each filter of cells was labelled with $1 \mathrm{mCi}^{32} \mathrm{P}$ - orthophosphate for 0.5 or 1.5 hours. The cells were lysed by freeze-thaw in $1 \mathrm{ml}$ of buffer A containing $5 \mathrm{mM}$ EGTA. Each lysate was centrifuged at 10,000 $X \mathrm{~g}$ for 5 mins. and mixed with $0.4 \mathrm{mls}$ of $5^{\prime} \mathrm{AMP}$ Sepharose for 20 mins at $4^{\circ} \mathrm{C}$. This mixture was centrifuged at $10,000 \times \mathrm{g}$ for 5 mins. The bound proteins were eluted off the resin with a pulse of $10 \mathrm{mM}$ 5'AMP. Both the 5'AMP flow-through and eluate samples were prepared for SDS-PAGE and western blotting. The resulting immunoblot and its autoradiogram are shown (Fig $16 \mathrm{~A}$ and $16 \mathrm{~B})$. (lanes 1-2) 5'AMP eluate of $1 \mathrm{hr}$ cells labelled for $0.5 \mathrm{hr}$, (lanes 3-4) 5'AMP eluate of $1 \mathrm{hr}$ cells labelled for $1.5 \mathrm{hrs}$, (lanes 5-6) 5'AMP eluate of $3 \mathrm{hr}$ cells labelled for $0.5 \mathrm{hr}$, (lanes 7-8) 5'AMP eluate of $3 \mathrm{hr}$ cells labelled for $1.5 \mathrm{hrs}$. (Lanes 9-10) S'AMP flow through of $1 \mathrm{hr}$ cells labelled for $0.5 \mathrm{hr}$, (lanes 11-12) 5'AMP flow through of $1 \mathrm{hr}$ cells labelled for $1.5 \mathrm{hr}$, (lanes 13-14) 5'AMP flow through of $3 \mathrm{hr}$ cells labelled for $0.5 \mathrm{hr}$, (lanes 15-16) 5'AMP flow through of $3 \mathrm{hr}$ cells labelled for $1.5 \mathrm{hr}$. The arrow indicates the position of the phosphorylated phosphorylase ' $\mathrm{b}$ ' subunit (92 kd). 


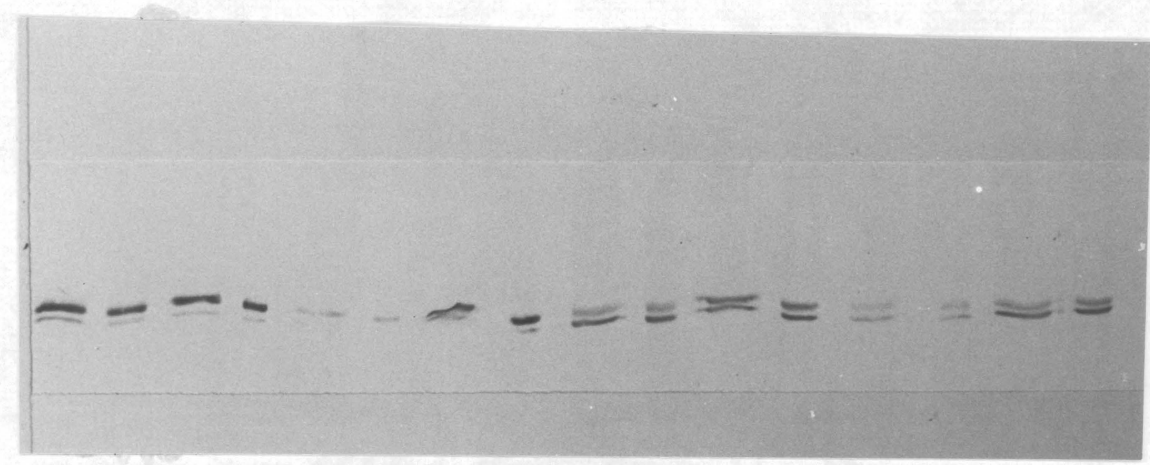

$\begin{array}{llllllllllllllll}1 & 2 & 3 & 4 & 5 & 6 & 7 & 8 & 9 & 10 & 11 & 12 & 13 & 14 & 15 & 16\end{array}$

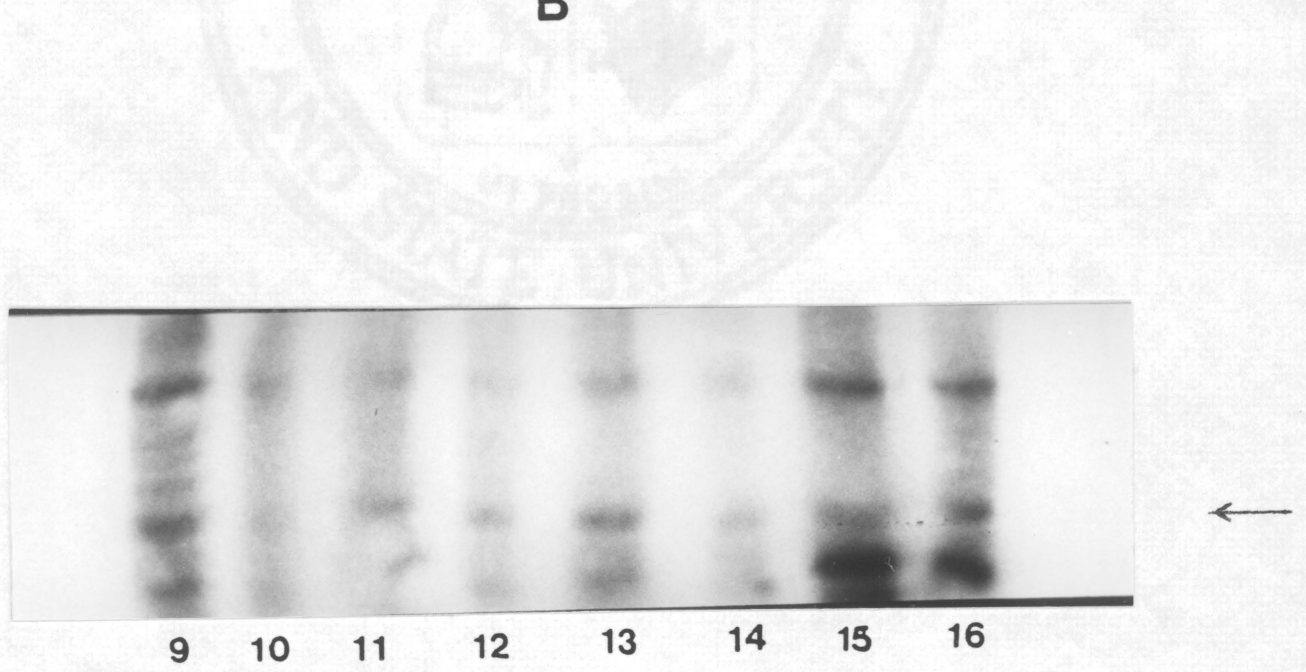

B 


\subsubsection{Characterization of the casein and 'b' kinase activities}

The biochemical requirements of the casein and endogenous ' $b$ ' kinase were investigated using samples obtained from De52 chromatography of amoeba stage cells. Since mammalian phosphorylase kinases characteristically show an activation at pH 8.2 versus 6.8 , we measured the casein and endogenous kinase activities at $\mathrm{pH} 6.8$ and 8.2 in the presence of various concentrations of Mn\&sup. ${ }^{+}$. Both casein and endogenous protein kinases showed low activity when assayed with similar concentrations of $\mathrm{Mg}^{2+}$. Figure 17 shows that both the casein and ' $\mathrm{b}$ ' kinase activities show an activation at $\mathrm{pH} 8.2$ in the presence of $1.5 \mathrm{mM} \mathrm{Mn}^{2+}$. Figure $17 \mathrm{~A}$ shows that the casein kinase activity was activated when assayed in the presence of $1-5 \mathrm{mM} \mathrm{Mn}{ }^{2+}$ at $\mathrm{pH}$ 8.2. as compared with its activity when assayed at $\mathrm{pH}$ 6.8. Likewise, the endogenous ' $b$ ' kinase was more active when assayed in the presence of $1-5 \mathrm{mM} \mathrm{Mn}{ }^{2+}$, at pH 8.2 versus 6.8 (Fig $17 \mathrm{~B}$ ). Thus, Figure 17 shows that both kinases show maximum activity when assayed with $\mathrm{Mn}^{2+}$ at $\mathrm{pH} 8.2$.

In figure 18, samples from experiment 17 B were prepared for SDS-PAGE immediately after termination of the kinase filter assay. The resulting western blot was stained with ' $b$ ' antiserum. Figure 18 showed that the phosphorylase ' $b$ ' is optimally phosphorylated under conditions where the ' $b$ ' kinase and casein kinase are active, that is, in the presence of $1.5 \mathrm{mM} \mathrm{Mn}^{2+}$ at $\mathrm{pH} 8.2$ (lanes 2-9). Phosphorylation of the ' $b$ ' enzyme was undetectable in the presence of identical concentrations of $\mathrm{Mg}^{2+}$ (lanes 10-17). Although low kinase activity was measured at pH 6.8 (figures $17 \mathrm{~A} \& \mathrm{~B})$, no endogenous phosphorylation of the $92 \mathrm{kd}$ ' $\mathrm{b}$ ' enzyme subunit was detected at this pH (data not shown). Thus, the similar pH and cation requirements of the two kinases lend further support to the hypothesis that the Dictyostelium casein kinase also phosphorylates phosphorylase ' $b$ '. Figure 18 also shows that the only protein that is phosphorylated in the region of overlap between casein kinase and phosphorylase ' $b$ ' activities is the phosphorylase ' $b$ ' 92 kd subunit (Figure 14, fractions 65-70). Therefore, as discussed in the previous section, the endogenous kinase activity observed in figures $14,15,17$ and 18 is entirely a result of ${ }^{32}$ - $P$ incorporation into the phosphorylase ' $\mathrm{b}$ ' protein. 
Figure $17 \mathrm{~A}: \mathrm{pH}$ and Cation requirements for casein kinase activity

Casein kinase activity purified through De52 cellulose chromatography was concentrated and desalted into buffer $\mathrm{A}$ at $\mathrm{pH} 8.2$ or buffer $\mathrm{C}$ at $\mathrm{pH}$ 6.8. The desalted enzyme sample was assayed for casein kinase activity in the presence of increasing concentrations of $\mathrm{Mg}^{2+}(0)$ or $\mathrm{Mn}^{2+}(\Delta)$ at pH 6.8 (open symbols) or pH 8.2 (closed symbols). 


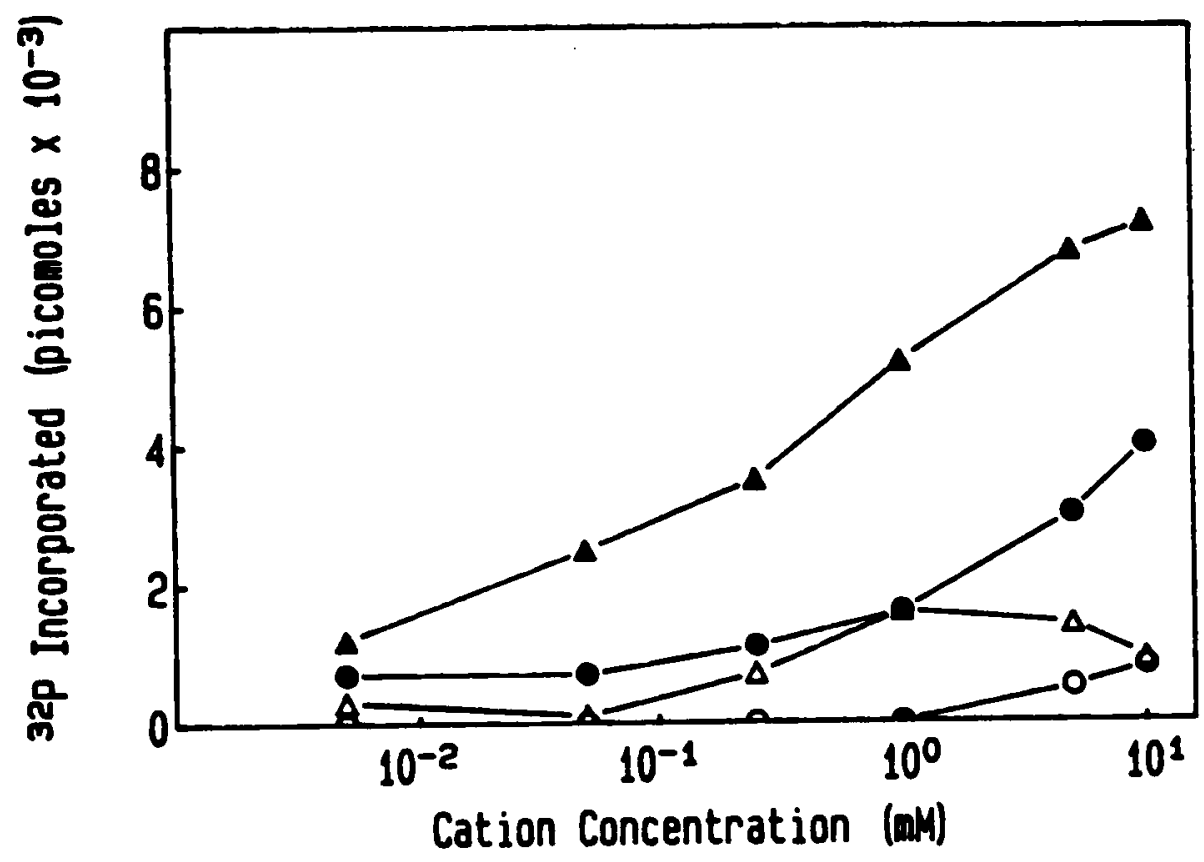


Figure $17 \mathrm{~B}$ : The $\mathrm{pH}$ and cation requirements for ' $\mathrm{b}$ ' kinase activity

Endogenous ' $b$ ' kinase activity from De52 chromatography of tissue from amoeba extracts. Pooled fractions were concentrated and desalted into buffer $\mathrm{A}$ at $\mathrm{pH} 8.2$ or buffer $\mathrm{C}$ at $\mathrm{pH}$ 6.8. The desalted sample was assayed for ' $b$ ' kinase activity in the absence of exogenously added substrate. Kinase activity was measured in the presence of increasing concentrations of $\mathrm{Mg}^{2+}(0)$ or $\mathrm{Mn}^{2+}(\Delta)$ at pH 6.8 (open symbols) or pH 8.2 (closed symbols). 


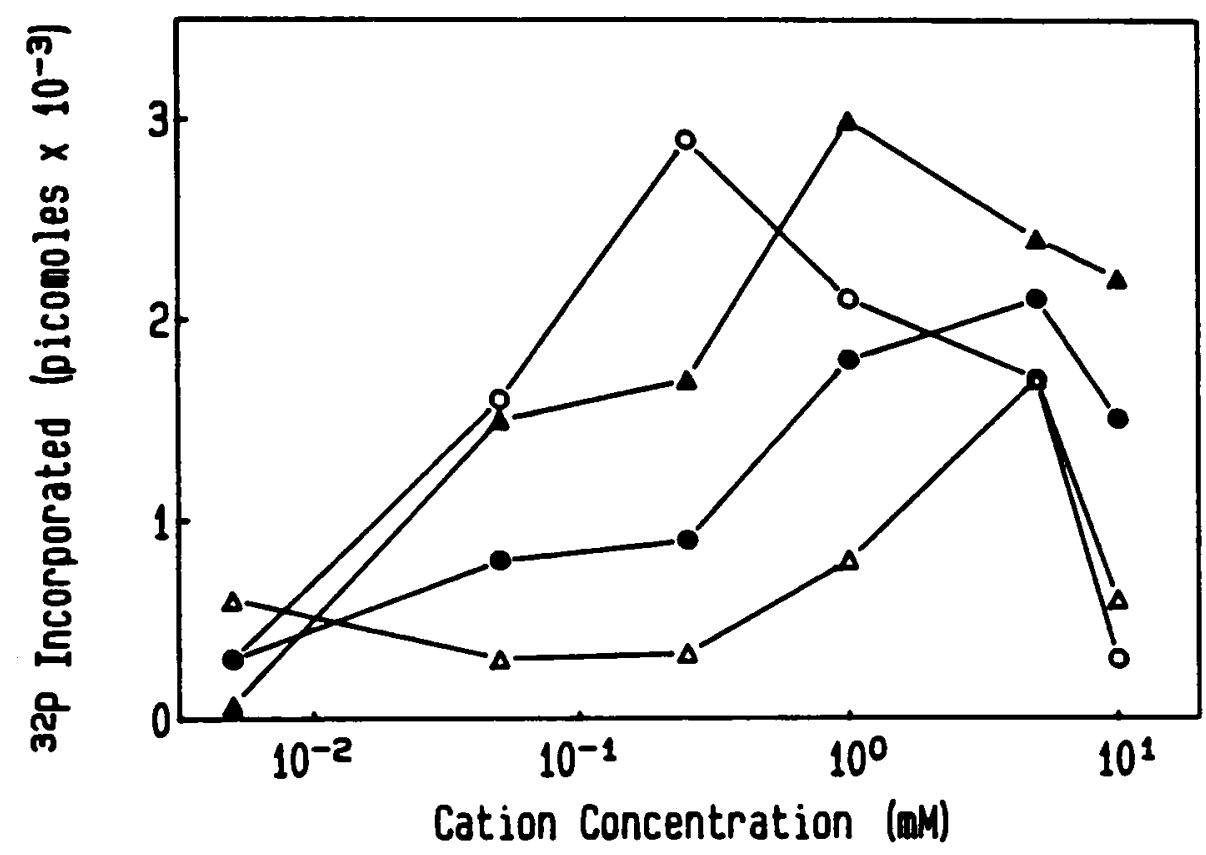


Figure 18 A: Manganese dependent phosphorylation of the $92 \mathrm{kd}$ ' $\mathrm{b}$ ' subunit by the ' $\mathrm{b}$ ' kinase in vitro (western blot)

The ' $b$ ' kinase reactions assayed in the experiment shown on Figure 17 B were terminated by boiling in the presence of $2 \%$ SDS and $5 \%$ DTT. The resulting samples were subjected to SDS-PAGE and western blotting. The nitrocellulose membrane was then stained with ' $b$ ' antiserum. (lane 1) rabbit muscle phosphorylase ' $b^{\prime}$. (lanes 2,3) $250 \mu \mathrm{m} \mathrm{Mn}^{2+}$, (lanes 4,5) $1 \mathrm{mM}$

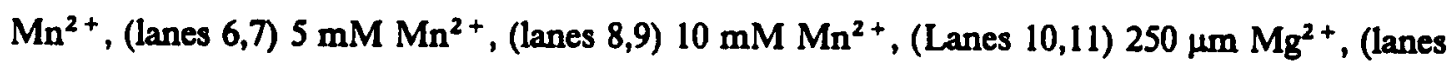
12,13) $1 \mathrm{mM} \mathrm{Mg}^{2+}$, (lanes 14,15$) 5 \mathrm{mM} \mathrm{Mg}{ }^{2+}$, (lanes 16,17$) 10 \mathrm{mM} \mathrm{Mg}^{2+}$, 
A

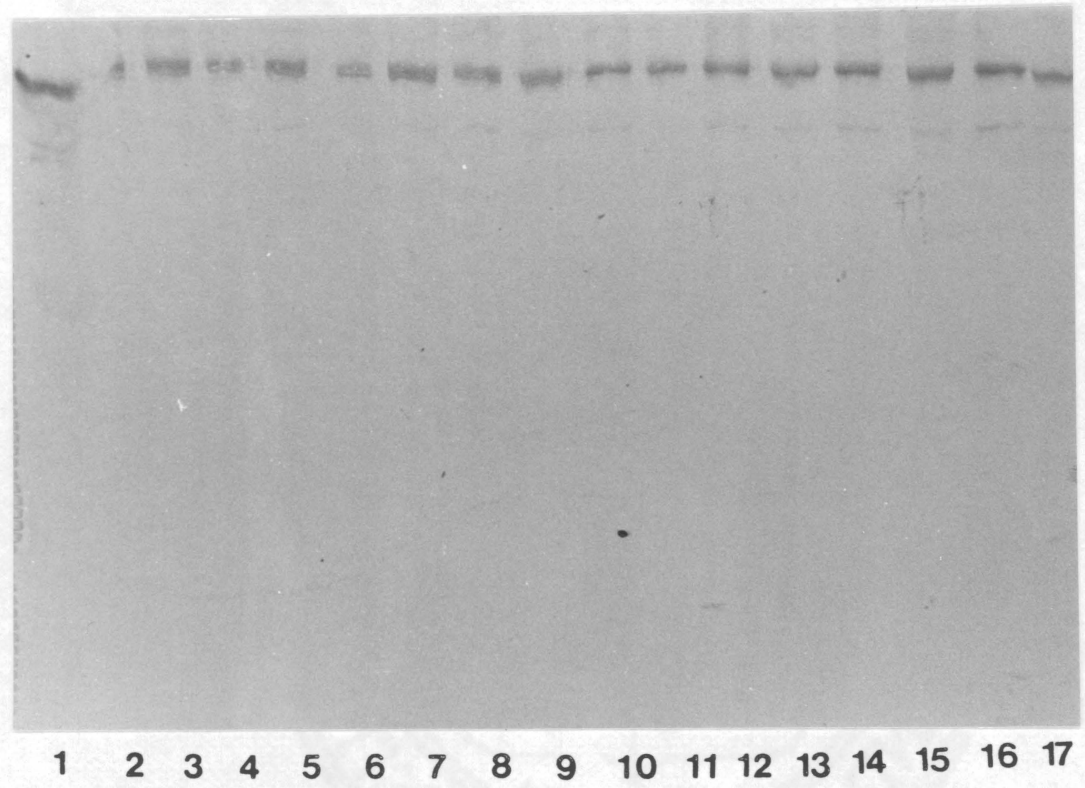


Figure 18 B: Manganese dependent phosphorylation of the $92 \mathrm{kd}^{\prime} \mathbf{b}$ ' subunit by the ' $b$ ' kinase in vitro (autoradiogram)

The ' $b$ ' kinase reactions assayed in the experiment shown on Figure 17 B were terminated by boiling in the presence of $2 \%$ SDS and $5 \%$ DTT. The resulting samples were subjected to SDS-PAGE and western blotting. The nitrocellulose membrane was then stained with ' $b$ ' antiserum. (lane 1) rabbit muscle phosphorylase ' $b$ '. (lanes 2,3) $250 \mu \mathrm{m} \mathrm{Mn}^{2+}$, (lanes 4,5) $1 \mathrm{mM}$ $\mathrm{Mn}^{2+}$, (lanes 6,7) $5 \mathrm{mM} \mathrm{Mn}^{2+}$, (lanes 8,9) $10 \mathrm{mM} \mathrm{Mn}^{2+}$, (Lanes 10,11$) 250 \mu \mathrm{m} \mathrm{Mg}^{2+}$, (lanes 12,13) $1 \mathrm{mM} \mathrm{Mg}^{2+}$, (lanes 14,15$) 5 \mathrm{mM} \mathrm{Mg}^{2+}$, (lanes 16,17$) 10 \mathrm{mM} \mathrm{Mg}^{2+}$, 


\section{B}

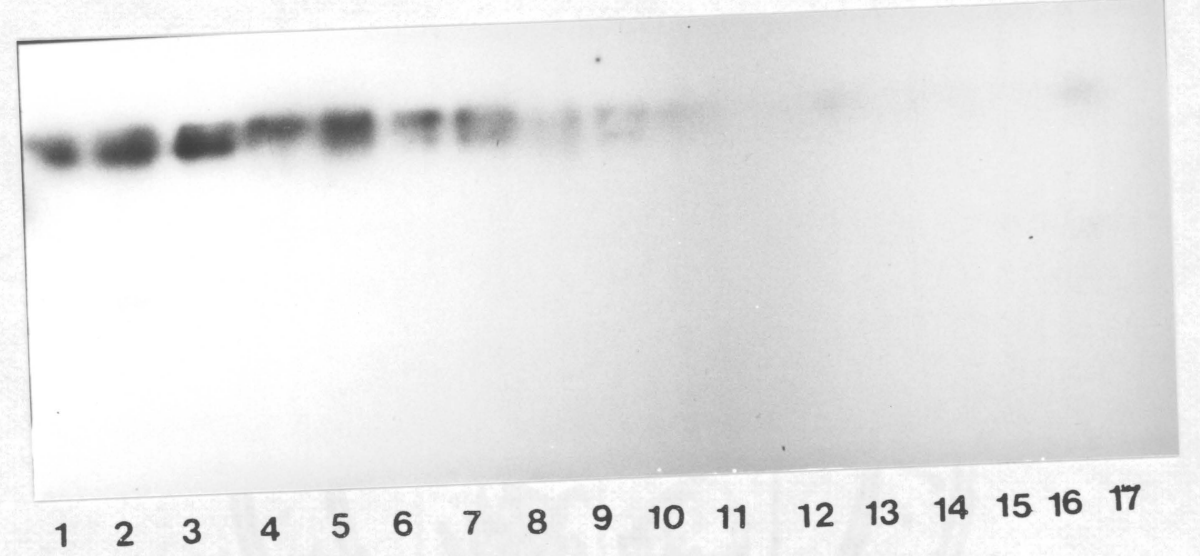


The substrate specificities of the casein and ' $b$ ' kinase activities were also investigated. Both activities were associated with histone kinase activity; in addition, the ' $\mathrm{b}$ ' kinase activity was capable of phosphorylating protamine sulfate. (data not shown). Both casein and ' $b$ ' kinase activities were unaffected by $10 \mu \mathrm{M}$ cAMP and $10 \mu \mathrm{M}$ cGMP. In addition, $\mathrm{Ca}^{2+}$ and calmodulin $(3 \mathrm{mM}$ and 20 units respectively) failed to activate both kinase activities (data not shown). In order to provide additional evidence that the two kinase activities represent a single enzyme, I attempted to add phosphorylase ' $b$ ' purified to homogeneity, back to partially purified casein kinase preparations. No phosphorylation of the added ' $b$ ' form was observed as measured by autoradiography. The lack of phosphorylation of the ' $b$ ' enzyme in this case may be due to alteration of the ' $b$ ' form during purification. Alternately, loss of an essential cofactor during purification of the ' $b$ ' enzyme may result in inability of the endogenous ' $b$ ' kinase to phosphorylate its substrate. We have also attempted conversion of the Dictyostelium ' $b$ ' enzyme by rabbit muscle phosphorylase kinase. As a result of several experiments, I conclude that the Dictyostelium ' $b$ ' enzyme is not a substrate for rabbit muscle phosphorylase kinase under conditions in which rabbit phosphorylase ' $b$ ' shows conversion to the ' $a$ ' form. 


\subsection{Discussion}

The data presented, show that the Dictyostelium phosphorylase ' $b$ ' from amoeba can be phosphorylated in vivo and in vitro (Figures 15,16 ). The in vitro phosphorylation of the ' $b$ ' enzyme occurred under conditions which resulted in the apparent conversion of phosphorylase ' $b$ ' activity into ' $a$ ' activity (table 3). Specifically, loss of 5'AMP dependence of the ' $b$ ' form and detection of the phosphorylated $92 \mathrm{kd} \mathrm{'b'} \mathrm{subunit} \mathrm{protein} \mathrm{in} \mathrm{vitro} \mathrm{occured} \mathrm{only} \mathrm{in} \mathrm{the} \mathrm{presence}$ of $1-10 \mathrm{mM} \mathrm{Mn}^{2+}$ (Fig 18, table 3).

The endogenous ' $b$ ' protein kinase appeared similar to a Dictyostelium casein kinase with respect to its $\mathrm{pH}$ and cation requirements (Figures $17 \mathrm{~A}$ and $\mathrm{B}$ ). The casein kinase required pH 8.2 and $1-5 \mathrm{mM} \mathrm{Mn}^{2+}$ in order to phosphorylate casein. Phosphorylation of the 'b' enzyme however, also occurred in the presence of $1-5 \mathrm{mM} \mathrm{Mn}^{2+}$ at $\mathrm{pH} 8.2$ (Fig 18). It is interesting to note at this point, that several mammalian casein kinases are capable of phosphorylating the mammalian 'b' enzyme (Delange et al 1968). The Dictyostelium casein kinase reported by Renart et al is a $\mathrm{Mg}^{2+}$ dependent nuclear enzyme, and is therefore presumably not equivalent to the cytosolic, $\mathrm{Mn}^{2+}$ dependent kinase activity reported here (Renart et al 1984). The phosphorylation of the ' $\mathrm{b}$ ' enzyme was also detected in vivo, suggesting that the observed in vitro phosphorylation of this enzyme was physiologically significant (Fig 16). Since the late stage phosphorylase activity is first detectable in the late aggregation stage of development, it is perhaps significant that the in vivo phosphorylation of the ' $b$ ' enzyme occurred at the amoeba and aggregation stages. Interconversion between the two forms of phosphorylase by phosphorylation-dephosphorylation would explain our previous data: for example, we have consistently observed that the sum of the specific activities of the ' $b$ ' and ' $a$ ' forms remains constant during Dictyostelium development (Rutherford \& Cloutier 1986). Secondly, we have observed cAMP induction of a 5'AMP independent phosphorylase ' $a$ ' activity, suggesting that a phosphorylation cascade initiated by the cAMP dependent protein kinase may be regulating the interconversion between the two forms of Dictyostelium phosphorylase (Brickey, Ph.D thesis). 
On the other hand, our previous work has shown that the partially purified late stage phosphorylase has a subunit molecular weight of $104 \mathrm{kd}$ (see section 2.4.3). Since phosphorylation of the $92 \mathrm{kd}$ ' $\mathrm{b}$ ' enzyme subunit did not appear to alter its molecular weight (figures 15,16), we cannot conclude that the apparent activation of the ' $b$ ' enzyme resulted in production of the late stage phophorylase (table 3). It is clear, however, that a S'AMP independent activity, and a phosphorylated $92 \mathrm{kd} \mathrm{'} \mathrm{b}$ ' subunit are detected only in the presence of 5-15 $\mathrm{mM} \mathrm{Mn}^{2+}$ (figure 18 , table 3). Therefore, it is possible that incomplete phosphorylation of the ' $b$ ' subunit was obtained (figures $8,15 \mathrm{~B} \& \mathrm{C}, 16,18$ ) (see section 2.4 .3 for a detailed discussion). Indeed, it is entirely possible that the two forms of Dictyostelium phosphorylase represent separate gene products, one of which can be additionally modulated by phosphorylation. This mechanism of regulation would allow for a coarse and fine control of phosphorylase activity and therefore glycogen levels during development. In particular, the in vivo phosphorylation of phosphorylase ' $b$ ' from the amoeba stage may represent an example of fine contro, i.e. phosphorylation of the ' $b$ ' form could activate the enzyme during early development, when the active 'a' enzyme is absent. This mechanism of fine control would enable glycogen degradation during early development if it were required, perhaps as an energy source for migrating amoebae. According to this model, the late stage phosphorylase would be regulated at the level of protein synthesis, thus reflecting the use of glycogen as a source of glucose for the synthesis of the cellulose during differentiation. This dual mechanism may be effective, perhaps essential, for an organism which uses glycogen for the synthesis of developmentally regulated end products. We are current investigating these ideas by sequencing the two forms of the phosphorylase and cloning their gene (s). 
Table 1. Glycogen Phosphorylase Activity During the Life Cycle of Dictyostelium discoideum ${ }^{2}$

\begin{tabular}{|c|c|c|c|c|}
\hline $\begin{array}{l}\text { Stage of } \\
\text { Development }\end{array}$ & \multicolumn{2}{|c|}{ Glycogen Phosphorylase Activity } & $\begin{array}{c}\text { Total Glycogen } \\
\text { Phosphorylase Activity } \\
\text { (nanomoles/min/mg) } \\
\text { dry weight) }\end{array}$ & $\begin{array}{l}\text { Fold } \\
\text { Dependence }\end{array}$ \\
\hline $\begin{array}{l}\text { Amoebae (oh) } \\
\text { Rippled Amoebae ( } 6 \\
\text { Aggregation (12 h) } \\
\text { Early Slug (14 h) } \\
\text { Migrating Slug (16 h) } \\
\text { Early Culmination (2 } \\
\text { Late Culmination (2 }\end{array}$ & $\begin{array}{lr} & 19 \\
6 \text { h) } & 28 \\
& 141 \\
151 \\
132 \\
20 \text { h) } & 245 \\
(4 \text { h) } & 217\end{array}$ & $\begin{array}{l}236 \\
189 \\
114 \\
104 \\
104 \\
19 \\
38\end{array}$ & $\begin{array}{l}255 \\
217 \\
255 \\
255 \\
236 \\
264 \\
255\end{array}$ & $\begin{array}{c}13.5 \mathrm{X} \\
7.8 \mathrm{X} \\
1.8 \mathrm{X} \\
1.7 \mathrm{X} \\
1.8 \mathrm{X} \\
\text { non-dependent } \\
\text { non-dependent }\end{array}$ \\
\hline
\end{tabular}

${ }^{1} 0.1 \mathrm{~g}$ cells at the desired developmental stage were harvested, lysed, and extracted as described in the experimental procedures. The resulting $14,500 \times \mathrm{g}$ supernatants were assayed for glycogen phosphorylase activity as described. Glycogen phosphorylase " $\mathrm{a}$ " activity was determined by assaying in the absence of 5' AMP; glycogen phosphorylase "b" activity was determined by assaying in the presence of S'AMP and subtracting " $a$ " activity from this value. Enzyme assays were performed in duplicate. The entire experiment was repeated 7 times. The variation in total phosphorylase activity did not exceed $20 \%$. 
Table 2. Immunoinhibition Analyses of Glycogen Phosphorylase " $a$ " and " $b$ " Activities"

\begin{tabular}{ccc}
\hline & \multicolumn{2}{c}{ Percent inhibition of } \\
\cline { 2 - 3 } Antiserum used & "a" activity & "b" activity \\
\hline \multirow{2}{*}{ anti-a } & $67 \%$ & $15 \%$ \\
anti-b & $0 \%$ & $97 \%$ \\
\hline
\end{tabular}

${ }^{1}$ Glycogen phosphorylase "a" and " $\mathrm{b}$ " activities from slug stage cell extracts were eluted from a DES2 column and were adjusted to $7.5 \mathrm{nmol} / \mathrm{ml} / \mathrm{min}$. Antisera (diluted $1: 5$ in Buffer A) were incubated with equal volumes of enzyme overnight at $4^{\circ} \mathrm{C}$ and then centrifuged at $12,000 \times \mathrm{g}$ for $10 \mathrm{~min}$; activity remaining in the resultant supernatant was assayed and percent inhibition was calculated. Preimmune controls were performed in all cases; no inhibition was seen with preimmune serum. These values represent an average of four assays. Data obtained with ' $b$ ' antiserum showed a maximum variation of $5 \%$ whereas data obtained with ' $a$ ' antiserum showed a maximum variation of $25 \%$. 
Table 3. Effects of nucleotides and cations on the 5'AMP dependence of phosphorylase "b"

Treatment

A Untreated "b" enzymeb

"b" enzyme + $4.7 \mathrm{mM} \mathrm{ATPc}$

"b" enzyme + $4.7 \mathrm{mM} \mathrm{GTPc}$
Phosphorylase activitya (nanomoles/min/ml)

$$
+ \text { 5'AMP }
$$

Fold dependence

$\begin{array}{ccc}0.06 & 0.01 & 6 \\ 0.23 & 0.28 & \text { nondependent } \\ 0.17 & 0.04 & 4.2\end{array}$

0.36

0.10

3.6

B Untreated "b" enzyme

0.44

0.28

1.6

$1 \mathrm{mM} \mathrm{CaCl}, 10 \mu \mathrm{m}$ cAMP

0.42

0.32

1.3

" $b$ " enzyme + 'phosphorylase kinase prep'
, $5 \mathrm{mM}$ ATP, $10 \mathrm{mM} \mathrm{MgCl}_{2}, 1 \mathrm{mM} \mathrm{CaCl}$, $10 \mu \mathrm{m}$ cAMP

C

$$
\begin{aligned}
& \text { Untreated "b" enzymeb } \\
& \text { "b" + } 15 \mathrm{mM} \mathrm{MgCl} \xi \\
& \text { "b" + } 15 \mathrm{mM} \mathrm{CaCl} \xi \\
& \text { "b" + } 15 \mathrm{mM} \mathrm{MnCl} \xi
\end{aligned}
$$

$1.5 \quad 0.36$

$\begin{array}{ll}1.6 & 0.28\end{array}$

1.4

0.40

3.5

nondependent

${ }^{a}$ Each value represents an average of triplicates

'Phosphorylase "b" activity from De52 chromatography of amoebal tissue was concentrated by ultra filtration and desalted by washing in buffer $A$.

TTe "b" enzyme was preincubated with the appropriate nucleotide or cations for 30 mins at $23^{\circ} \mathrm{C}$ and assayed for physphorylase activity in the presence/absence of 5'AMP.

"Phosphorylase "b" activity from De52 chromatography of slug tissue was pooled and adjusted to pH 6.0 with 0 . IN HCl. The resulting precipitate was pelleted by centrifugation at $9,000 \times \mathrm{g}$. The $9,000 \times \mathrm{g}$ pellet was resuspended in buffer $\mathrm{A}$ at $\mathrm{pH} 8.5$ and preincubated with/without " $\mathrm{b}$ " enzyme for 30 mins. at $23^{\circ} \mathrm{C}$. The resulting phosphorylase activities are reported.

The " $b$ " enzyme was preincubated with the appropriate cation for 5 mins at $23^{\circ} \mathrm{C}$ prior to measurement of phosphorylase activity. 
Table 4. Substrate Specificities of Casein/Endogenous Protein Kinase Activities

\begin{tabular}{lcc}
\hline Substrate $^{2}$ & Casein Kinase" $^{1}$ & Endogenous "b" Kinase $^{1}$ \\
Histone II-S & 3.7 & 3.6 \\
Histone III-S & 0 & 1.4 \\
Histone VI-S & 1.1 & 3.2 \\
Histone H-1 & 5.5 & 6.8 \\
Protamine Sulfate & 0 & 4.1 \\
No substrate added & 8.6 & 5.2 \\
\hline
\end{tabular}

${ }^{1}$ The casein and endogenous "b" kinase samples had equivalent amounts of total protein. The kinase activities were obtained from De52 chromatography of tissue from the amoeba stage. The appropriate column fractions were concentrated by ultrafiltration and desalted by washing in buffer A. Protein kinase assays were performed with $2.5 \mathrm{mM} \mathrm{MnCl}$ and an incubation time of 7 mins at $23^{\circ} \mathrm{C}$.

${ }^{2}$ All substrates were added at a final concentration of $\mathrm{lmg} / \mathrm{ml}$ protein.

${ }^{3}$ Protein kinase activity measured in the absence of any added exogenous substrates. These values were subtracted from each of the values reported for the 5 substrates tested. 


\section{Literature Cited}

Barklis, E., and Lodish, H.F. (1983). Regulation of Dictyostelium mRNAS specific for prespore or prestalk cells. Cell 32, 1129-1143.

Bonner, J.T., and Slifkin,. M.K. (1949). A study of the control of differentiation: the proportions of stalk and spore cells in the slime mold Dictyostelium discoideum. Amer. J. Bot. 36, 727-734.

Blumberg, D.D., Chung, S., Landfear, S.M. and Lodish, H.F. (1982) Embryonic Development, Part B. Cellular Aspects. pp. 167-182. Alan Liss, Inc., New York.

Cohen,P. (1973). The subunit structure of rabbit skeletal muscle phosphorylase kinase, and the molecular basis of its activation reactions. Eur. J. Biochem. 34, 1-14.

Cohen,P. (1973). The subunit structure of rabbit skeletal muscle phosphorylase kinase, and the molecular basis of its activation. Eur. J. Biochem. 34, 1-14.

Cohen,P., (1985). The role of phosphorylation in the hormonal control of enzyme activity. Eur. J. Biochem. 151, 439-448.

Cooper, S., Dasen, K., Lawton, M., and Ferguson, A. (1983). Reconstitution of a cyclic AMP dependent-protein kinase from Dictyostelium discoideum. Biochim. Biophys. Acta. 746, 120-123.

Dahmus, M.E. (1981a). Purification and Properties of Calf Thymus Casein Kinases I and II. J. Biol Chem. 256, 3319-3335

Datta,S., and Firtel,R.A. (1987). Identification of the sequences controlling cyclic AMP regulation and cell-type-specific expression of a prestalk specific gene in Dictyostelium discoideum.

DeGunzburg, J.D., Part, N., Guiso, and Veron, M. (1984). An unusual adenine 3'5'-phosphate dependent protein kinase from Dictyostelium discoideum. Biochem 23, 3805-3812.

Delange, R.J., Kemp,R.T., Riley,W.D., Cooper,R.A., and Krebs, E.G. (1968). Activation of skeletal muscle phosphorylase kinase by ATP and cAMP. J.Biol.Chem. 243, 2200- 2210. 
Ferris, D.K.,and Rutherford, C.L. (1986). Chromatographic resolution of soluble and particulate protein phosphatases from Dictyostelium discoideum. Arch. Biochem. Biophys, Vol. 248, 10-20.

Firtel, R.A., and Bonner, J. T. (1972b). Developmental control of alpha 1-4 glucan phosphorylase in the cellular slime mold Dictyostelium discoideum. Dev Biol 29, 85-103.

Fisher,E.H., and Krebs, E. (1955). Conversion of phosphorylase ' $b$ ' to phosphorylase ' $a$ ' in muscle extracts. J. Biol.Chem 216, 121-133.

Fosset, M., Muir, L.W., Nielsen, L.D., and Fischer, E.H. (1971). Purification and Properties of Yeast Glycogen Phosphorylase a and b. Biochemistry, Vol. 10, No. 22, $4105-4113$.

George, R.P., Hohl, H.R. and Raper, K.B. (1972). Ultrastructural development of stalk producing cells in Dictyostelium discoideum, a cellular slime mold. J. Gen. Microbiol. 70, 477-489.

George, R.P., (1977). Disruption of the multicellular organization in the cellular slime mold by cAMP. Cell. Differ. 5, 293-300.

Gross, J.G., Town,C.D., Brookman, J.J., Jermyn, K.A., Peacey, M.J., and Kay, R.R. (1981). Cell patterning in Dictyostelium. Phil. Trans. R. Soc. Lond B295,497-508.

Gustafson, G.L., and Wright, B.E. (1972). Analysis of approaches used in studying differentiation of the cellular slime mold. Crit. Rev. Microbiol. 1, 453-478.

Haribabu, B., and Dottin, R. (1986). Pharmacological Characterization of cyclic AMP receptors mediating gene regulation in Dictyostelium discoideum. Mol. \& Cell. Biol. 6, 2402-2408.

Hayakawa, Y. (1985). Activation mechanism of insect fat body phosphorylase by cold. Insect Biochem. Vol 15, No.1, 123-128.

Higgins, R.C., and Dahmus, M.E. (1982). Glycogen Phosphorylase synthesis in Dictyostelium discoideum. . J. Biol Chem. 257, 5068-5076.

Hoh, H.R., and Hamamoto, S.T. (1969b). Ultrastructure of spore differentiation in Dictyostelium : the prespore vacuole. 'J. Ultrastr. Res. 26, 442-453.

Jones, T.H.D., and Wright, B.E. (1970). Partial purification and characterization of glycogen of Dictyostelium discoideum. spores. J. Bacteriol. 104, 754-761

Kay, R.R., C.D. Town, and Gross, J.D. (1979). Cell Differentiation in Dictyostelium discoideum. Differentiation 13, 7-14.

Kay, R.R., and Jermyn, K.A. (1983; . A possible morphogen controlling differentiation in Dictyostelium. Nature 303, 242-244.

Konijin, T.M., Barkley, D., Chang, Y.Y., and Bonner J. (1968). Cyclic AMP: a naturally occurring acrasin in the cellular slime molds. Am. Nat 102. 225-233.

Krebs, E., and Fisher, E.H. (1960) The role of metals in the activation of muscle phosphorylase. Ann. N. Y. Acad. Sci 88, 378-384.

Landfear, S.M., Lefebvre, P., Chung, S., and Lodish, H.F. (1982). Transcriptional control of gene expression during development of Dictyostelium discoideum. Mol. Cell. Biol. 2, 1417-1426. 
Laemmli, U.K., and Favre, M. (1973). Maturation of the head of Bacteriophage T4. 1. DNA Packaging events. J.Mol. Biol. 80, 575-599

Leichtling, B.H., Majerfield, I.H., Spitz, E., Schaller, K.L., Woffendin, C., Kakinuma, S., and Rickenberg, H.V. (1984). A cytosolic cyclic AMP dependent protein kinase in Dictyostelium discoideum. II. Developmental Regulation. J. Biol. Chem. 259, 662-668.

Maeda, Y., and Maeda,M. (1974). Heterogeneity of the cell populations of the cellular slime mold Dictyostelium discoideum before aggregation, and its relation to subsequent locations of the cells. Exp. Cell. Res. 84, 88-94.

Maeda, Y., and Takeuchi, I. (1969). Cell differentiation and fine structures in the development of the cellular slime molds. Dev. Growth. Differentiation. 11, 232-245.

Majerfield, I.H., Leichtling, B.H., Meligeni, J.A., Spitz, E. and Rickenberg, H.V. (1984). A cytosolic cyclic AMP-dependent protein kinase in Dictyostelium discoidewm. I. Properties. J. Biol. Chem. 259, 656-661.

Malkinson,A,M., and Ashworth, J.M. (1973). Adenosine 3'5' cyclic monophosphate concentrations and phosphodiesterase activities during axenic growth and differentiation of cells of the cellular slime mold Dictyostelium discoideum. Biochem. J. 134, 311-319.

Marshall, R., Sargent, D., and Wright, B.E. (1970). Glycogen turnover in Dictyostelium discoideum. Biochem. 9, 3087-3094.

Matskuma, S., and Durston,A.J., (1979). Chemotactic cell sorting in Dictyostelium discoideum. J. Embryol. Exp. Morphol. 50, 243-252.

Mayer, R.J., and Walker, J.H. (1980). Immunochemical Methods in the Biological Sciences: Enzymes and Proteins, 39-45. Academic Press, London.

Merkle, R.K., Cooper, K.K. and Rutherford, C.L. (1984). Localization and levels of Cyclic AMP during development of Dictyostelium discoideum. Cell Differentiation 26, 23-30

Mehdy, M.C., Ratner, D., and Firtel, R.A. (1983). Induction and modulation of cell type specific gene expression in Dictyostelium. Cell 32, 763-771.

Oyama, M., and Blumberg, D. (1986). Interaction of cAMP with the cell surface receptor induces cell-type specific mRNA accumulation in Dictyostelium discoideum. PNAS 83, 4819-4823.

Pahlic, M. and C.L. Rutherford. (1979). Adenylate cyclase activity and cyclic AMP levels during the development of Dictyostelium discoideum. J. Biol. Chem. 254, 9703-9709.

Raper, K.B. (1940b). Pseudoplasmodium formation and organization in Dictyostelium discodeum J.E. Mitchell. Sci.Soc. 56,241-282.

Renart,M.F., Sastre,L., and Sebastian,J. (1984) Purification and properties of cAMP independent nuclear protein kinase from Dictyostelium discoideum. Eur. J. Biochem, 140, 47-54.

Rosness, P.A., and Wright, B.E., (1974). In vivo changes of cellulose, trehalose and glycogen during differentiation of Dictyostelium discoideum. Arch. Biochem. Biophys. 164, 60-72.

Rutherford, C.L., and Harris, J.F. (1976). Localization of glycogen phosphorylase in specific cell types of Dictyostelium discoiderum. Arch. Biochem. Biophys. 175, 453-462. 
Rutherford, C.L., Taylor, R.D., Frame,L.T., and Auck, R.L. (1982). A cyclic AMP dependent protein kinase in Dictyostelium discoideum Biochem Biophys. Res. Commm. 108, 1210-1220.

Rutherford, C.L., Vaughan, R.L., Cloutier, M.J., Ferris, D.K. and Brickey, D.A. (1984). Chromatographic behaviour of cyclic AMP dependent protein Kinase and its subunits from Dictyostelium discoideum. Biochemistry 23, 4611-4617.

Rutherford, C.L., and Cloutier, M.J. (1986). Identification of Two Forms of Glycogen Phosphorylase in Dictyostelium. Arch. of Biochem and Biophys Vol 250, No. 2, 435-439.

Sampson, J. (1977). Developmentally regulated cyclic AMP dependent protein kinases in Dictyostelium discoidewn. Cell 11, 173-180.

Sargent, D., and Wright, B.E. (1971). Trehalose synthesis during differentiation in Dictyostelium discoideum. II. in vivo determinations.

Schapp, P., and van Driel, R. (1985). Induction of Post-aggregative Differentiation in Dictyostelium discoideum. by cAMP - Evidence of involvement of the cell surface receptor. Exp. Cell. Res. 159, 388-398.

Schoen, C., Arents, and van Driel, R. (1983). Isolation and properties of cyclic AMP dependent-protein kinase from Dictyostelium discoideum. Biochim. Biophys. Acta. 784, 1-8.

Stemfield, J., and David, C.N., (1981). Cell sorting during pattern formation in Dictyostelium discoideum. Differentiation 20, 10-21.

Sussman, M., and Osborn, M.J. (1964). UDP galactose polysaccharide transferase in the cellulat slime mold Dictyostelium discoideum, appearance and disappearance of activiy during cell differentiation. PNAS 52, 81-87.

Tellez-Inon, M.T., and Torres, H.N. (1970). Interconvertible forms of glycogen phosphorylase in Neurospora crassa. . PNAS 2, 459-463.

Thomas,D.A., and Wright, B.E. (1976). Glycogen Phosphorylase in Dictyostelium discoideum. Part 1: Purification and properties of the enzyme. J. Biol Chem 251, 1253-1257. Part II: Synthesis and degradation during differentiaton. J. Biol. Chem. 251, 1258-1253.

Town, C.D., Gross, J., and Kay, R.R. (1976). Cell differentiatin without morphogenesis in Dictyostelium discoideum Nature 262, 717-719.

Town, C.D., and Gross, J. (1978). The role of cyclic nucleotides and cell agglomeration in postaggregative enzyme synthesis in Dictyostelium discoideum. Dev. Biol. 63, 412-420.

Vaughan, R.L., (1985). Characterization and localization of a cAMP dependent protein kinase from Dictyostelium discoideum. Ph.D. Thesis.

Walsh, D.A., Perkins, J.P. and Krebs, E.G. (1968). An adenosine 3,'-5'monophosphate-dependent protein kinase from rabbit skeletal muscle. J. Biol. Chem. 243, 3763-3774.

Ward, C., and Wright, B.E. (1965). Cell wall synthesis in Dictyostelium discoideum. 1. In vitro synthesis from uridine diphosphoglucose. Biochem. 4, 2021-2027.

Weinstein, B., and Koritz, S. (1973). A protein kinase assayable with intact cells of the cellular slime mold Dictyostelium discoideum. Dev. Biol. 34, 159-162. 
Woffendin,C., Chambers,T.C., Schaller,K.L., Leichtling,B.H., and Rickenburg,H.V. (1986). Translocation of CAMP-dependent protein kinase to the nucleus during development of Dictyostelium discoideum. Dev. Biol. 115,1-8.

Wright, B.E., Simon, W. and Walsh, B.T. (1968). A kinetic model of metabolism essential to differentiation in Dictyostelium discoideum. PNAS 60, 644-651. 


\section{SUMMARY}

The slime mold Dictyostelium discoideum has two developmentally regulated forms of the enzyme glycogen phosphorylase. The inactive ' $b$ ' form requires 5'AMP for activity and is present in early development, whereas the active ' $a$ ' form is S'AMP independent and is present in late development. The two forms of Dictyostelium phosphorylase differ in their elution from De52 cellulose, thermal stability, affinity constants, affinity for S'AMP Sepharose, and susceptibility to protease action. The following data support the hypothesis that the ' $a$ ' and ' $b$ ' forms represent separate gene products: Polyclonal antibodies raised to purified forms of the enzyme show low cross-reactivity. The anti-' $\mathrm{a}^{\prime}$ is specific for a $104 \mathrm{kd}$ protein associated with partially purified phosphorylase ' $a$ ' activity; the anti-' $b$ ' is specific for a $92 \mathrm{kd}$ protein associated with purified ' $b$ ' enzyme activity. The two antibodies inhibit the activities of their corresponding antigens, and, specifically immunoprecipitate the antigens they were raised aaginst. Furthermore, each antibody recognizes the proteolytic products of its specific antigen only.

The evidence suggesting that the ' $a$ ' and ' $b$ ' forms of Dictyostelium phosphorylase represent forms interconvertible by phosphorylation is as follows: In the presence of exogenously added $\mathrm{Mn}^{2+}$ and ATP, the ' $\mathrm{b}$ ' form shows apparent conversion to a S'AMP independent form as detected spectrophotometrically. This apparent conversion is accompanied by in vitro phosphorylation of the ' $\mathrm{b}$ ' enzyme by a $\mathrm{Mn}^{2+}$ dependent protein kinase. The ' $\mathrm{b}$ ' kinase also phosphorylates casein in the presence of $\mathrm{Mg}^{2+}$ or $\mathrm{Mn}^{2+}$. In vivo phosphorylation of the ' $\mathrm{b}$ ' form was observed in early development. Phosphorylation of the ' $b$ ' form did not result in the appearance of the $104 \mathrm{kd}$ protein. It is important to note that the evidence presented for the "different gene product" hypothesis does not rule out the possibility of CAMP dependent phosphorylation as the mechanism of conversion of the ' $a$ ' and ' $b$ ' forms for the following reasons: Rabbit muscle phosphorylase ' $a$ ' and ' $b$ ' forms are interconvertible by reversible phosphorylation and yet demonstrate different peptide maps. Low crossreactivity between the ' $a$ ' and ' $b$ ' antigens, and their different subunit molecular weights could be due to profound conformational changes occurring upon phosphorylation of the ' $b$ ' enzyme. At this point, it is unclear whether Dictyostelium phosphphorylase ' $a$ ' represents a phosphorylated and activated form of the ' $b$ ' form, or whether it represents a separate gene product. 
The two page vita has been removed from the scanned document. Page 1 of 2 


\section{The two page vita has been removed from the scanned document. Page 2 of 2}

